\title{
TBP and Diluent Mass Balances in the PUREX Plant at Hanford $1955-1991$
}

J. P. Sederburg

Westinghouse Hanford Company

J. A. Reddick

Los Alamos Technical Associates

Date Published

December 1994

Prepared for the U.S. Department of Energy Office of Environmental Restoration and Waste Management

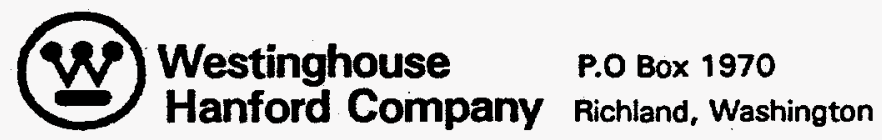

Hanford Operations and Engineering Contractor for the

U.S. Department of Energy under Contract DE-AC06-87RL10930

Approved for Public Release 


\section{RELEASE AUTHORIZATION}

Document Number: WHC-MR-0483, REV. 0

Document Title: $\quad$ TBP AND DILUENT MASS BALANCES IN THE PUREX PLANT AT HANFORD 1955-1991

Release Date: $\quad$ December 14, 1994

This document was reviewed following the procedures described in WHC-CM-3-4 and is:

APPROVED FOR PUBLIC RELEASE

WHC Information Release Administration Specialist:

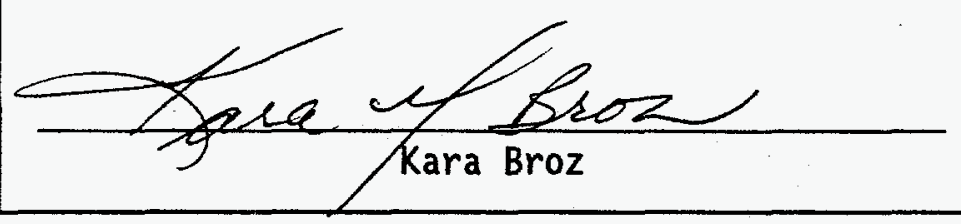




\section{DISCLAIMER}

This report was prepared as an account of work sponsored by an agency of the United States Government. Neither the United States Government nor any agency thereof, nor any of their employees, make any warranty, express or implied, or assumes any legal liability or responsibility for the accuracy, completeness, or usefulness of any information, apparatus, product, or process disciosed, or represents that its use would not infringe privately owned rights. Reference herein to any specific commercial product, process, or service by trade name, trademark, manufacturer, or otherwise does not necessarily constitute or imply its endorsement, recommendation, or favoring by the United States Government or any agency thereof. The views and opinions of authors expressed herein do not necessarily state or reflect those of the United States Government or any agency thereof. 


\section{DISCLAIMER}

Portions of this document may be illegible in electronic image products. Images are produced from the best available original document. 
WHC-MR-0483

Revision 0

TBP AND DILUENT MASS BALANCES IN THE

PUREX PLANT AT HANFORD 1955-1991

Westinghouse Hanford Company Approvals:

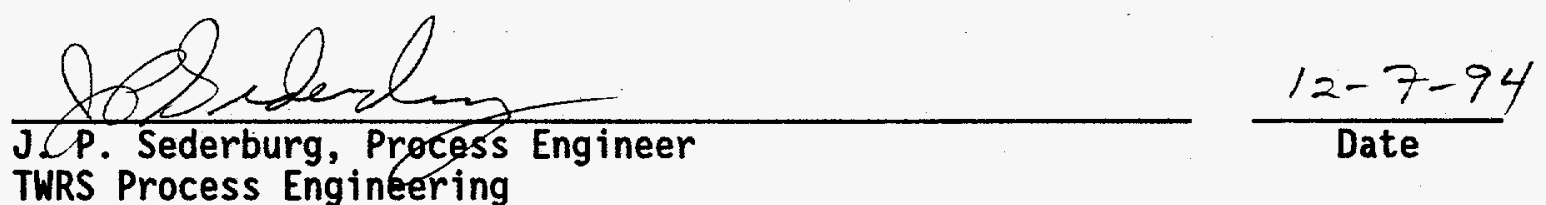

$\frac{\text { Ofdidealmy far D. Turner by telecon }}{\begin{array}{l}\text { D. Turner, Program Manager } \\ \text { Organic Safety Program }\end{array}} \frac{12-14-94}{\text { Date }}$




\section{TBP AND DILUENT MASS BALANCES}

\section{IN THE PUREX PLANT AT HANFORD}

$$
1955 \text { - } 1991
$$

by

Julie A. Reddick

Los Alamos Technical Associates

8633 Gage Boulevard

Kennewick, Washington 99352

June 21, 1994 


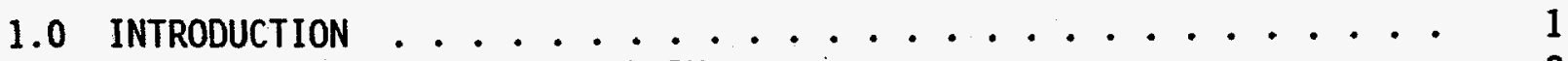

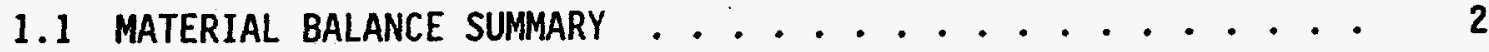

2.0 PUREX PROCESS HISTORY $\ldots \ldots \ldots \ldots$

2.1 NORMAL OPERATIONS .................... 5

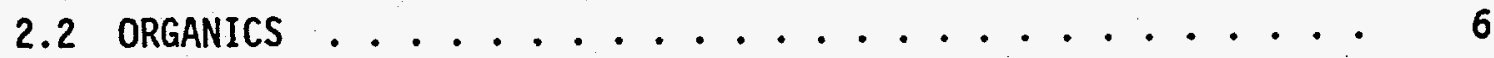

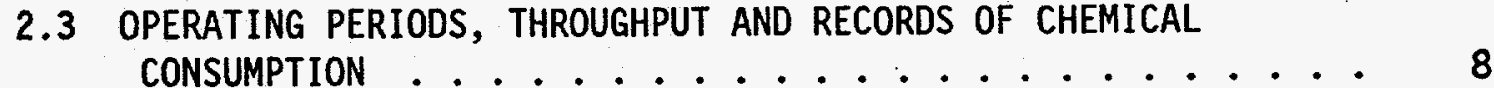

3.0 PUREX TBP/NPH MASS BALANCE .................. 26

3.1 ESTIMATED TBP/NPH DISTRIBUTION IN WASTES AND EFFLUENTS ... 27

3.2 ESTIMATED TOTAL LOSSES AND FATE OF TBP/NPH IN THE TANK FARMS 27

4.0 OTHER SOURCES OF ORGANICS IN THE TANK FARMS ......... 27

5.0 CONCLUSIONS AND RECOMMENDATIONS $\ldots \ldots \ldots \ldots$

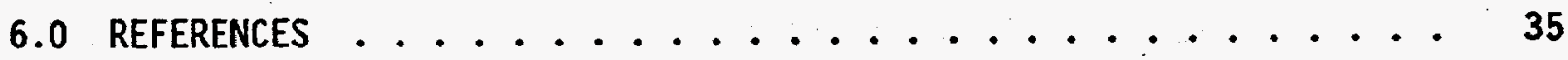

APPENDIX A: MASS BALANCE CALCULATIONS FOR PUREX ORGANIC CONSUMPTION

\section{LIST OF TABLES AND FIGURES}

Table 2-1: Properties of TBP, DBP and MBP...................... 7

Table 2-2: Properties of Shell E-2342, Soltrol-170, and NPH.......... 8

Table 2-3: Estimated Solvent Losses from 1955 to 1967 based on HAPO and CPD Monthly Reports............................ 9

Table 2-3: Estimated Solvent Losses from 1965 to 1991 based on Essential Materials Consumption Records..................... 20

Table 3-1: Estimated Annual Distribution of Organics in Purex P1ant Streams....................................... 28

Table 3-2: Crib Disposal of Spent Organic...................... 33

Figure 3-1: Estimated Organic Discharged to Organic Wash Waste, Ventilation Stack, and Process Condensate from Purex...... 30

Figure 3-2: Estimated Organic Discharged to High Level Waste and in UNH Product................................... 31

Figure 3-3: Estimated Gallons of Organic Discharged to Tank Farms in Organic Wash Waste.............................. 32 


\subsection{INTRODUCTION}

The purpose of this report is to develop an estimate of the quantities of tributyl phosphate and diluent discharged in aqueous waste streams to the tank farms from the Hanford Purex Plant over its operating life. Purex was not the sole source of organics in the tank farms, but was a major contributor.

Tributyl phosphate (TBP) and diluent, which changed from She11 E-2342® to Soltrol-170 ${ }^{\circledR}$ and then to normal paraffin hydrocarbon (NPH), were organic chemicals used in the Purex solvent extraction process at Hanford to separate plutonium and uranium from spent nuclear fuels. This report is an estimate of the material balances for these chemicals in the Purex Plant at Hanford over its entire operating life. The Purex Plant had cold start up in November 1955 and shut down in 1990. It's process used a solution of 30 vol\% TBP in diluent.

The Purex Plant was a source for some of the organic chemicals that are mixed with the radioactive waste stored in the Hanford 200 Area Tank. Farms. Early chemical processing in the Purex Plant involved diluents other than NPH. Section 2 of this report contains a discussion of the process history of the Purex Plant, including diluents, operating periods, and chemical consumption records. Section 3 contains the estimated material balance for the Purex Plant, based on flowsheet information and the plant technical manuals. This section contains the estimated quantities of organics transferred to the tank farms.

Other Hanford facilities also used organic chemicals and also were known or potential sources of organics in the tank waste. A brief discussion of these facilities is given in Section 4 . Section 5 contains conclusions and recommendations.

One question that was asked as part of this study was whether an organic balance around the Magnox Plant at Sellafield, England could be used to estimate Purex Plant organic losses. The Magnox Plant, which is still operating, uses a solution of 20 vol\% TBP in odorless kerosene. Both plants were designed to reprocess spent nuclear fuel. Solvent extraction equipment at Purex used pulsed columns. The Magnox Plant does not have pulsed columns, but uses mixer-settlers for solvent extraction. A review of the Magnox Plant balance indicates that such an extrapolation would not accurately reflect Purex Plant operations. There are significant differences in operating history, throughput, diluents and equipment. 


\subsection{MATERIAL BALANCE SUMMARY}

The organic balance around the Purex Plant is described, in general, in this section. A detailed description of the calculations is located in Appendix A. The scope of the calculations includes the entire plant life, from the original cold startup in the fall of 1955 to the present. The balance is based on reported consumption of organic at Purex. For the early years, organic consumption was estimated based on information located in the Chemical Processing Department's Monthiy Reports. Many of these reports included a discussions of solvent losses, in terms of percent of solvent throughput in the solvent treatment systems. Solvent throughput was then estimated, based on the tons of uranium processed in the plant during the month, and the flowsheet in effect at the time. For several years the monthly reports also list references for actual chemical consumption at Purex (1 report per month), but there was insufficient time in this task to locate and extract the information from them. Actual records of organic consumption in Purex are readily available, starting with the year 1965. These records were used in this study for the remainder of the plant life.

The major focus of this material balance is to determine what happened to the organic that was consumed in the plant. Most of the organic losses involved six streams. These streams involve:

- Disposal to the organic Crib A-2 in early operations, and later, briefly to Crib A-31.

- Soluble organic in high level (boiling) waste transferred to tank farms.

- Entrained and soluble organic in organic wash (solvent treatment) wastes transferred to tank farms.

- Entrained and soluble organic in Process Condensate disposed to a crib.

- Soluble organic in the Uranium (UNH) product stream.

- Organic evaporated into the vessel ventilation system and lost as gaseous effluent.

In addition to these losses, some of the organic was degraded due to radiolysis and acid hydrolysis during use. Most of these degradation products were removed in the solvent treatment process and left the plant with the organic wash wastes. 
The purpose of solvent treatment was to remove degradation products (which affected processing) and reduce the dose rate in the organic, which was reused in the plant. Two treatment systems were employed. The first system (No.1) was used to treat the organic from first cycle solvent extraction, which contained the most contaminants, and had the highest dose rate. The second system (No. 2) was used to treat less highly contaminated solvent from subsequent separations in the plant. On occasion, solvent from the No. 2 system was added to the No. 1 system. (But not the reverse, since it was desirable to maintain a low dose rate in the No. 2 solvent.)

Solvent sometimes arrived in solvent treatment loaded with product or fission products that were not easily removed. Some of these batches were reworked in Tank F-8, beginning with a long period of acid digestion to break down the organics. The organic fragments from the digestion, being lighter, would have been more volatile and would likely have left the plant through the stack, via the vessel ventilation system. Organic that was collected in cell sumps was similarly reworked.

Flowsheet information and physical data from Purex Technical Manuals were used to estimate the fraction of the lost organic that went to the various streams. These fractions were then applied to the reported organic consumption to complete the estimate of how much organic was distributed to each location.

The current Purex Flowsheet, PFD-P-020-00001, was used as the basis for following the path of organic through the plant. The flowsheet does not show the smal1 quantities of organic present in the aqueous streams due to solubility or entrainment. It also does not show degradation products. The material balance in Appendix A develops this information, based on solubility data, information about entrainment over Purex pulse columns, and information about TBP degradation products. The material balance begins with the organic feed to solvent extraction and follows the organic through the plant to the waste, product and effluent streams. At that point, the only organic losses not accounted for are the amount discharged via the stack and the amount entrained in the organic wash (solvent treatment) waste. The losses accounted for in the balance at this point are smaller than the fresh organic shown by the flowsheet as being added to the system. The difference between the known losses and the fresh organic was assumed to go $20 \%$ to the stack, and $80 \%$ to entrainment in the organic wash waste. There are no data available to document stack losses, however, the estimate is conservative in that it shows the majority of the material is lost to the tank farm.

The estimated total organic losses to each stream were then divided by 
the flowsheet figure for fresh solvent makeup in order to develop a percent distribution. The distribution was then applied to the monthly consumption data to arrive at the overall estimated losses to each stream.

The current Purex flowsheet was used as the basis for the material balance. It does not, however, accurately reflect plant operation over its entire history, due to the many modifications that occurred over the years. To account for some of these changes, the material balance was completed for four cases, and the flowsheet information was modified to account for major plant changes. The four cases are:

Case 1: $\quad$ Actual flowsheet conditions (includes recycle of process condensate). Fresh solvent makeup of 114 gallons/day. Applies to 1982 and thereafter.

Case 2: $\quad$ Same as Case 1, but fresh solvent makeup is assumed to be 200 gallons per day, according to historical solvent addition rate. applies to the years 1970 - 1981 .

Case 3: $\quad$ Fresh solvent makeup is assumed to be 260 gallons per day (an average from monthly reports), but process condensate is not recycled, so more organic is disposed via the process condensate stream to a crib. Applies to the years 1963 to 1969.

Case 4: Assumes fresh solvent makeup of 300 gallons per day, based on early operations, and no recycle of process condensate. Applies from startup to 1963 , when the plant began recycling the spent wash solution from the No. 2 System to the No. 1 System.

The results of the material balance are presented in Sections 2 and 3 of this report. The total gallons of solvent (TBP plus diluent) estimated to have been consumed in the Purex Plant (not including crib discharge) is $1,234,000$ gallons. Of this amount, about 655,000 gallons were estimated to have been discharged in the organic wash waste, 412,000 gallons in process condensate, 164,000 gallons in the stack gaseous effluent, and 2,000 gallons in the high level waste. Monthly reports indicate about 59,000 gallons of spent solvent disposed to Organic Crib A-2, while liquid waste discharge records indicate disposal of a total of 98,000 gallons of spent solvent to Cribs $A-2$ and $A-31$.

The monthly Hanford Atomic Products Operation -(HAPO) and Chemical Processing Department Reports reviewed for this report (1955-1967) show that, 
at least early on, the organic wash waste was sometimes discharged in two components. The bulk of the waste, also called carbonate waste, was transferred to high level waste tanks, initially in A-Farm. In 1956, organic that accumulated in a separate layer in Purex tanks TK-R8 and TK-G8 was transferred separately to C-Farm. This was done because too much organic was being distilled from the high level waste tanks. This was thought to cause percolation problems in the high level waste condensate crib. (The total flow to the high level waste condensate crib was eventually reduced significantly by replacing the tank farms contact condensers with surface condensers that did not add water to the stream in order to cool it.) The records examined for this report do not identify when the Plant stopped routinely sending the organic wash waste to the same tank as the high level waste.

\subsection{PUREX PROCESS HISTORY}

\subsection{NORMAL OPERATIONS}

Normal operations in the Purex Plant used a solution of TBP in diluent for. solvent extraction, with subsequent washing of the TBP-diluent mixture to remove contaminants and degradation products. The washed organic was reused in the facility, and the aqueous wash solution was transferred to the tank farms from Purex Tanks R-8 and G-8. (In later operations, spent wash solution from the No. 2 Solvent Treatment System was reused in the No. 1 System and only Tank G-8 was used for transfers to the tank farms. This change reduced solvent losses.) Organics were present in the wash solution due to solubility and entrainment. Additional organic could al so have been transferred to the tank farms depending on decanting operations, where it was necessary to detect the aqueous/organic interface to separate the layers. (In early operations, accumulated organic in these tanks was deliberately transferred to the tank farms. Later operations involved recovering and reusing the accumulated organic.)

Aqueous waste from Purex Tank F-18 could also have occasionally contained organic, since this tank was used to accumulate waste from cell sumps, including those in the organic wash area. Organics collected in Tank F-18 would usually, however, have been reworked in Tank F-8, and not sent to the tank farms.) High level waste from Purex Tank F-16 was another source of organic, due to solubility occurring during solvent extraction of uranium and plutonium. 
Organics and decomposition products al so left the plant during normal operations in streams that were not routed to the tank farms. These streams included condensates from the process ventilation system and gaseous

effluents. During early operations, some spent organic was routed to a crib for disposal into the soil. This practice was discontinued when NPH became the diluent, since washing remained effective indefinitely for the TBP-NPH mixture. The use of diluents at Purex is described in section 2.2, below. The distribution of soluble and entrained organic is estimated in Appendix $A$.

\subsection{ORGANICS}

The Purex Plant was completed in 1955 and cold startup runs were begun in October of that year. Hot startup began in mid-January of 1956 (Raab 1977). The plant was originally designed for a nominal instantaneous rate of 8.33 tons of uranium per day, with an expansion capacity of 12 to 13 tons following minor equipment changes, according to the plant technical manual (GE, 1955). The expansion was expected to be completed prior to startup. Subsequent modifications increased the capacity even further.

At startup the solvent used in the extraction process was 30 vol\% tributyl phosphate (TBP) in diluent. The original diluent, however, was not normal paraffin hydrocarbon (NPH). The original Purex Plant Technical Manual, page 436, (GE, 1955) listed 6 commercial products that met the specifications for diluent. At the time the technical manual was written, a Phillips Chemical Company product called Soltrol-170 had been tentatively selected for use in the plant. The original diluent was, however Shell E2342. Soltrol-170 came into later use, in September of 1961 (Walser, 1966). When Soltrol-170 became the new diluent, the old TBP/She11-E2342 solvent was not disposed to the organic crib, but was consumed in the plant by blending it in with the new TBP/Soltrol mixture.

Records show that NPH replaced Soltrol-170 as the diluent on February 15, 1966 (Zahn, 1966). Crib discharge records for 1963-1966 show 6, 340 gallons of organic disposed to Crib A-31 during that time frame, which could have been some of the old TBP/Soltrol solvent. Properties of TBP and degradation products DBP and MBP, are shown in Table 2-1. Properties of Shell E-2342, Soltrol-170, and NPH are shown in Table 2-2. 
TABLE 2-1 PROPERTIES OF TBP, DBP and MBP

\begin{tabular}{|c|c|c|c|}
\hline & $\begin{array}{l}\text { Tributyl } \\
\text { Phosphate (TBP) }\end{array}$ & $\begin{array}{l}\text { Dibutyl } \\
\text { Phosphate (DBP) }\end{array}$ & $\begin{array}{l}\text { Monobuty } \\
\text { Phosphate (MBP) }\end{array}$ \\
\hline Formula & (n-C4H9O)3PO & (nC4H9O)2(OH)PO & $(\mathrm{nC} 4 \mathrm{H} 9 \mathrm{O})(\mathrm{OH}) 2 \mathrm{PO}$ \\
\hline Molecular weight & 266.32 & 210.2 & 154.1 \\
\hline Color & colorless & pale yellow & colorless \\
\hline Odor & mildly sweet & - & - \\
\hline Density $\left(\mathrm{g} / \mathrm{ml}\right.$ at $\left.25^{\circ} \mathrm{C}\right)$ & 0.9730 & 1.065 & 1.220 \\
\hline Refractive index (n 20/D) & 1.4245 & 1.4260 & 1.419 \\
\hline Refractive index (n 25/D) & 1.4226 & 1.4227 & 1.429 \\
\hline Melting point ${ }^{\circ} \mathrm{C}$ & $<-80$ & - & - \\
\hline Specific Heat (cal/g ${ }^{\circ} \mathrm{C}$ at $25^{\circ} \mathrm{C}$ ) & 0.41 & - & - \\
\hline $\begin{array}{l}\text { Latent heat of vaporization } \\
\text { (cal/gram mole) }\end{array}$ & 14,680 & - & 11,400 \\
\hline $\begin{array}{l}\text { Boiling point }\left({ }^{\circ} \mathrm{C} \text { at } 760 \mathrm{~mm} \mathrm{Hg}\right. \\
\text { pressure) }\end{array}$ & 289 & $\begin{array}{c}190 \text { (decomposition } \\
\text { temperature) }\end{array}$ & $\begin{array}{c}105 \text { (decomposition } \\
\text { temperature) }\end{array}$ \\
\hline $\begin{array}{l}\text { Boiling point ( }{ }^{\circ} \mathrm{C} \text { at } 25 \mathrm{~mm} \mathrm{Hg} \\
\text { pressure) }\end{array}$ & 177 & - & 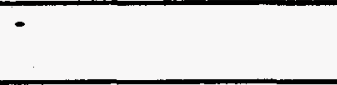 \\
\hline $\begin{array}{l}\text { Boiling point }\left({ }^{\circ} \mathrm{C} \text { at } 1 \mathrm{~mm} \mathrm{Hg}\right. \\
\text { pressure) }\end{array}$ & 121 & - & - \\
\hline $\begin{array}{l}\text { Vapor pressure (mm Hg at } \\
\left.100^{\circ} \mathrm{C}\right)\end{array}$ & ca. 1.0 & - & - \\
\hline $\begin{array}{l}\text { Vapor pressure (mm Hg at } \\
\left.25^{\circ} \mathrm{C}\right)\end{array}$ & 0.006 & - & - \\
\hline $\begin{array}{l}\text { Flash point }\left({ }^{\circ} \mathrm{F}, \text { Tag closed }\right. \\
\text { cup) }\end{array}$ & $295\left(146^{\circ} \mathrm{C}\right)$ & - & - \\
\hline Solubility in water ( $g / L$ at $25^{\circ} \mathrm{C}$ ) & 0.39 & 18 & - \\
\hline
\end{tabular}

Note: Physical properties for TBP, DBP and MBP are from the Purex Technical Manual (GE, 1955).

Losses of TBP during processing occurred through entrainment and solubility in the aqueous phase, acid hydrolysis, radiolysis, and evaporation. Identified degradation products are DBP, MBP, butanol and phosphoric acid. NPH is more resistant to chemical and radiolytic degradation, with losses occurring mainly through entrainment, evaporation and a small solubility in the aqueous phase. Prior diluents were more susceptible to degradation than $\mathrm{NPH}$. 
TABLE 2-2: PROPERTIES OF SHELL E-2342, SOLTROL-170, AND NPH

\begin{tabular}{|c|c|c|c|}
\hline & Shell E-2342 & Soltrol-170 & $\begin{array}{l}\text { Normal Paraffin } \\
\text { Hydrocarbon (NPH) }\end{array}$ \\
\hline Period of Use & 1955 to $9 / 1961$ & $9 / 1961$ to $2 / 1966$ & $2 / 1966$ to 1989 \\
\hline Density at $25^{\circ} \mathrm{C}(\mathrm{g} / \mathrm{ml})$ & 0.801 & 0.773 & 0.76 (max) \\
\hline Viscosity (centipoise at $25^{\circ} \mathrm{C}$ ) & 1.7 & 2.3 & 1.8 \\
\hline Boiling range and midpoint $\left({ }^{\circ} \mathrm{C}\right)$ & - & $208-239,(225)$ & $174-252$ \\
\hline Flash point & $166^{\circ} \mathrm{F}$ & $192^{\circ} \mathrm{F}$ & $80^{\circ} \mathrm{C}\left(176^{\circ} \mathrm{F}\right) \mathrm{min}$. \\
\hline Aromatic content & 0.1 vol\% & Nil & $\begin{array}{l}0.2 \mathrm{wt} \% \text { max as } 1,2,3,4 \\
\text { tetrahydronaphthalene }\end{array}$ \\
\hline Naphthene content & about 80 vol\% & $\mathrm{Nil}$ & $-\quad-2-2-2$ \\
\hline lodine number & - & $<1.1$ bromine number & $\begin{array}{l}0.1 \mathrm{w} \% \text { max olefins as } \\
\text { wt } \% 1 \text {-tetradecene }\end{array}$ \\
\hline Solubility in water & $\begin{array}{l}<0.004 \mathrm{~g} / \text { at } 25^{\circ} \mathrm{C} \\
\text { and } 50^{\circ} \mathrm{C}\end{array}$ & very slight & $\begin{array}{l}<0.005 \mathrm{~g} / \mathrm{h} \text { between } 25^{\circ} \mathrm{C} \\
\text { and } 50^{\circ} \mathrm{C}\end{array}$ \\
\hline Composition & $\begin{array}{l}\text { about } 80 \text { vol\% } 5 \text { and } 6 \\
\text { carbon cycloparaffins } \\
\text { (cyclopentane, } \\
\text { cyclohexane) }\end{array}$ & $\begin{array}{l}\text { mixture of highly } \\
\text { branched aliphatic } \\
\text { hydrocarbons }\end{array}$ & $\begin{array}{l}\text { mixture of C10 to C14 } \\
\text { straight chain (normal) } \\
\text { aliphatic hydrocarbons }\end{array}$ \\
\hline
\end{tabular}

Note: Physical properties for Shell E-2342 and Soltrol-170 are from the Purex Technical Manual (GE, 1955). Composition of Soltrol-170 is from (Walser, 1966). Properties of NPH are from the Purex Technical Manual (RHO, 1983.) Composition for She11 E-2342 is based on the definition for naphthenes given in (Merck, 1989).

\subsection{OPERATING PERIODS, THROUGHPUT AND RECORDS OF CHEMICAL CONSUMPTION}

The Purex Plant started up with cold runs in 1955 and initially reprocessed aluminum-clad fuel. Later modifications enabled the plant to change to process aluminum or zirconium clad fuel. Over the years there have been many process and flowsheet changes. Table 2-3 shows the uranium throughput and estimated consumption of solvent based on HAPO and Chemical Processing Department Monthiy Reports from November of 1955 to August of 1967. This table also contains a list of Purex Essential Materials Consumption Report document numbers, which were not examined for this study but might be found useful in other efforts. The monthly reports frequently discussed solvent losses in terms of the percent of solvent throughput in the No. 1 and No 2 Solvent Treatment Systems. Solvent losses were estimated in this table, based on Purex Chemical Flowsheet No. 4 (HW-35225). This Flowsheet shows solvent throughput in the No.1 System of 3,001 gallons per ton of uranium processed and throughput in the No 2 Solvent Treatment System of 2,486 gallons per ton of uranium, for a total of 5,487 gallons/ton. These figures, combined with the reported uranium production numbers, were used to generate the estimated solvent throughput and solvent losses. Using this 
Table 2-3: Estimated Solvent Losses from 1955 to 1967 based on HAPO and CPD Monthly Reports

\begin{tabular}{|c|c|c|c|c|c|c|c|c|}
\hline Date & $\begin{array}{l}\text { HAPOKPD } \\
\text { Monthly } \\
\text { Report No. }\end{array}$ & $\begin{array}{l}\text { Essential } \\
\text { Materials } \\
\text { Report No. }\end{array}$ & $\begin{array}{c}\text { Tons } \\
\text { Uranium } \\
\end{array}$ & $\begin{array}{c}\text { Est.\# of } \\
\text { Operating } \\
\text { Days }\end{array}$ & $\begin{array}{c}\text { Reported Solvent } \\
\text { Loss* (\% of } \\
\text { throughput) }\end{array}$ & $\begin{array}{c}\text { Est. solvent } \\
\text { throughput } \\
\text { (gal) }\end{array}$ & $\begin{array}{c}\text { Est. } \\
\text { Solvent } \\
\text { Loss* (gal) } \\
\end{array}$ & Notes \\
\hline Nov-55 & HW-40182 & - & cold runs & - & 0.3 & - & 4,700 & $\begin{array}{l}\text { Since start of cold runs, } 46,000 \mathrm{gal} \text { of } 30 \% \text { TBP added. By } \\
11 / 19 \text {, about } 24,000 \text { gallons had been discarded [to crib], due to } \\
\text { interface control, centrifuge bowl leak and normal losses. } 11 / 19 \\
\text { to } 11 / 26 \text { lost only } 1100 \text { gal, } 0.3 \% \text { of organic throughput. }\end{array}$ \\
\hline Dec-55 & $H W-40962$ & - & cold runs & $\cdot$ & 1 & & 5,200 & \\
\hline \multicolumn{2}{|c|}{ Total 1955} & & & & & & 9,900 & \\
\hline & & & & & & & & \\
\hline Jan-56 & $H W-41205$ & HW-40729 & 67 & 31 & - & 367,629 & 1,103 & $\begin{array}{l}\text { Completed cold runs Jan 22. Hot startup Jan 13. Flowsheet \#, } \\
\mathrm{HW}-40574 \text {. About } 7,000 \text { gallons of solvent discarded [to crib]. } \\
\text { Completely new inventory was available at startup. }\end{array}$ \\
\hline Feb-56 & $\mathrm{HW}-41702$ & $H W-41321$ & 246.8 & 19 & 0.2 & $1,354,192$ & 2,708 & 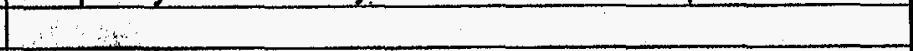 \\
\hline Mar-56 & $H W-42219$ & $\mathrm{HW}-43387$ & 130 & 13 & 0.6 & 713,310 & 11,280 & $\begin{array}{l}\text { Organic losses excessive. } 7,000 \text { gallons lost during shutdown. } \\
\text { Continue to be } 0.6 \% \text { of throughput. }\end{array}$ \\
\hline Apr-56 & $H W-42626$ & $H W-42893$ & 197 & 18 & 0.3 & $1,080,939$ & 7,243 & $\begin{array}{l}\text { One large solvent loss of } 4,000 \text { gallons when pre-cycle system } \\
\text { temorarily shut down April } 10 \text {. }\end{array}$ \\
\hline May-56 & HW-43137 & $\mathrm{HW}-43482$ & 133 & 14 & 0.5 & 729,771 & 3,649 & $\begin{array}{l}\text { Replaced entire organic inventory in No. } 1 \text { system. } 7,000 \\
\text { gallons discarded [to crib]. Steady state loss } 0.5 \% \text { of } \\
\text { throughput. } 10 \mathrm{~W} \text { and } 2 \text { OW routed to TK-110-C. 1WW to TK- } \\
103-A \text {. }\end{array}$ \\
\hline Jun-56 & HW-43938 & $\mathrm{HW}-44017$ & 341 & 30 & - & $1,871,067$ & 9,859 & $\begin{array}{l}\text { No. } 1 \text { System losses }>1 \% \text { of throughput, decreased to } 0.37 \% \text {. } \\
\text { No. } 2 \text { System losses } 0.33 \% \text {. }\end{array}$ \\
\hline Jul-56 & $H W-44580$ & HW-44725 & 112.7 & 12 & & 618,385 & 6,108 & $\begin{array}{l}\text { No. } 1 \text { losses } 0.35 \% \text {. No. } 2 \text { losses } 0.33 \% \text {. Does not include } \\
4,000 \text { gallons lost at shutdown/startup. No. } 1 \text { system inventory } \\
\text { replaced with No. } 2 \text { inventory. No. } 2 \text { inventory replaced with } \\
\text { fresh solvent. }\end{array}$ \\
\hline Aug-56 & $H W-45115$ & $H W-45182$ & 239.5 & .24 & - & $1,314,137$ & 4,733 & $\begin{array}{l}\text { No. } 1 \text { losses } 0.41 \% \text { of gallons processed. Organic waste routed } \\
\text { to } 110-\mathrm{C} \text { to reduce emulsion in A-8 crib. TK-103-A bumps about } \\
\text { every } 8 \mathrm{hrs}(5-10 \text { in WG). }\end{array}$ \\
\hline Sep-56 & $H W-45707$ & $H W-45691$ & 315 & 26 & 0.25 & $1,728,405$ & 4,321 & $\begin{array}{l}\text { CPD established. Total solvent losses of } 0.25 \% \text { of gallons } \\
\text { processed in spite of a loss of } 2,800 \text { gallons due to } \\
\text { shutdown/startup. R-8 \& G-8 organic to C-Farm. Previously had } \\
\text { gone to 103-A, distilled there \& affected TF condensate crib. } \\
\text { See quote below. }\end{array}$ \\
\hline
\end{tabular}


Table 2-3: Estimated Solvent Losses from 1955 to 1967 based on HAPO and CPD Monthly Reports

\begin{tabular}{|c|c|c|c|c|c|c|c|c|}
\hline Date & $\begin{array}{l}\text { HAPORPD } \\
\text { Monthly } \\
\text { Report No. }\end{array}$ & $\begin{array}{l}\text { Essential } \\
\text { Materials } \\
\text { Report No. }\end{array}$ & $\begin{array}{l}\text { Tons } \\
\text { Uranium }\end{array}$ & $\begin{array}{c}\text { Est.\# of } \\
\text { Operating } \\
\text { Days }\end{array}$ & $\begin{array}{c}\text { Peported Solvent } \\
\text { Loss* (\% of } \\
\text { throughput) }\end{array}$ & $\begin{array}{c}\text { Est. solvent } \\
\text { throughput } \\
\text { (gal) }\end{array}$ & $\begin{array}{c}\text { Est. } \\
\text { Solvent } \\
\text { Loss* (gal) }\end{array}$ & Notes \\
\hline & & & & & & & & $\begin{array}{l}\text { "Organic which normally accumulates in TK-GB and TK-RB is } \\
\text { currently being separated and routed to C-Farm for storage. } \\
\text { Previously, waste organic was mixed with the carbonate wastes } \\
\text { and sent to } 241-A-103 \text { which resulted in excessive }\end{array}$ \\
\hline & & & & & & & & $\begin{array}{l}\text { solvent reaching the boiling waste storage tank. Solvent distilled } \\
\text { from this self-concentrating tank into the tank farm condensate } \\
\text { crib probably restricted the crib percolation rate." }\end{array}$ \\
\hline Oct-56 & $H W-46432$ & $H W-46425$ & 186 & 17 & - & $1,020,582$ & 2,551 & $\begin{array}{l}\text { Replaced No. } 1 \text { organic column T-G2. New column has } \\
\text { interface probe in center of column rather than in a side } \\
\text { chamber. Recommend surface condensers in Tank Farms. }\end{array}$ \\
\hline Nov-56 & HW-47056 & $\mathrm{HW}-47071$ & 272 & 21 & 0.225 & $1,492,464$ & 3,358 & $\begin{array}{l}\text { Solvent losses dropped from } 0.25 \% \text { to } 0.20 \% \text {, a } \$ 100 / \text { day } \\
\text { savings. Attributed to new column. }\end{array}$ \\
\hline Dec-56 & $H W-47675$ & $H W-47664$ & 279 & 19 & 0.32 & $1,530,873$ & 4,899 & $\begin{array}{l}\text { Reworked } 42 \text { tons of out-of-spec. uranium. TK-103-A boils at } \\
6.2 \text { gpm. }\end{array}$ \\
\hline \multicolumn{2}{|c|}{ Total 1956} & & 2,519 & 244 & & & 61,813 & 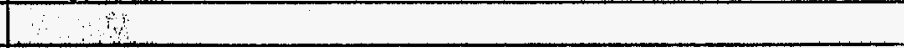 \\
\hline & & & & & & & & \\
\hline Jan-57 & $H W-48132$ & HW-48092 & 300.98 & 25 & 0.52 & $1,651,477$ & 8,588 & $\begin{array}{l}\text { 241-A Tank Farm receives Neutr. 1WW, carbonate washes \& } \\
\text { cell drainage \& flushes. Coating waste \& organic transfer line to } \\
\text { 104-C plugged completely. }\end{array}$ \\
\hline Feb-57 & $H W-48835$ & $H W-48850$ & 284 & 22 & - & $1,558,308$ & 5,324 & $\begin{array}{l}\text { Solvent loss } 0.47 \% \text { of throughput, including } 2,000 \text { gal spilled to } \\
\text { cell floor and discarded. } 1 \mathrm{WW} \text { and solvent wash waste to TK- } \\
103-\mathrm{A} \text {. }\end{array}$ \\
\hline Mar-57 & HW-49503 & HW-49475 & 299 & 22 & 0.31 & $1,640,613$ & 5,086 & $\begin{array}{l}\text { Using flowsheet HW-47712 with some changes. TK-103-A boils } \\
8 \text { to } 9 \mathrm{gpm} \text {. }\end{array}$ \\
\hline Apr-57 & HW-50089 & HW-50073 & 405.85 & 28 & 0.29 & $2,226,899$ & 6,458 & $\begin{array}{l}\text { Added used organic from TBP [U] plant: } 3,200 \text { gal of } 19 \% \text { TBP. } \\
\text { Caused shutdown. Waste routes to C-Farm returned to normal } \\
\text { (unplugged). No. } 1 \text { system has } 14,000 \text { gal. inventory. }\end{array}$ \\
\hline May-57 & HW-50584 & HW-50589 & 355.9 & 24 & 0.29 & $1,952,823$ & 5,663 & $\begin{array}{l}0.29 \% \text { loss excludes accidental } 2,000 \mathrm{gal} \text { loss through the } 10 \\
\text { column vent line. }\end{array}$ \\
\hline Jun-57 & $H W-51211$ & $H W-51310$ & 369.1 & 28 & 0.36 & $2,025,252$ & 7,291 & $\begin{array}{l}\text { Current [1WW] waste routed to TK-101-A on } 6 / 27 \text {. Until self } \\
\text { concentration starts in 101-A, organic carbonate wastes and } \\
\text { misc. wastes to } 241-A-102 \text {, to be transferred to C-Farm. }\end{array}$ \\
\hline
\end{tabular}


Table 2-3: Estimated Solvent Losses from 1955 to 1967 based on HAPO and CPD Monthly Reports

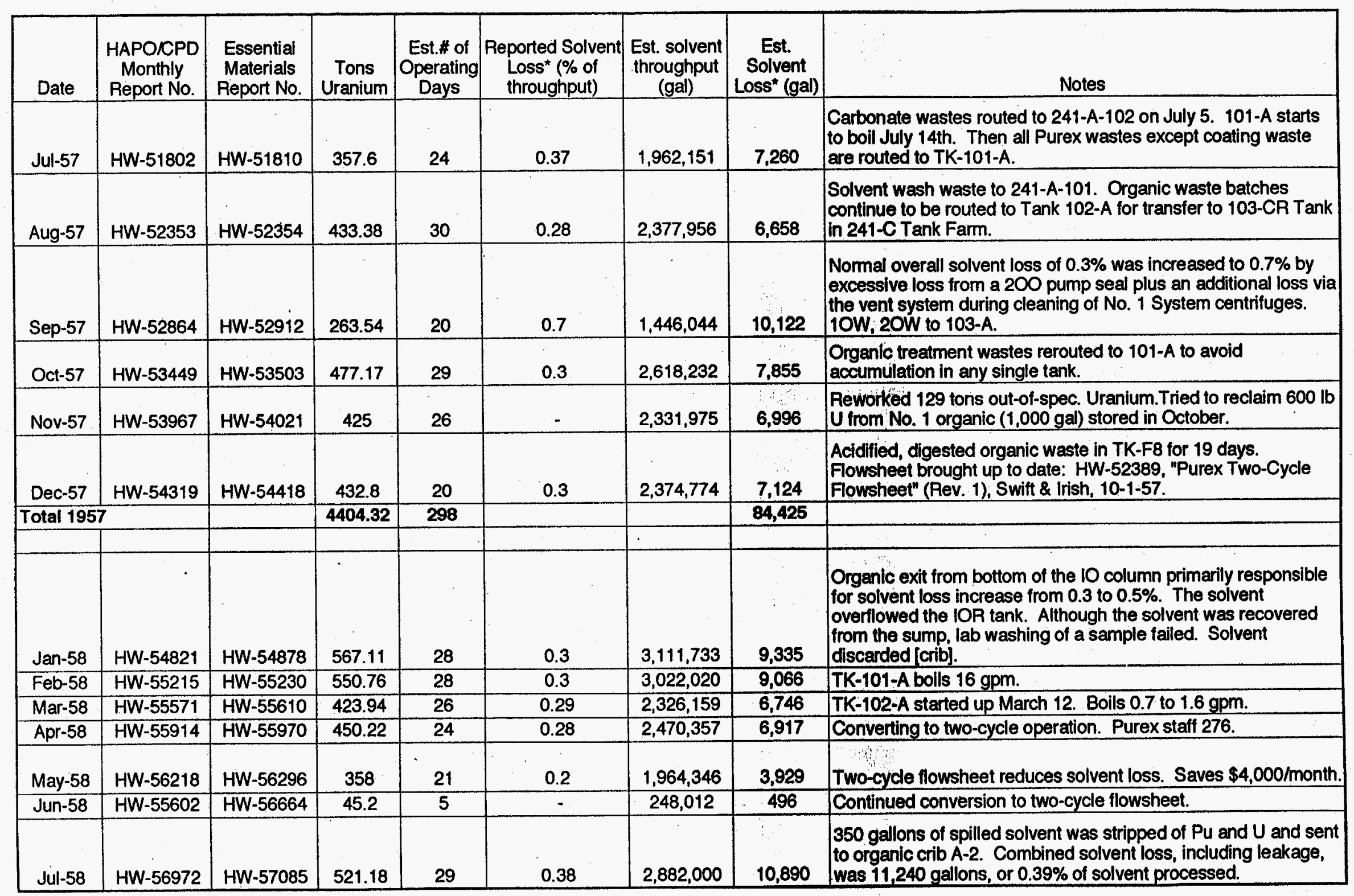


Table 2-3: Estimated Solvent Losses from 1955 to 1967 based on HAPO and CPD Monthly Reports

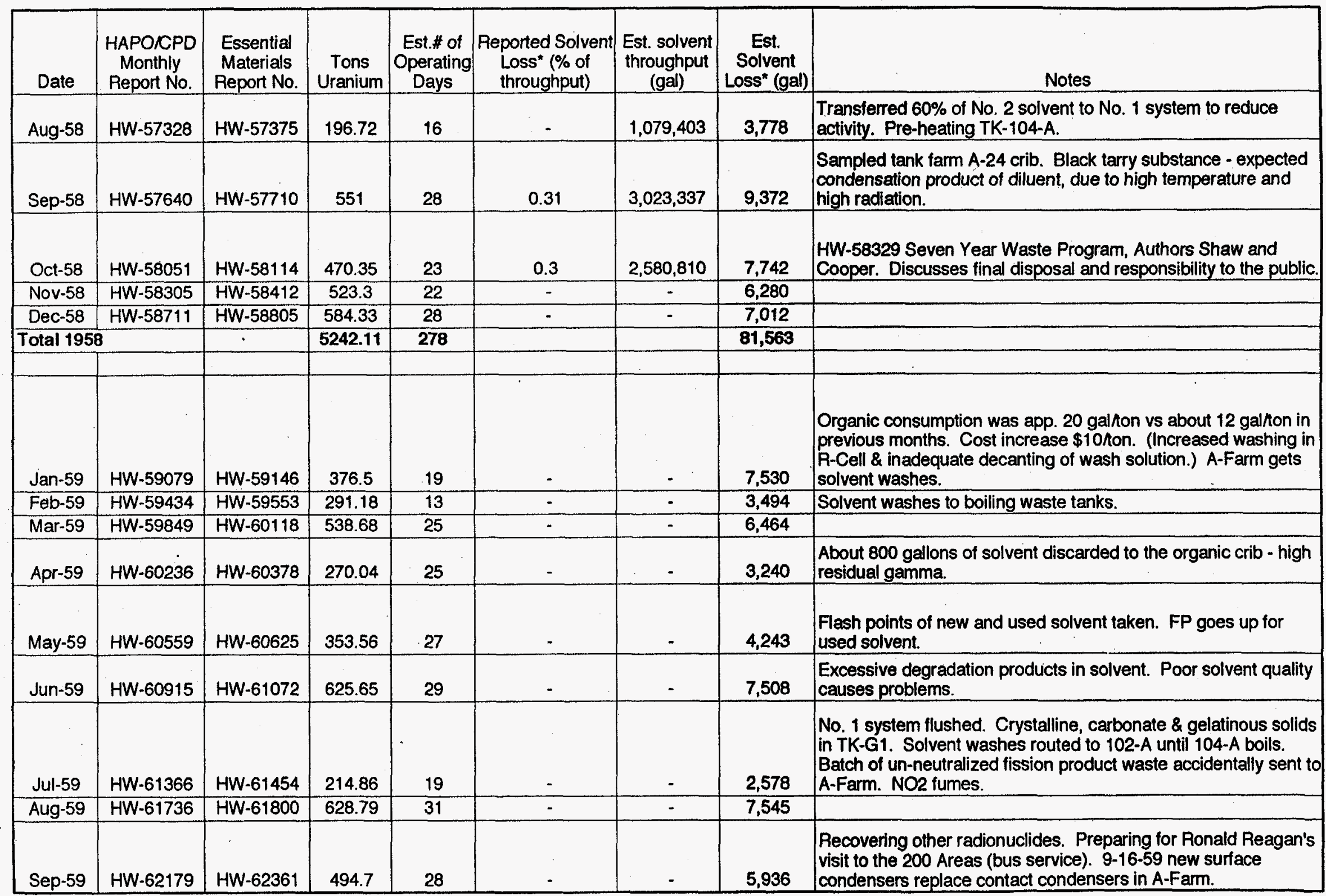


Table 2-3: Estimated Solvent Losses from 1955 to 1967 based on HAPO and CPD Monthly Reports

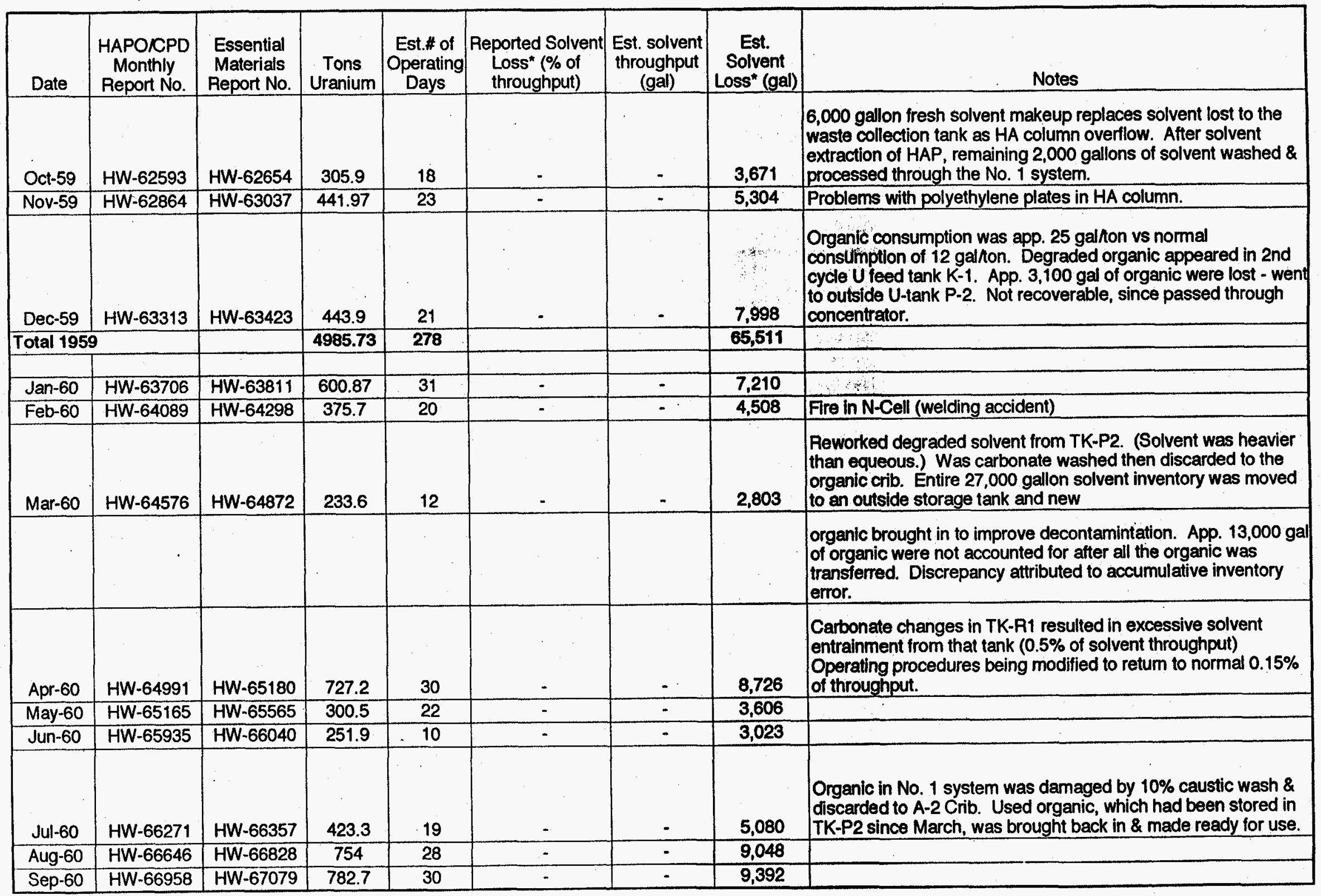


Table 2-3: Estimated Solvent Losses from 1955 to 1967 based on HAPO and CPD Monthly Reports

\begin{tabular}{|c|c|c|c|c|c|c|c|c|}
\hline Date & $\begin{array}{l}\text { HAPOKPD } \\
\text { Monthly } \\
\text { Report No. }\end{array}$ & $\begin{array}{l}\text { Essential } \\
\text { Materials } \\
\text { Report No. }\end{array}$ & $\begin{array}{l}\text { Tons } \\
\text { Uranium }\end{array}$ & $\begin{array}{c}\text { Est.\# of } \\
\text { Operating } \\
\text { Days }\end{array}$ & $\begin{array}{l}\text { Reported Solvent } \\
\text { Loss }{ }^{*} \% \text { of } \\
\text { throughput })\end{array}$ & $\begin{array}{l}\text { Est. solvent } \\
\text { throughput } \\
\text { (gal) }\end{array}$ & $\begin{array}{c}\text { Est. } \\
\text { Solvent } \\
\text { Loss* (gal) }\end{array}$ & Notes \\
\hline Oct-60 & HW-67252 & $\mathrm{HW}-67387$ & 403.7 & 27 & - & - & 4,844 & \\
\hline Nov-60 & $H W-67459$ & HW-67743 & 685.7 & 30 & - & - & 8,228 & \\
\hline Dec-60 & HW-67985 & $H W-68117$ & 702.9 & 26 & 0.3 & $3,856,812$ & 11,570 & $\begin{array}{l}200 \text { gallon purge of TK-G1 caused } 0.1 \% \text { increase in overall } \\
\text { normal solvent loss }(0.3 \%)\end{array}$ \\
\hline \multicolumn{2}{|c|}{ Total 1960} & & 6242.07 & 285 & & & 78,040 & \\
\hline Jan-61 & $H W-68345$ & $H W-68422$ & 331.8 & 22 & - & $1,820,587$ & 5,462 & \\
\hline Feb-61 & $H W-68700$ & HW-68758 & 474.9 & 19 & - & $2,605,776$ & 7,817 & $\begin{array}{l}\text { Accelerated solvent washing to control quality. High level waste } \\
\text { routed to TK-106-A for preheating. Cs recovery in Purex. }\end{array}$ \\
\hline Mar-61 & $\mathrm{HW}-69051$ & $H W-69089$ & 564.8 & 29 & - & $3,099,058$ & 9,297 & HW-68146 proposal to replace A-2 Crib. \\
\hline Apr-61 & HW-69443 & $\mathrm{HW}-69474$ & 360.76 & 22 & - & $1,979,490$ & 5,938 & Replacing more polyethelene cartridges with stainless steel. \\
\hline May-61 & HW-69803 & HW-69872 & 694.95 & 27 & - & $3,813,191$ & $28 ; 599$ & $\begin{array}{l}\text { Solvent losses from the No. } 1 \text { system have been } 3 \text { fold above } \\
\text { flowsheet. Were substantially reduced to } 0.6 \% \text { of throughput, } \\
\text { which is twice the regular loss. }\end{array}$ \\
\hline Jun-61 & HW-70165 & $\mathrm{HW}-70311$ & 580.36 & 27 & 0.36 & $3,184,435$ & 11,464 & \\
\hline Jul-61 & HW-70588 & - & 480.18 & 22 & - & $2,634,748$ & 7,904 & \\
\hline Aug-61 & HW-70918 & $\cdot$ & 634.63 & 28 & - & $3,482,215$ & 10,447 & $\begin{array}{l}\text { In order to test a new diluent, the entire plant inventory of } \\
\text { organic was removed from the plant and stored for later use. } \\
\text { New diluent charging activities begun. }\end{array}$ \\
\hline Sep-61 & $\mathrm{HW}-71187$ & 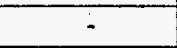 & 496.54 & 20 & - & $2,724,515$ & 8,174 & Testing Soltrol. \\
\hline Oct-61 & $\mathrm{HW}-71577$ & $\because$ & 371.42 & 14 & $\cdot$ & $2,037,982$ & 6,114 & Purex running out of aged feed. \\
\hline Nov-61 & HW-71895 & $\cdot$ & 282.11 & 14 & - & $1,547,938$ & 4,644 & \\
\hline Dec-61 & HW-72154 & - & 678.87 & 29 & - & - & 14,500 & $\begin{array}{l}\text { Test of carbonate wash re-use terminated when excessive } \\
\text { emulsion transferred to TK-G1. Replacement of solvent to No. } 2 \\
\text { System was about } 500 \text { gal/day, compared to a normal loss of } \\
\text { about } 80 \text { gallons/day. }\end{array}$ \\
\hline \multicolumn{2}{|c|}{ Total 1961} & & 5951.32 & 273 & 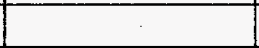 & & 120,360 & \\
\hline & & & & & & & & \\
\hline Jan-62 & HW-72551 & - & 313.29 & 22 . & - & $1,719,022$ & 5,157 & \\
\hline Feb-62 & HW-72890 & - & 144.79 & 10 & : & 794,463 & 2,383 & $\begin{array}{l}\text { During the shutdown period, used, stored solvent (composed of } \\
\text { TBP and Shell E-2342) was used to replenish the No. } 1 \text { Solvent } \\
\text { System inventory. }\end{array}$ \\
\hline
\end{tabular}


Table 2-3: Estimated Solvent Losses from 1955 to 1967 based on HAPO and CPD Monthly Reports

\begin{tabular}{|c|c|c|c|c|c|c|c|c|}
\hline Date & $\begin{array}{l}\text { HAPOKPD } \\
\text { Monthly } \\
\text { Report No. }\end{array}$ & $\begin{array}{l}\text { Essential } \\
\text { Materials } \\
\text { Report No. }\end{array}$ & $\begin{array}{l}\text { Tons: } \\
\text { Uranium }\end{array}$ & $\begin{array}{c}\text { Est.\# of } \\
\text { Operating } \\
\text { Days }\end{array}$ & $\begin{array}{c}\text { Reported Solvent } \\
\text { Loss* (\% of } \\
\text { throughput) }\end{array}$ & $\begin{array}{c}\text { Est. solvent } \\
\text { throughput } \\
\text { (gal) }\end{array}$ & $\begin{array}{c}\text { Est. } \\
\text { Solvent } \\
\text { Loss }^{*} \text { (gal) } \\
\end{array}$ & Notes \\
\hline Mar-62 & $H W-73193$ & - & 305 & 20 & - & $1,673,535$ & 5,021 & \\
\hline Apr-62 & $H W-73525$ & - & 302.39 & 20 & - & $1,659,214$ & 4,978 & Criticality at 234-5 on April 7th. Purex operations slowed. \\
\hline May-62 & HW-73884 & - & 620.56 & 31 & 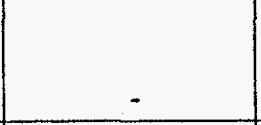 & $3,405,013$ & 10,215 & $\begin{array}{l}\text { Solvent losses from the No. } 2 \text { System increased a factor of four } \\
\text { to } 400 \text { gallons/day. However, the "lost" solvent was segregated } \\
\text { from the washes and stored for future recovery. }\end{array}$ \\
\hline Jun-62 & $H W-74151$ & - & 555.25 & 25 & - & $3,046,657$ & 9,140 & $\begin{array}{l}\text { Flushed No. } 1 \text { Organic System. New policy requires sampling all } \\
\text { waste streams leaving Purex. }\end{array}$ \\
\hline Jul-62 & HW-74505 & - & 776.79 & 31 & - & $4,262,247$ & 12,787 & $\begin{array}{l}\text { Processed } 1030 \text { cans of button line supematant. Solvent losses } \\
\text { from } 20 \text { column reduced about } 17 \% \text {. }\end{array}$ \\
\hline Aug-62 & HW-74804 & - & 271.05 & 17 & - & $1,487,251$ & 4,462 & \\
\hline Sep-62 & HW-75145 & - & 498.97 & 23 & - & $2,737,848$ & 8,214 & $\begin{array}{l}\text { Numerous equipment failures. Testing Cs recovery with } \\
\text { ferrocyanide (HW-75051). Transfer of used organic wash } \\
\text { solutions from No. } 2 \text { to No. } 1 \text { systems for reuse and disposal } \\
\text { started on Sept 19. R1 jetted to G1. R2 jetted to G2. }\end{array}$ \\
\hline & & & & & & & & $\begin{array}{l}\text { Purpose is to reduce solvent losses and reduce chemical } \\
\text { consumption in the solvent treatment systems. }\end{array}$ \\
\hline Oct-62 & $H W-75470$ & - & 772.43 & 28 & - & $4,238,323$ & 8,900 & $\begin{array}{l}\text { Reused all No. } 2 \text { System washes in No. } 1 \text { Solvent treatment } \\
\text { system. Result is } 50 \% \text { reduction in organic wash solutions and } \\
30 \% \text { reduction in solvent losses. }\end{array}$ \\
\hline Nov-62 & HW-75702 & - & 695.01 & 25 & - & $3,813,520$ & 8,008 & \\
\hline Dec-62 & $H W-76054$ & - & 784.51 & 29 & - & $4,304,606$ & 9,040 & \\
\hline \multicolumn{2}{|c|}{ Total 1962} & & 6040.04 & 281 & & & 88,304 & \\
\hline Jan-63 & HW-76443 & - & 9.63 & 0 & - & 52,840 & 111 & $\begin{array}{l}\text { Shut down all month - lack of feed. } 2 \text { nd cycle } U \text { system } \\
\text { operated } 4 \text { days. Following the run, No. } 2 \text { System did not } \\
\text { reposnd completely to treatment \& was set aside for additional } \\
\text { batch treatment. }\end{array}$ \\
\hline \multirow[t]{2}{*}{ Feb-63 } & HW.76848 & - & 405.62 & 17 & - & $2,225,637$ & 4,674 & $\begin{array}{l}\text { The last of the mixed diluent (Shell E-2342, Soltrol-170) was } \\
\text { introduced into the plant and a transition to all Soltrol-170 was } \\
\text { started. The } 3,900 \text { gal of solvent ( } 48 \% \text { TBP) which passed } \\
\text { through the } 1 \text { CU concentrator was stored for future use. }\end{array}$ \\
\hline & & & & & & & & Testing sugar denitration of high level waste. \\
\hline Mar-63 & HW-77138 & - & 867.24 & 29 & - & $4,758,546$ & 9,993 & \\
\hline
\end{tabular}


Table 2-3: Estimated Solvent Losses from 1955 to 1967 based on HAPO and CPD Monthly Reports

\begin{tabular}{|c|c|c|c|c|c|c|c|c|}
\hline Date & $\begin{array}{l}\text { HAPOKCPD } \\
\text { Monthly } \\
\text { Report No. }\end{array}$ & $\begin{array}{l}\text { Essential } \\
\text { Materials } \\
\text { Report No. }\end{array}$ & $\begin{array}{c}\text { Tons } \\
\text { Uranium }\end{array}$ & $\begin{array}{c}\text { Est.\# of } \\
\text { Operating } \\
\text { Days }\end{array}$ & $\begin{array}{l}\text { Reported Solvent } \\
\text { Loss* (\% of } \\
\text { throughput) }\end{array}$ & $\begin{array}{c}\text { Est. solvent } \\
\text { throughput } \\
\text { (gal) }\end{array}$ & $\begin{array}{c}\begin{array}{c}\text { Est. } \\
\text { Solvent } \\
\text { Loss* (gal) }\end{array} \\
\end{array}$ & Notes \\
\hline Apr -63 & HW-77504 & - & 13.12 & 2 & - & 71,989 & 151 & $\begin{array}{l}\text { Used up available feed. Boron raschig rings installed in E-Cell } \\
\text { sump. Replaced HS Column. }\end{array}$ \\
\hline May-63 & HW-77795 & $\cdot$ & 669.07 & 24 & - & $3,671,187$ & 7,709 & Replaced HA Column. \\
\hline Jun-63 & $\mathrm{HW}-78076$ & - & 773.9 & 30 & - & $4,246,389$ & 8,917 & $50 \% \mathrm{NaOH}$ added to $\mathrm{A}-3$ dissolver heel - violent reaction. \\
\hline Jul-63 & HW-78484 & $\cdot$ & 12.28 & 0 & - & 67,380 & 141 & $\begin{array}{l}\text { Plant scale test of trilaurylamine for extraction of } \mathrm{Pu} \text { and } \mathrm{Np} \text { from } \\
\mathrm{IWW} \text {. }\end{array}$ \\
\hline Aug-63 & HW-78817 & - & 202.3 & 14 & - & $1,110,020$ & 2,331 & $\begin{array}{l}\text { Degraded solvent in both systems. } 5,100 \text { gallons inadvertently } \\
\text { boiled in the } 1 \mathrm{CU} \text { concentrator during } \mathrm{Np} \text { recovery period. }\end{array}$ \\
\hline Sep-63 & HW-79097 & - & 621.29 & 30 & - & $3,409,018$ & 7,159 & \\
\hline Oct-63 & HW-79480 & - & 453.56 & 28 & - & $2,488,684$ & 5,226 & \\
\hline Nov-63 & HW-79768 & - & 721.07 & 27 & - & $3,956,511$ & 8,309 & Preparing for additional trilaurylamine studies. \\
\hline Dec-63 & $\mathrm{HW}-80243$ & - & 668.02 & 24 & - & $3,665,426$ & 7,697 & \\
\hline \multicolumn{2}{|c|}{ Total 1963} & & 5417.1 & 225 & & & 62,420 & \\
\hline & & & & & & & & \\
\hline Jan-64 & HW-80672 & - & 235 & 24 & - & $1,289,445$ & 2,708 & \\
\hline Feb-64 & HW-81078 & - & 3 & 3 & - & 16,461 & 35 & $\begin{array}{l}\text { Trilaurylamine tests resumes after installing high efficiency } \\
\text { agitator. }\end{array}$ \\
\hline Mar-64 & $H W-81620$ & - & 805 & 29 & - & $4,417,035$ & 9,276 & \\
\hline Apr-64 & HW-82809 & - & 298 & 20 & - & $1,635,126$ & 3,434 & Ammonium nitrate on Purex Canyon filter decreases air flow. \\
\hline May-64 & HW-82526 & - & 471 & 22 & - & $2,584,377$ & 5,427 & 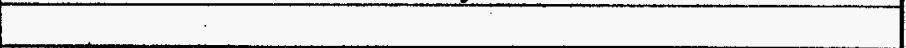 \\
\hline Jun-64 & $\mathrm{HW}+83102$ & - & 727 & 29 & - & $3,989,049$ & 8,377 & \\
\hline Jul-64 & HW-83508 & - & 289 & 16 & - & $1,585,743$ & 3,330 & Testing with trilaurylamine. \\
\hline Aug-64 & $\mathrm{HW}-83876$ & - & 856 & 31 & - & $4,696,872$ & 9,863 & Starting process design for Thorium separations. \\
\hline Sep-64 & HW-84354 & 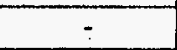 & 508 & 28 & - & $2,787,396$ & 5,854 & \\
\hline Oct-64 & RL-SEP-52 & - & 843 & 29 & - & $4,625,541$ & 9,714 & \\
\hline Nov-64 & RL-SEP-112 & - & 606 & 30 & - & $3,325,122$ & 6,983 & Studying new diluent from Hol Semiworks - NPH \\
\hline Dec-64 & RL-SEP-197 & - & 118 & 7 & - & 647,466 & 1,360 & Conducting operability tests in AX Tank Farm. RL-SEP-9 \\
\hline \multicolumn{2}{|c|}{ Total 1964} & & 5759 & 268 & & & 66,359 & \\
\hline & & & & & & & & \\
\hline Jan-65 & RL-SEP-282 & - & 0 & 0 & - & 0 & 0 & $\begin{array}{l}\text { Whole month involved thorium test run. } 40 \mathrm{hrs} \text { of solvent } \\
\text { extraction. TK-105-A bumped, first instance where circulators } \\
\text { were believed to be operating. }\end{array}$ \\
\hline Feb-65 & RL-SEP-332 & - & 391 & 14 & - & $2,145,417$ & 4,505 & Thoria test finished Feb 4th. Poor solvent quality. \\
\hline
\end{tabular}


Table 2-3: Estimated Solvent Losses from 1955 to 1967 based on HAPO and CPD Monthly Reports

\begin{tabular}{|c|c|c|c|c|c|c|c|c|}
\hline Date & $\begin{array}{l}\text { HAPO/CPD } \\
\text { Monthly } \\
\text { Report No. }\end{array}$ & $\begin{array}{l}\text { Essential } \\
\text { Materials } \\
\text { Report No. }\end{array}$ & $\begin{array}{c}\text { Tons } \\
\text { Uranium }\end{array}$ & $\begin{array}{c}\text { Est.\# of } \\
\text { Operating } \\
\text { Days }\end{array}$ & $\begin{array}{l}\text { Reported Solvent } \\
\text { Loss }{ }^{*} \text { (\% of } \\
\text { throughput) }\end{array}$ & $\begin{array}{l}\text { Est. solvent } \\
\text { throughput } \\
\text { (gal) }\end{array}$ & $\begin{array}{c}\text { Est. } \\
\text { Solvent } \\
\text { Loss* (gal) }\end{array}$ & Notes \\
\hline Mar-65 & RL-SEP-405 & + & 807 & 26 & - & $4,428,009$ & 9,299 & 103-AX boiled at end of month. \\
\hline Apr-65 & RL-SEP-476 & - & 909 & 29 & - & $4,987,683$ & 10,474 & Earth tremor April 29th. \\
\hline May-65 & RL-SEP-509 & - & .884 & 31 & - & $4,850,508$ & $10 ; 186$ & \\
\hline Jun-65 & RL-SEP-618 & - & 529 & 23 & - & $2,902,623$ & 6,096 & $\begin{array}{l}\text { No. } 1 \text { Solvent System chemically flushed. No. } 2 \text { solvent } \\
\text { transferred to No. } 1 \text { System and replaced with fresh. }\end{array}$ \\
\hline Jul-65 & RL-SEP-654 & - & 262 & 10 & - & $1,437,594$ & 3,019 & Purex staff 366. \\
\hline Aug-65 & RL-SEP-706 & - & 459 & 25 & - & $2,518,533$ & 5,289 & Renovating A-Cell, new annular dissolver installed. \\
\hline Sep-65 & RL-SEP-755 & - & 506 & 23 & - & $2,776,422$ & 5,830 & Recovering $\mathrm{Np}, \mathrm{Sr}$. \\
\hline Oct-65 & RL-SEP-837 & - & 389 & 27 & - & $2,134,443$ & 4,482 & Preparing to install new B-Cell dissolver. \\
\hline \multirow[t]{2}{*}{ Nov-65 } & RL-SEP-874 & - & 211 & 13 & - & $1,157,757$ & 2,431 & $\begin{array}{l}\text { Lab investigation concludes reactions between solid nitrate salts } \\
\text { and ferrocyanides occur only at abnormally high concentrations } \\
\text { of the constituents and at elevated temperature. There appears } \\
\text { no possibility of a reaction with }\end{array}$ \\
\hline & & & & & & 0 & 0 & $\begin{array}{l}\text { the } 0.005 \mathrm{M} \text { concentrations specified in the flowsheet. An } \\
\text { efficient method of destroying cyanide complexes even at low } \\
\text { concentrations is being sought. }\end{array}$ \\
\hline Dec-65 & RL-SEP-913 & - & 425 & 23 & - & $2,331,975$ & 4,897 & $\begin{array}{l}\text { Effective midnight on 12/31 Chemical Processing Department is } \\
\text { transferred to Isochem. }\end{array}$ \\
\hline \multicolumn{2}{|c|}{ Total 1965} & & 5772 & 244 & & & 66,509 & \\
\hline & & & & & & & & \\
\hline Jan-66 & ISO-89 & $\therefore$ & 413 & 21 & & $2,266,131$ & 4,759 & $\begin{array}{l}\text { BNWL-CC-1070, "A Survey of B-Plant Wasteform Explosion } \\
\text { Hazards, J. F. Phillips Jr., 1967. }\end{array}$ \\
\hline Feb-66 & ISO-143 & - & 398 & 24 & - & $2,183,826$ & 4,586 & $\begin{array}{l}\text { Entire working volume of solvent was replaced in mid February. } \\
\text { New diluent is NPH from South Hampton Oil Co. }\end{array}$ \\
\hline Mar-66 & ISO-210 & - & 632 & 27 & - & - & 5670 & Dissolution \& first production campaign of zircaloy clad fuel. \\
\hline Apr-66 & ISO-276 & - & 279 & 13 & - & - & 2730 & Preparing for thoria processing. \\
\hline May-66 & ISO-315 & - & 17 & - & 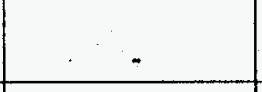 & - & 840 & $\begin{array}{l}\text { Production is tons of thorium. Thoria charged to dissolvers May } \\
11 \text { th. }\end{array}$ \\
\hline Jun-66 & ISO-365 & - & 130 & 27 & - & & 11,097 & $\begin{array}{l}\text { Production is tons of thorium. Severe emulsification in No. } 2 \\
\text { washes. Overall solvent losses for June averaged } 411 \mathrm{gal} / \mathrm{day} \\
\text { vs } 210 \text { gal/day average during previous experience with NPH. }\end{array}$ \\
\hline
\end{tabular}


Table 2-3: Estimated Solvent Losses from 1955 to 1967 based on HAPO and CPD Monthly Reports

\begin{tabular}{|c|c|c|c|c|c|c|c|c|}
\hline Date & $\begin{array}{l}\text { HAPOKPD } \\
\text { Monthly } \\
\text { Report No. }\end{array}$ & $\begin{array}{l}\text { Essential } \\
\text { Materials } \\
\text { Report No. }\end{array}$ & \begin{tabular}{c|} 
Tons \\
Uranium \\
\end{tabular} & $\begin{array}{c}\text { Est.\# of } \\
\text { Operating } \\
\text { Days }\end{array}$ & $\begin{array}{c}\text { Reported Solvent } \\
\text { Loss }{ }^{*}(\% \text { of } \\
\text { throughput) }\end{array}$ & $\begin{array}{l}\text { Est. solvent } \\
\text { throughput } \\
\text { (gal) }\end{array}$ & $\begin{array}{c}\text { Est. } \\
\text { Solvent } \\
\text { Loss* (gal) }\end{array}$ & Notes \\
\hline Jul-66 & ISO-428 & . & 41 & 7 & - & - & 1470 & $\begin{array}{l}\text { Production is tons of thorium. "SECRETARY" computer } \\
\text { program calculates tank data. includes heat, salt, rad. inventory } \\
\text { for all tanks. Includes decay and waste transfers. }\end{array}$ \\
\hline Aug-66 & ISO-476 & - & 29 & 4 & - & - & 840 & Uranium restarted August 28. \\
\hline Sep-66 & ISO-512 & - & 578 & 28 & - & - & 5880 & $\begin{array}{l}\text { New annular dissolver in C-Cell. NPH process test continues. } \\
\text { "SECRETARY" program includes } \mathrm{OH}, \mathrm{CO}, \mathrm{AlO2}, \mathrm{F}, \mathrm{Cl}, \mathrm{NO} \text {, } \\
\mathrm{CN}, \mathrm{pH} \text {. Adding intertank transfer subroutine. Report to be } \\
\text { issued: } 15 \mathrm{SO}-489 \text {. }\end{array}$ \\
\hline Oct-66 & $150-563$ & - & 915 & 31 & - & - & 6510 & $\begin{array}{l}\text { Resumed 3-dissolver operations Oct. 8th. Lab tests show } \\
\text { negligible degradation products are formed using NPH vs Soltrol. }\end{array}$ \\
\hline Nov-66 & ISO-610 & - & 491 & 22 & - & - & 4620 & Discussion of $\mathrm{KOH}$ metathesis step. \\
\hline Dec-66 & ISO-642 & $\cdot$ & 431 & 20 & $\cdot$ & - & 4200 & $\begin{array}{l}\text { Developed rapid go-no-go method for cyanide at } 100 \text { ppm level } \\
\text { for tank farm waste samples. }\end{array}$ \\
\hline \multicolumn{2}{|c|}{ Total 1966} & & 4354 & 224 & & & 53,202 & \\
\hline Jan-67 & $150-707$ & - & 751 & 30 & - & - & 6300 & \\
\hline Feb-67 & 150.708 & - & 221 & 8 & - & - & 1680 & $\begin{array}{l}\text { Fission product recovery contract cancelled. Deactivating the } \\
\text { REDOX Plant. }\end{array}$ \\
\hline Mar-67 & $150-709$ & - & 293 & 12 & - & - & 2520 & \\
\hline Apr-67 & $150-710$ & - & 701 & 28 & - & - & 5880 & \\
\hline May-67 & $1 S 0-711$ & $\because$ & 487 & 24 & - & - & 5040 & \\
\hline Jun-67 & ISO-712 & - & 195 & 11 & - & - & 2310 & $\begin{array}{l}\text { New HA column - unidiameter. Installed ammonia monitor on } \\
\text { coating waste tank. }\end{array}$ \\
\hline Jul-67 & $1 \mathrm{SO}-713$ & - & 177 & 22 & - & - & 4620 & \\
\hline Aug-67 & 150.714 & - & 400 & 18 & - & - & 3780 & Ammonia monitor on Tank 102-C. \\
\hline & & & & . & & & & \\
\hline \multicolumn{9}{|c|}{\begin{tabular}{l|l|l|l|l} 
Notes: & & & & \\
\end{tabular}} \\
\hline \multicolumn{9}{|c|}{\begin{tabular}{|l|l|l|l|} 
"Solvent losses do not include amounts disposed to crib. & & & \\
\end{tabular}} \\
\hline \multicolumn{9}{|c|}{ Estimated solvent throughput is based on Purex Chemical flowsheet No. 4, HW-35225, March 4, 1955.} \\
\hline & \multicolumn{7}{|c|}{\begin{tabular}{|l|l|l|} 
This flowsheet shows a No. 1 System throughput of 3,001 gal/ton of uranium, & \\
\end{tabular}} & \\
\hline & \multicolumn{7}{|c|}{ and a No. 2 System throughput of $2,486 \mathrm{gal} / \mathrm{ton}$ of uranium, with a total of 5,487 galion. } & \\
\hline & & & & & & & & \\
\hline
\end{tabular}


technique, the estimated losses could be somewhat low in some months, because the production numbers would not include solutions that were set aside for rework because they did not meet specifications, and therefore were not counted as product.

Readily available records of actual consumption of diluent and TBP at Purex are extensive, beginning in 1965 (Logbooks HWN-3610, ARH-N-134, WHC-N676, and essential materials monthly consumption reports). These records are summarized in Table 2-4. The original essential materials records used in this study recorded consumption in pounds, except the diluent, which was originally recorded in gallons. For some years, the data were repeated in more than one portion of the logbook. In 1966/67 the units for NPH were changed to pounds, but the exact point of the change is not clear. A subsequent repetition of the 1967 data, however, was positive on the use of pounds. Negative entries indicated that the plant had transferred some of its NPH or TBP to another plant.

Record keeping in the logbooks was eventually discontinued, with essential material consumption being recorded on monthly data sheets only. For the most part, the data sheets identified each plant with a cost code. While there is no index to these codes, the plants can be identified by their consumption of unique chemicals. Purex, for example, used AFAN (ammonium fluoride/ammonium nitrate) and B-Plant used ammonia. Units for TBP and NPH in the monthly reports were in units of pounds. The code on the monthiy records for units for these chemicals was listed as "C," meaning hundredweight. However, this code was merely an instruction for personnel to divide by 100 when sending information out. The dates used to compile the monthly figures are not exact for each month, but rather are for a period covering most of the month, for example, 12-20-82 to 1-24-83 was 1isted as January 1983. The essential materials records differ from the Chemical Processing Department Monthly Reports, in that the Plant was not ordering chemicals on a day to day basis, but would wait until stocks were reduced. As a result, the essential materials records are not useful to reflect consumption in the short term, but are more reasonable when summed for the year.

The CPD Monthly Reports and the Essential Materials Records overlap for the years 1965 and 1966. In these years, the essential materials records indicate higher consumption than the CPD Monthly Reports. For 1965, the essential materials consumption was 102,000 gallons and the monthly reports indicate losses of 67,000 gallons. For 1966, the essential materials consumption was 71,000 gallons and the monthly reports indicate losses of 53,000 gallons. The records do not shed any light on the discrepancy, although the diluent was changed from Soltrol-170 to NPH in February of 1966. 
Revision 0

Table 2-4: Estimated Solvent Losses from 1965 to 1991 Based on Essential Materials Consumption Records

\begin{tabular}{|c|c|c|c|c|c|c|c|c|}
\hline Month & Tons U* & Ib TBP & Ib Diluent & Gal TBP & Gal Diluent & Total Gal Solvent & Gal/Ton U & \\
\hline & & & & & & 3201 & - & Soltrol \\
\hline Jan-65 & 0 & 25,995 & 0 & 3,201 & 0 & 3,201 & - & Soltrol \\
\hline Feb-65 & 391 & 47,127 & 79,781 & 5,804 & 12,371 & 18,175 & 46 & \\
\hline Mar-65 & 807 & 27,989 & 42,589 & 3,447 & 6,604 & 10,051 & 12 & \\
\hline Apr-65 & 909 & 47,671 & 48,064 & 5,871 & 7,453 & 13,324 & 15 & \\
\hline May-65 & 884 & 0 & 64,064 & 0 & 9,934 & 9,934 & 11 & \\
\hline Jun-65 & 529 & 44,228 & 11,621 & 5,447 & 1,802 & 7,249 & 14 & \\
\hline Jul-65 & 262 & 3,558 & 9,686 & 438 & 1,502 & 1,940 & 7 & \\
\hline Aug-65 & 459 & 24,508 & 41,532 & 3,018 & 6,440 & 9,458 & 21 & \\
\hline Sep-65 & 506 & 16,644 & 34,070 & 2,050 & 5,283 & 7,333 & 14 & \\
\hline Oct-65 & 389 & 21,363 & 32,903 & 2,631 & 5,102 & 7,733 & 20 & \\
\hline Nov-65 & 211 & 16,023 & 24,003 & 1,973 & 3,722 & 5,695 & 27 & \\
\hline Dec-65 & 425 & 18,458 & 34,102 & 2,273 & 5,288 & 7,561 & 18 & \\
\hline Total 1965 & 5,772 & 293,564 & 422,416 & 36,153 & 65,501 & 101,654 & 18 & \\
\hline Jan-66 & 413 & 21,115 & 29,053 & 2,600 & 4,505 & 7,105 & 17 & \\
\hline Feb-66 & 398 & 84,787 & 1,902 & 10,442 & 300 & 10,742 & 27 & $\mathrm{NPH}$ \\
\hline Mar-66 & 632 & 13,495 & 0 & 1,662 & 0 & 1,662 & 3 & \\
\hline Apr-66 & 279 & 9,995 & 0 & 1,231 & 0 & 1,231 & 4 & \\
\hline May-66 & 17 & 25,493 & 0 & 3,140 & 0 & 3,140 & 185 & \\
\hline Jun-66 & 130 & 3,827 & 70,196 & 471 & 11,072 & 11,543 & 89 & \\
\hline Jul-66 & 41 & 97,262 & 0 & 11,978 & 0 & 11,978 & 292 & \\
\hline Aug-66 & 29 & $-63,707$ & 33,397 & $-7,846$ & 5,343 & $-2,503$ & -86 & \\
\hline Sep-66 & 578 & 30,223 & 32,664 & 3,722 & 5,152 & 8,874 & 15 & \\
\hline Oct-66 & 915 & 20,746 & 35,846 & 2,555 & 5,654 & 8,209 & 9 & \\
\hline Nov-66 & 491 & 18,208 & 23,033 & 2,242 & 3,633 & 5,875 & 12 & \\
\hline Dec-66 & 431 & 8,515 & 16,135 & 1,049 & 2,545 & 3,594 & 8 & \\
\hline Total 1966 & 4,354 & 269,959 & 242,227 & 33,246 & 38,204 & 71,450 & 16 & \\
\hline $\operatorname{Jan}-67$ & 751 & 18,914 & 57,315 & 2,329 & 9,040 & 11,370 & 15 & \\
\hline Feb-67 & 221 & 0 & 52,820 & 0 & 8,331 & 8,331 & 38 & \\
\hline Mar-67 & 293 & 14,622 & 3,490 & 1,801 & 550 & 2,351 & 8 & \\
\hline Apr-67 & 701 & 19,415 & 3,201 & 2,391 & 505 & 2,896 & 4 & \\
\hline May-67 & 487 & 10,493 & $-71,634$ & 1,292 & $-11,299$ & $-10,006$ & -21 & \\
\hline Jun-67 & 195 & 10,839 & 50,014 & 1,335 & 7,889 & 9,223 & 47 & \\
\hline Jul-67 & 177 & 12,725 & $-44,699$ & 1,567 & $-7,050$ & $-5,483$ & -31 & \\
\hline Aug-67 & 400 & 9,512 & 20,674 & 1,171 & 3,261 & 4,432 & 11 & \\
\hline Sep-67 & 504 & 26,045 & $-21,868$ & 3,208 & $-3,449$ & -242 & 0 & \\
\hline Oct-67 & 434 & 8,484 & 14,012 & 1,045 & 2,210 & 3,255 & 7 & \\
\hline Nov-67 & 587 & 10,427 & 16,013 & 1,284 & 2,526 & 3,810 & 6 & \\
\hline Dec-67 & 120 & 5,968 & 126,100 & 735 & 19,890 & 20,625 & 172 & \\
\hline Total 1967 & 4,870 & 147,444 & 205,438 & 18,158 & 32,404 & 50,562 & 10 & \\
\hline Jan-68 & 289 & 17,089 & $-12,019$ & 2,105 & $-1,896$ & 209 & 1 & \\
\hline
\end{tabular}


WHC-MR-0483

Revision 0

Table 2-4: Estimated Solvent Losses from 1965 to 1991 Based on Essential Materials Consumption Records

\begin{tabular}{|c|c|c|c|c|c|c|c|c|}
\hline Month & Tons U* & Ib TBP & 16 Diluent & Gal TBP & Gal Diluent & Total Gal Solvent & Gal/ton U & \\
\hline Feb-68 & 179 & 3,770 & 0 & 464 & 0 & 464 & 3 & \\
\hline Mar-68 & 543 & 7,199 & $-64,722$ & 887 & $-10,209$ & $-9,322$ & -17 & \\
\hline Apr-68 & 345 & 16,652 & 7,496 & 2,051 & 1,182 & 3,233 & 9 & \\
\hline May-68 & 269 & 9,286 & 18,363 & 1,144 & 2,896 & 4,040 & 15 & \\
\hline Jun-68 & 680 & 26,088 & 46,579 & 3,213 & 7,347 & 10,560 & 16 & \\
\hline Jul-68 & 103 & 8,482 & 12,013 & 1,045 & 1,895 & 2,939 & 29 & \\
\hline Aug- 68 & 486 & 8,670 & 28,018 & 1,068 & 4,419 & 5,487 & 11 & \\
\hline Sep-68 & 192 & 21,526 & 20,019 & 2,651 & 3,158 & 5,809 & 30 & \\
\hline Oct-68 & 570 & $-1,609$ & 23,169 & -198 & 3,654 & 3,456 & 6 & \\
\hline Nov-68 & 354 & 7,540 & 16,013 & 929 & 2,526 & 3,454 & 10 & \\
\hline Dec-68 & 299 & 2,827 & 10,006 & 348 & 1,578 & 1,926 & 6 & \\
\hline Total 1968 & 4,309 & 127,520 & 104,935 & 15,704 & 16,551 & 32,256 & 7 & \\
\hline Jan-69 & 0 & 13,446 & 18,013 & 1,656 & 2,841 & 4,497 & - & \\
\hline Feb-69 & 128 & 8,484 & 6,006 & 1,045 & 947 & 1,992 & 16 & \\
\hline Mar-69 & 346 & 2,762 & 10,006 & 340 & 1,578 & 1,918 & 6 & \\
\hline Apr-69 & 270 & 12,254 & 30,025 & 1,509 & 4,736 & 6,245 & 23 & \\
\hline May-69 & 460 & 9,425 & 0 & 1,161 & 0 & 1,161 & 3 & \\
\hline Jun-69 & 110 & 6.598 & 10,006 & 813 & 1,578 & 2,391 & 22 & \\
\hline Jul-69 & 18 & -65 & 0 & -8 & 0 & -8 & 0 & \\
\hline Aug-69 & 369 & 5,655 & 12,013 & 696 & 1,895 & 2,591 & 7 & \\
\hline Sep-69 & 384 & 6,598 & 5,546 & 813 & 875 & 1,687 & 4 & \\
\hline Oct-69 & 318 & 14,886 & 0 & 1,833 & 0 & 1,833 & 6 & \\
\hline Nov-69 & 304 & 10,987 & 26,019 & 1,353 & 4,104 & 5,457 & 18 & \\
\hline Dec-69 & 318 & 6,847 & 14,012 & 843 & 2,210 & 3,053 & 10 & \\
\hline Total 1969 & 3,025 & 97,877 & 131,646 & 12,054 & 20,764 & 32,818 & 11 & \\
\hline Jan-70 & 246 & 6,598 & 18,013 & 813 & 2,841 & 3,654 & 15 & \\
\hline Feb-70 & 84 & 5,656 & 10,006 & 697 & 1,578 & 2,275 & 27 & \\
\hline Mar-70 & 9.6 & 4,585 & 14,012 & 565 & 2,210 & 2,775 & 289 & \\
\hline Apr-70 & 312 & 7,541 & 38,032 & 929 & 5,999 & 6,927 & 22 & \\
\hline May-70 & 62 & 6,596 & $-14,013$ & 812 & $-2,210$ & $-1,398$ & -23 & \\
\hline Jun-70 & 52 & 944 & 38,032 & 116 & 5,999 & 6,115 & 118 & \\
\hline Jul-70 & 0 & 5,655 & 43,677 & 696 & 6,889 & 7,586 & - & \\
\hline Aug-70 & 0 & 18,724 & $-74,202$ & 2,306 & $-11,704$ & $-9,398$ & - & \\
\hline Sep-70 & 122 & 29,218 & 136,044 & 3,598 & 21,458 & 25,056 & 205 & Thorium \\
\hline Oct-70 & 28 & 12,442 & 18,013 & 1,532 & 2,841 & 4,373 & 156 & Thorium \\
\hline Nov-70 & 155 & 18,859 & 24,018 & 2,323 & 3,788 & 6,111 & 39 & Thorium \\
\hline Dec-70 & 90 & 7,343 & $-1,416$ & 904 & -223 & 681 & 8 & Thorium \\
\hline Total 1970 & 1,161 & 124,161 & 250,216 & 15,291 & 39,466 & 54,757 & 47 & \\
\hline Jan-71 & 0 & 0 & 4,000 & 0 & 631 & 631 & - & \\
\hline Feb-71 & 0.4 & 0 & 0 & 0 & 0 & 0 & 0 & Thorium \\
\hline Mar-71 & 0 & 0 & 0 & 0 & 0 & 0 & + & \\
\hline
\end{tabular}


WHC-MR-0483

Revision 0

Table 2-4: Estimated Solvent Losses from 1965 to 1991 Based on Essential Materials Consumption Records

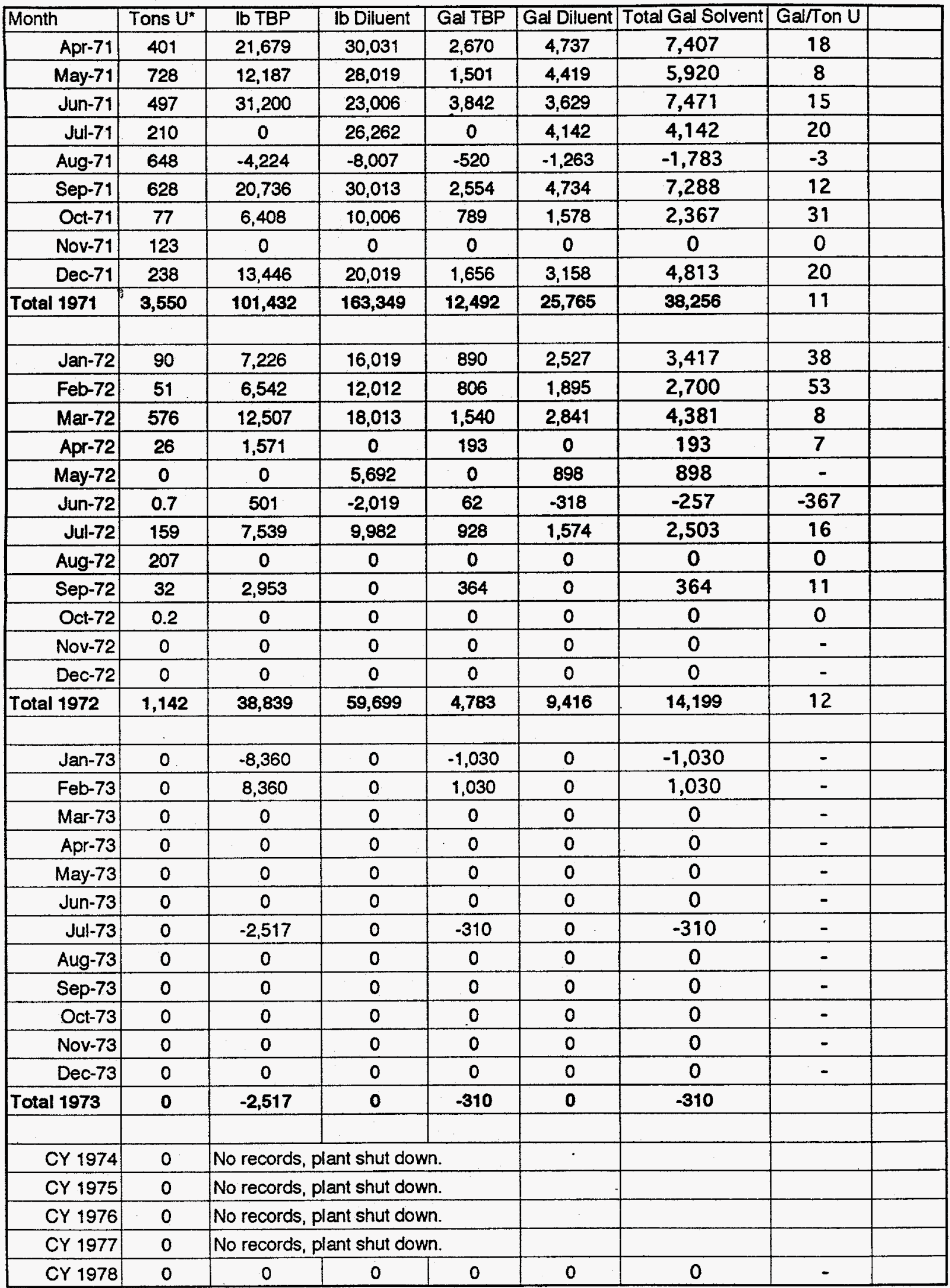




\section{WHC-MR-0483}

Revision 0

Table 2-4: Estimated Solvent Losses from 1965 to 1991 Based on Essential Materials Consumption Records

\begin{tabular}{|c|c|c|c|c|c|c|c|c|}
\hline Month & Tons $\mathrm{U}^{*}$ & Ib TBP & Ib Diluent & Gal TBP & Gal Diluent & Total Gal Solvent & Gal/Ton U & \\
\hline CY 1979 & 0 & 0 & 1,892 & 0 & 298 & 298 & - & \\
\hline CY 1980 & 0 & 0 & 0 & 0 & 0 & 0 & - & \\
\hline CY 1981 & 0 & 0 & 0 & 0 & 0 & 0 & - & \\
\hline CY 1982 & 0 & 6,697 & 0 & 825 & 0 & 825 & - & \\
\hline Jan-83 & 0 & 0 & 8,003 & 0 & 1,262 & 1,262 & - & \\
\hline Feb-83 & 0 & 0 & 0 & 0 & 0 & 0 & - & \\
\hline Mar-83 & 0 & 4,748 & 12,009 & 585 & 1,894 & 2,479 & - & \\
\hline Apr -83 & 0 & 0 & 0 & 0 & 0 & 0 & - & \\
\hline May-83 & 0 & 481 & 0 & 59 & 0 & 59 & - & \\
\hline Jun-83 & 0 & 6,735 & 14,008 & 829 & 2,209 & 3,039 & - & \\
\hline Jul-83 & 0 & 943 & 0 & 116 & 0 & 116 & - & \\
\hline Aug-83 & 0 & 0 & 0 & 0 & 0 & 0 & - & \\
\hline Sep-83 & 0 & 11,310 & 0 & 1,393 & 0 & 1,393 & - & \\
\hline Oct-83 & 0 & 6,593 & 24,017 & 812 & 3,788 & 4,600 & - & \\
\hline Nov-83 & 43 & 5,655 & 12,075 & 696 & 1,905 & 2,601 & 60 & \\
\hline Dec-83 & 55 & 944 & 17,853 & 116 & 2,816 & 2,932 & 53 & \\
\hline Total 1983 & 98 & 37,409 & 87,965 & 4,607 & 13,875 & 18,482 & 189 & \\
\hline Jan-84 & 113 & 11,311 & 4,031 & 1,393 & 636 & 2,029 & 18 & \\
\hline Feb-84 & 46 & 12,253 & 14,188 & 1,509 & 2,238 & 3,747 & 81 & \\
\hline Mar-84 & 136 & 9,436 & 6,600 & 1,162 & 1,041 & 2,203 & 16 & \\
\hline Apr-84 & 136 & 0 & 0 & 0 & 0 & 0 & 0 & \\
\hline May-84 & 100 & 20,736 & 31,887 & 2,554 & 5,029 & 7,583 & 76 & \\
\hline Jun-84 & 113 & 1,885 & .754 & 232 & -119 & 113 & 1 & \\
\hline Jul-84 & 160 & 0 & 0 & 0 & 0 & 0 & 0 & \\
\hline Aug-84 & 172 & 5,655 & 14,038 & 696 & 2,214 & 2,911 & 17 & \\
\hline Sep-84 & 80 & 6,597 & 15,554 & 812 & 2,453 & 3,266 & 41 & \\
\hline Oct-84 & 0 & 0 & 0 & 0 & 0 & 0 & - & \\
\hline Nov-84 & 34 & 18,529 & 24,010 & 2,282 . & 3,787 & 6,069 & 178 & \\
\hline Dec-84 & 115 & 11,159 & 18,007 & 1,375 & 2,840 & 4,216 & 37 & \\
\hline Total 1984 & 1,205 & 97,571 & 127,561 & 12,016 & 20,120 & 32,136 & 27 & \\
\hline $\operatorname{Jan}-85$ & 160 & 8,526 & 10,002 & 1,050 & 1,578 & 2,628 & 16 & \\
\hline Feb-85 & 90 & 0 & 0 & 0 & 0 & 0 & 0 & \\
\hline Mar-85 & 168 & 5,690 & 13,915 & 701 & 2,195 & 2,896 & 17 & \\
\hline Apr-85 & 166 & 0 & 0 & 0 & 0 & 0 & 0 & \\
\hline May-85 & 56 & 10,341 & 10,102 & 1,274 & 1,593 & 2,867 & 51 & \\
\hline Jun-85 & 45 & 942 & 1,686 & 116 & 266 & 382 & 8 & \\
\hline Jul-85 & 132 & 6,599 & 18,006 & 813 & 2,840 & 3,653 & 28 & \\
\hline Aug-85 & 166 & 15,080 & 10,002 & 1,857 & 1,578 & 3,435 & 21 & \\
\hline Sep-85 & 33 & 9,362 & 5,991 & 1,153 & 945 & 2,098 & 64 & \\
\hline Oct- 85 & 78 & 0 & 10,010 & 0 & 1,579 & 1,579 & 20 & \\
\hline Nov-85 & 133 & 0 & 0 & 0 & 0 & 0 & 0 & \\
\hline
\end{tabular}


WHC-MR-0483

Revision 0

Table 2-4: Estimated Solvent Losses from 1965 to 1991 Based on Essential Materials Consumption Records

\begin{tabular}{|c|c|c|c|c|c|c|c|c|}
\hline Month & Tons $U^{*}$ & Ib TBP & Ib Diluent & Gal TBP & Gal Diluent & Total Gal Solvent & Gal/Ton U & \\
\hline Dec-85 & 33 & 2,175 & 9,204 & 268 & 1,452 & 1,720 & 52 & \\
\hline Total 1985 & 1,260 & 58,715 & 88,918 & 7,231 & 14,025 & 21,256 & 17 & \\
\hline Jan-86 & 54.3 & 12,969 & 8,802 & 1,597 & 1,388 & 2,985 & 55 & \\
\hline Feb-86 & 118 & 8,484 & 7,290 & 1,045 & 1,150 & 2,195 & 19 & \\
\hline Mar-86 & 229 & 4,711 & 8,663 & 580 & 1,366 & 1,947 & 9 & \\
\hline Apr-86 & 109 & 0 & 8,602 & 0 & 1,357 & 1,357 & 12 & \\
\hline May-86 & 104 & 4,000 & 23,691 & 493 & 3,737 & 4,229 & 41 & \\
\hline Jun-86 & 67 & 1,655 & 2,725 & 204 & 430 & 634 & 9 & \\
\hline Jul-86 & 163 & 2,828 & 3,599 & 348 & 568 & 916 & 6 & \\
\hline Aug-86 & 98 & 4,940 & 3,758 & 608 & 593 & 1,201 & 12 & \\
\hline Sep-86 & 0 & 4,486 & 6,245 & 552 & 985 & 1,537 & - & \\
\hline Oct-86 & 0 & 0 & 0 & 0 & 0 & 0 & - & \\
\hline Nov-86 & 0 & 0 & 0 & 0 & 0 & 0 & - & \\
\hline Dec-86 & 0 & 0 & 0 & 0 & 0 & 0 & - & \\
\hline Total 1986 & 942 & 44,073 & 73,375 & 5,428 & 11,573 & 17,001 & 18 & \\
\hline Jan-87 & 0 & 0 & 0 & 0 & 0 & 0 & - & \\
\hline Feb-87 & 8 & 0 & 0 & 0 & 0 & 0 & 0 & \\
\hline Mar-87 & 8 & 6,655 & 13,425 & 820 & 2,118 & 2,937 & 367 & \\
\hline Apr-87 & 8 & 4,467 & 13,472 & 550 & 2,125 & 2,675 & 334 & \\
\hline May-87 & 8 & 4,750 & 10,802 & 585 & 1,704 & 2,289 & 286 & \\
\hline Jun-87 & 8 & 2,015 & 10,218 & 248 & 1,612 & 1,860 & 232 & \\
\hline Jul-87 & 33 & 3,075 & 43 & 379 & 7 & 385 & 12 & \\
\hline Aug-87 & 65 & 3,733 & 8,462 & 460 & 1,335 & 1,794 & 28 & \\
\hline Sep-87 & 0 & 8,011 & 6,005 & 987 & 947 & 1,934 & - & \\
\hline Oct-87 & 0 & 0 & 0 & 0 & 0 & 0 & - & \\
\hline Nov-87 & 0 & 0 & 0 & 0 & 0 & 0 & - & \\
\hline Dec-87 & 0 & 0 & 0 & 0 & 0 & 0 & - & \\
\hline Total 1987 & 138 & 32,706 & 62,427 & 4,028 & 9,847 & 13,874 & 101 & \\
\hline Jan-88 & 22 & 0 & 0 & 0 & 0 & 0 & 0 & \\
\hline Feb-88 & 71 & 3,111 & 5,592 & 383 & 882 & 1,265 & 18 & \\
\hline Mar-88 & 53 & 0 & 0 & 0 & 0 & 0 & 0 & \\
\hline Apr-88 & 0 & 0 & 0 & 0 & 0 & 0 & - & \\
\hline May-88 & 11 & 5,843 & 11,210 & 720 & 1,768 & 2,488 & 226 & \\
\hline Jun-88 & 84 & 0 & 0 & 0 & 0 & 0 & 0 & \\
\hline Jul-88 & 42 & 4,525 & 2,402 & 557 & 379 & 936 & 22 & \\
\hline Aug-88 & 103 & 3,394 & 9,607 & 418 & 1,515 & 1,933 & 19 & \\
\hline Sep-88 & 103 & 4,501 & 9,605 & 554 & 1,515 & 2,069 & 20 & \\
\hline Oct-88 & 62 & 0 & 0 & 0 & 0 & 0 & 0 & \\
\hline Nov- 88 & 65 & 1,750 & 9,600 & 216 & 1,514 & 1,730 & 27 & \\
\hline Dec-88 & 32 & 5,655 & $9 ; 609$ & 696 & 1,516 & 2,212 & 69 & \\
\hline Total 1988 & 648 & 28,779 & 57,625 & 3,544 & 9,089 & 12,633 & 19 & \\
\hline
\end{tabular}


Revision 0

Table 2-4: Estimated Solvent Losses from 1965 to 1991 Based on Essential Materials Consumption Records

\begin{tabular}{|c|c|c|c|c|c|c|c|c|}
\hline Month & Tons $U^{*}$ & Ib TBP & Ib Diluent & Gal TBP & Gal Diluent & Total Gal Solvent & Gal/Ton U & \\
\hline Jan-89 & 0 & 0 & 0 & 0 & 0 & 0 & - & \\
\hline Feb-89 & 0 & 0 & 0 & 0 & 0 & 0 & - & \\
\hline Mar-89 & 0 & 0 & 0 & 0 & 0 & 0 & - & \\
\hline Apr-89 & 0 & 0 & 0 & 0 & 0 & 0 & - & \\
\hline May-89 & 0 & 0 & 0 & 0 & 0 & 0 & - & \\
\hline Jun-89 & 0 & 0 & 0 & 0 & 0 & 0 & - & \\
\hline Jul-89 & 0 & 0 & 0 & 0 & 0 & 0 & - & \\
\hline Aug-89 & 0 & 0 & 0 & 0 & 0 & 0 & - & \\
\hline Sep-89 & 0 & 0 & 0 & 0 & 0 & 0 & - & \\
\hline Oct-89 & 0 & 0 & 0 & 0 & 0 & 0 & - & \\
\hline Nov-89 & 0 & 0 & 0 & 0 & 0 & 0 & - & \\
\hline Dec-89 & 0 & 0 & 0 & 0 & 0 & 0 & - & \\
\hline Total 1989 & 0 & 0 & 0 & 0 & 0 & 0 & - & \\
\hline Jan-90 & 0 & 0 & 5,259 & 0 & 829 & 829 & - & \\
\hline Feb-90 & 60 & 0 & 0 & 0 & 0 & 0 & 0 & \\
\hline Mar-90 & 0 & 0 & 2,454 & 0 & 387 & 387 & - & \\
\hline Apr-90 & 0 & 0 & 0 & 0 & 0 & 0 & - & \\
\hline May-90 & 0 & 0 & 0 & 0 & 0 & 0 & - & \\
\hline Jun-90 & 0 & 0 & 0 & 0 & 0 & 0 & - & \\
\hline Jul-90 & 0 & 0 & 4,784 & 0 & 755 & 755 & - & \\
\hline Aug-90 & 0 & 1,702 & 0 & 210 & 0 & 210 & - & \\
\hline Sep-90 & 0 & 0 & 0 & 0 & 0 & 0 & - & \\
\hline Oct-90 & 0 & 0 & 0 & 0 & 0 & 0 & - & \\
\hline Nov-90 & 0 & 0 & 0 & 0 & 0 & 0 & - & \\
\hline Dec-90 & 0 & 0 & 0 & 0 & 0 & 0 & - & \\
\hline Total 1990 & 60 & 1,702 & 12,497 & 210 & 1,971 & 2,181 & 36 & \\
\hline & & & & & & & & \\
\hline Jan-91 & 0 & 0 & 2,393 & 0 & 377 & 377 & $=$ & \\
\hline Feb-91 & 0 & 0 & 0 & 0 & 0 & 0 & - & \\
\hline Mar-91 & 0 & 0 & 0 & 0 & 0 & 0 & - & \\
\hline Apr-91 & 0 & 0 & 0 & 0 & 0 & 0 & - & \\
\hline May-91 & 0 & 0 & 0 & 0 & 0 & 0 & - & \\
\hline Total 1991 & 0 & 0 & 2,393 & 0 & 377 & 377 & - & \\
\hline \multicolumn{8}{|c|}{ "Tons of Uranium are as reported in CPD Monthly Reports, in HW-89085, and per Ron Walser. } & \\
\hline & & & & & & & & \\
\hline
\end{tabular}


The method for disposing of the TBP/Soltrol mixture was not discussed. The estimated Purex solvent losses in this report are based on using the higher figures from the essential materials consumption records for 1965 and 1966.

According to a 1968 note found in the essential material history file for NPH, the Purex Plant required approximately 20,000 gallons "to fill system and maintain an operating inventory." Since TBP was 30 vol\% of the mixture used for solvent extraction, the operating inventory would also have included about 8,600 gallons of TBP. When the plant was shut down in 1972, the inventory of TBP and NPH was stored at Purex, and used when the plant was restarted in 1983.

Following shutdown of the plant in 1989 , the unused NPH $(44,0001 \mathrm{~b}$, about 6,900 gallons) and TBP (99,000 lb, about 12,200 gallons) were sold as excess (WHC, 1993). The used solvent mixture, about 21,000 gallons that is 25 vol\% TBP, is still located at the plant. This solvent contains very low levels of radioactive contamination. Tanks $G-5$ and $R-7$ in the building contain heels which total about 500 gallons. Another 3,500 gallons are located in a tank car outside the building. The balance is stored in Tank 40 in the 211-A chemical storage area. The solvent is being stored pending completion of efforts to find a suitable location for beneficial use. If reuse or chemical exchange options are exhausted, plans call for commercial incineration of the solvent.

\subsection{PUREX TBP/NPH MASS BALANCE}

The Purex Flowsheet (Allen, et al, 1985) and Purex Plant Technical Manuals (GE 1955 and Rockwell 1980) contain a great deal of information about processing in the Purex Plant and the properties of TBP and NPH. These references were used to estimate the distribution of TBP, NPH, and TBP degradation products that were lost via several streams leaving the $\mathrm{plant}$. Appendix A contains the detailed calculations along with a discussion and list of assumptions. Four distributions were estimated, due to changing operations in the plant. The data are presented on an annual basis because the monthly essential materials consumption records lag behind the operations (the plant would order fresh solvent after in-plant stock was depleted), and sometimes are negative (when the plant supplied chemicals to other plants). As a result, annual consumption is a better indicator of actual operations. 


\subsection{ESTIMATED TBP/NPH DISTRIBUTION IN WASTES AND EFFLUENTS}

Table 3-1 shows the estimated total organic loss and distribution for TBP and Diluent over the entire operating life of the Purex Plant. Figures 3-1, 3-2 and 3-3 show the organic losses for combined TBP and diluent in individual streams including the main stack, process condensate and organic wash waste, and high level waste and UNH product. Of these streams, the high level waste and organic wash waste were routed to the tank farms. The process condensate was routed to the process condensate crib. Table 3-2 is a summary of records of spent organic sent to the organic disposal crib. (Very little organic would likely have been discharged via any other streams leaving the Purex Plant.)

\subsection{ESTIMATED TOTAL LOSSES AND FATE OF TBP/NPH IN THE TANK FARMS}

The estimated total loss of organic from the plant is 452,000 gallons of TBP and 782,000 gallons of diluent, for a total of 1,234,000 gallons. The amount going to the tank farms is estimated to be about 2,000 gallons to high level waste and 655,000 gallons to organic wash waste.

In early operations, the organic wash waste was combined with the high level waste prior to transfer to the tank farms (both streams went to the high level waste tanks). Later operations separated the two streams, sending them to different tanks. This is significant, because boiling in the high level waste tanks would have distilled a lot of the organic, so that the organic would have ended up in a crib, via the condensate from the high level waste tanks. Organic wash waste stored in a non-boiling tank would be at a lower temperature and therefore would evaporate more slowly. In addition, TBP is also subject to alkaline hydrolysis (as well as radiolysis) and could be expected to degrade in the tank farms.

\subsection{OTHER SOURCES OF ORGANICS IN THE TANK FARMS}

Several of Hanford's other process plants have used of organic chemicals. U-Plant, Z-Plant, B-Plant, and Hot Semiworks (C-Plant) all involved the use of organic chemicals that may have been discharged to the tank farms as soluble or entrained species. While these facilities were not part of the scope of this study, their operations should be noted if the data are ever used to estimate total organic input to the tank farms. 
Table 3-1: Estimated Annual Distribution of Organics in Purex Plant Streams

\begin{tabular}{|c|c|c|c|c|c|c|c|c|c|c|c|c|}
\hline Year & $\begin{array}{l}\text { Total Gal } \\
\text { Solvent* }\end{array}$ & Gal TBP & Gal Diluent & $\begin{array}{c}\text { Organic } \\
\text { Wash } \\
\text { Waste } \\
\text { TBP (gal) }\end{array}$ & $\begin{array}{c}\text { Organic } \\
\text { Wash } \\
\text { Waste } \\
\text { TBP-dp** } \\
\text { (gal) }\end{array}$ & \begin{tabular}{|} 
Organic \\
Wash \\
Waste \\
Diluent (gal)
\end{tabular} & $\begin{array}{c}\text { Organic } \\
\text { Wash } \\
\text { Waste } \\
\text { Organic } \\
\text { (gal) }\end{array}$ & $\begin{array}{c}\text { Main Stack } \\
\text { Organic (gal) }\end{array}$ & $\begin{array}{c}\text { High Level } \\
\text { Waste } \\
\text { Organic (gal) }\end{array}$ & $\begin{array}{l}\text { UNH Product } \\
\text { Organic (gal) }\end{array}$ & $\begin{array}{c}\text { Process } \\
\text { Condensate } \\
\text { Organic (gal) } \\
\end{array}$ & $\begin{array}{l}\text { Organic Crib } \\
\text { Organic (gal) }\end{array}$ \\
\hline 1955 & 9,900 & 3,663 & 6,237 & 1610 & 31 & 3543 & 5184 & 1318 & \begin{tabular}{|l|}
15 \\
\end{tabular} & \begin{tabular}{|c|}
3 \\
\end{tabular} & 3374 & 24,000 \\
\hline 1956 & 61,813 & 22,871 & 38,942 & 10051 & 195 & 22119 & 32365 & 8229 & 93 & 19 & 21066 & 14,000 \\
\hline 1957 & 84,425 & 31,237 & 53,188 & 13728 & 266 & 30211 & 44205 & 11239 & 127 & 26 & 28772 & 4,000 \\
\hline 1958 & 81,563 & 30,178 & 51,385 & 13263 & 257 & 29187 & 42706 & 10858 & 123 & 25 & 27797 & 6,574 \\
\hline 1959 & 65,511 & 24,239 & 41,272 & 10653 & 206 & 23442 & 34302 & 8721 & 99 & 20 & 22326 & 800 \\
\hline 1960 & 78,040 & 28,875 & 49,165 & 12690 & 246 & 27926 & 40862 & 10389 & 118 & 24 & 26596 & 10,100 \\
\hline 1961 & 120,360 & 44,533 & 75,827 & 19572 & 379 & 43070 & 63020 & 16022 & 181 & 37 & 41019 & \\
\hline 1962 & 88,304 & 32,672 & 55,632 & 14359 & 278 & 31599 & 46236 & 11755 & 133 & 27 & 30094 & \\
\hline 1963 & 62,420 & 23,095 & 39,325 & 9116 & 215 & 20803 & 30133 & 7676 & 106 & 22 & 24509 & \\
\hline 1964 & 66,359 & 24,553 & 41,806 & 9691 & 228 & 22115 & 32035 & 8160 & 112 & 23 & 26056 & \\
\hline 1965 & 101,654 & 36,153 & 65,501 & 14270 & 336 & 34650 & 49256 & 12536 & 166 & 35 & 39703 & \\
\hline 1966 & 71,450 & 33,246 & 38,204 & 13122 & 309 & 20210 & 33641 & 8620 & 150 & 28 & 29042 & \\
\hline 1967 & 50,562 & 18,158 & 32,404 & 7167 & 169 & 17142 & 24478 & 6231 & 83 & 17 & 19773 & \\
\hline 1968 & 32,255 & 15,704 & 16,551 & 6198 & 146 & 8755 & 15100 & 3874 & 71 & 13 & 13212 & \\
\hline 1969 & 32,818 & 12,054 & 20,764 & 4758 & 112 & 10984 & 15854 & 4038 & 55 & 11 & 12873 & \\
\hline 1970 & 54,757 & 15,291 & 39,466 & 7340 & 1835 & 28613 & 37787 & 9171 & 83 & 23 & 7707 & \\
\hline 1971 & 38,257 & 12,492 & 25,765 & 5996 & 1499 & 18680 & 26175 & 6313 & 68 & 16 & 5694 & \\
\hline 1972 & 14,199 & 4,783 & 9,416 & 2296 & 574 & 6827 & 9696 & 2336 & 26 & 6 & 2138 & \\
\hline 1973 & 0 & 0 & 0 & 0 & 0 & 0 & 0 & 0 & 0 & 0 & 0 & \\
\hline 1974 & 0 & 0 & 0 & 0 & 0 & 0 & 0 & 0 & 0 & 0 & 0 & \\
\hline 1975 & 0 & 0 & 0 & 0 & 0 & 0 & 0 & 0 & 0 & 0 & 0 & \\
\hline 1976 & 0 & 0 & 0 & 0 & 0 & 0 & 0 & 0 & 0 & 0 & 0 & \\
\hline 1977 & 0 & 0 & 0 & 0 & 0 & 0 & 0 & 0 & 0 & 0 & 0 & \\
\hline 1978 & 0 & 0 & 0 & 0 & 0 & 0 & 0 & 0 & 0 & 0 & 0 & \\
\hline 1979 & 298 & 0 & 298 & 0 & 0 & 216 & 216 & 54 & 0 & 0 & 28 & \\
\hline 1980 & 0 & 0 & 0 & 0 & 0 & 0 & 0 & 0 & 0 & 0 & 0 & \\
\hline 1981 & 0 & 0 & 0 & 0 & 0 & 0 & 0 & 0 & 0 & 0 & 0 & \\
\hline 1982 & 825 & 825 & 0 & 266 & 149 & 0 & 415 & 79 & 6 & 1 & 323 & \\
\hline 1983 & 18,482 & 4,607 & 13,875 & 1483 & 834 & 9033 & 11350 & 2704 & 39 & 12 & 4359 & \\
\hline 1984 & 32,136 & 12,016 & 20,120 & 3868 & 2176 & 13098 & 19142 & 4433 & 98 & 22 & 8412 & \\
\hline 1985 & 21,256 & 7,231 & 14,025 & 2328 & 1309 & 9130 & 12767 & 2980 & 59 & 14 & 5415 & \\
\hline 1986 & 17,001 & 5,428 & 11,573 & 1747 & 983 & 7534 & 10264 & 2407 & 45 & 11 & 4257 & \\
\hline 1987 & 13,875 & 4,028 & 9,847 & 1297 & 729 & 6410 & 8436 & 1992 & 33 & 9 & 3391 & \\
\hline
\end{tabular}


Table 3-1: Estimated Annual Distribution of Organics in Purex Plant Streams

\begin{tabular}{|c|c|c|c|c|c|c|c|c|c|c|c|c|}
\hline Year & $\begin{array}{l}\text { Total Gal } \\
\text { Solvent }\end{array}$ & Gal TBP & Gal Diluent & $\begin{array}{l}\text { Organic } \\
\text { Wash } \\
\text { Waste } \\
\text { TBP (gal) }\end{array}$ & $\begin{array}{c}\text { Organic } \\
\text { Wash } \\
\text { Waste } \\
\text { TBP-dp** } \\
\text { (gal) }\end{array}$ & $\begin{array}{c}\text { Organic } \\
\text { Wash } \\
\text { Waste } \\
\text { Diluent (gal) }\end{array}$ & $\begin{array}{c}\text { Organic } \\
\text { Wash } \\
\text { Waste } \\
\text { Organic } \\
\text { (gal) }\end{array}$ & $\begin{array}{c}\text { Main Stack } \\
\text { Organic (gal) }\end{array}$ & $\begin{array}{c}\text { High Level } \\
\text { Waste } \\
\text { Organic (gal) }\end{array}$ & $\begin{array}{l}\text { UNH Product } \\
\text { Organic (gal) }\end{array}$ & $\begin{array}{c}\text { Process } \\
\text { Condensate } \\
\text { Organic (gal) }\end{array}$ & $\begin{array}{l}\text { Organic Crib } \\
\text { Organic (gal) }\end{array}$ \\
\hline 1988 & 12,633 & 3,544 & 9,089 & 1141 & 642 & 5917 & 7700 & 1822 & 29 & \begin{tabular}{|c|}
8 \\
\end{tabular} & 3062 & \\
\hline 1989 & 0 & 0 & 0 & 0 & 0 & 0 & 0 & 0 & 0 & 0 & 0 & \\
\hline 1990 & 2,181 & 210 & 1,971 & 68 & 38 & 1283 & 1389 & 341 & 2 & 1 & 445 & \\
\hline 1991 & 377 & 0 & 377 & 0 & 0 & 245 & 245 & 61 & 0 & 0 & 69 & \\
\hline Total & $1,233,711$ & 451,687 & 782,024 & 188,078 & 14,141 & 452,741 & 654,960 & 164,360 & 2,119 & 456 & 411,513 & 59,474 \\
\hline \multicolumn{13}{|c|}{\begin{tabular}{l|l|} 
Notes: & \\
\end{tabular}} \\
\hline \multicolumn{13}{|c|}{ [1] "Total solvent does not include disposal to the organics crib from startup through 1964.} \\
\hline \multicolumn{13}{|c|}{\begin{tabular}{|l|l|l|l} 
[2] **TBP-dp denotes TBP degradation products. & & & \\
\end{tabular}} \\
\hline & & & & & & & & & & & & \\
\hline \multicolumn{13}{|c|}{ [3] Data for 1955 to 1964 are from HAPO/Chemical Processing Department Monthly Reports. } \\
\hline & \multicolumn{12}{|c|}{\begin{tabular}{|l|l|l|l|} 
These records provide estimates of the total monthly loss of solvent. & & & \\
\end{tabular}} \\
\hline & \multirow{2}{*}{\multicolumn{12}{|c|}{ The distribution is assumed to be $37 \%$ TBP and $63 \%$ diluent, based on consumption from 1965-1972. }} \\
\hline & & & & & & & & & & & & \\
\hline \multicolumn{13}{|c|}{ [4] Data for 1965 through 1991 are from Essential Material Consumption Records. } \\
\hline & \multirow{2}{*}{\multicolumn{12}{|c|}{ These records show actual amounts of TBP and NPH consumed by the plant. }} \\
\hline & & & & & & & & & & & & \\
\hline \multicolumn{13}{|c|}{ [5] Figures for disposal of organic to crib are from Monthly Reports only. } \\
\hline & \multicolumn{4}{|c|}{ See Table $2-4$ for crib discharge records. } & & & & & & & & \\
\hline & & & & & & & & & & & & \\
\hline \multirow[t]{4}{*}{ [6] } & \multicolumn{2}{|c|}{ Case 4: 1955-1962 } & & & & & & & & & & \\
\hline & \multicolumn{2}{|c|}{ Case 3: $1963-1969$} & & & & & & & & & & \\
\hline & \multicolumn{2}{|c|}{ Case 2: $1970-1981$} & & & & & & & & & & \\
\hline & Case 1: 19 & $82-1991$ & & & & & & & & & & \\
\hline
\end{tabular}


WHC-MR-0483

Revision 0
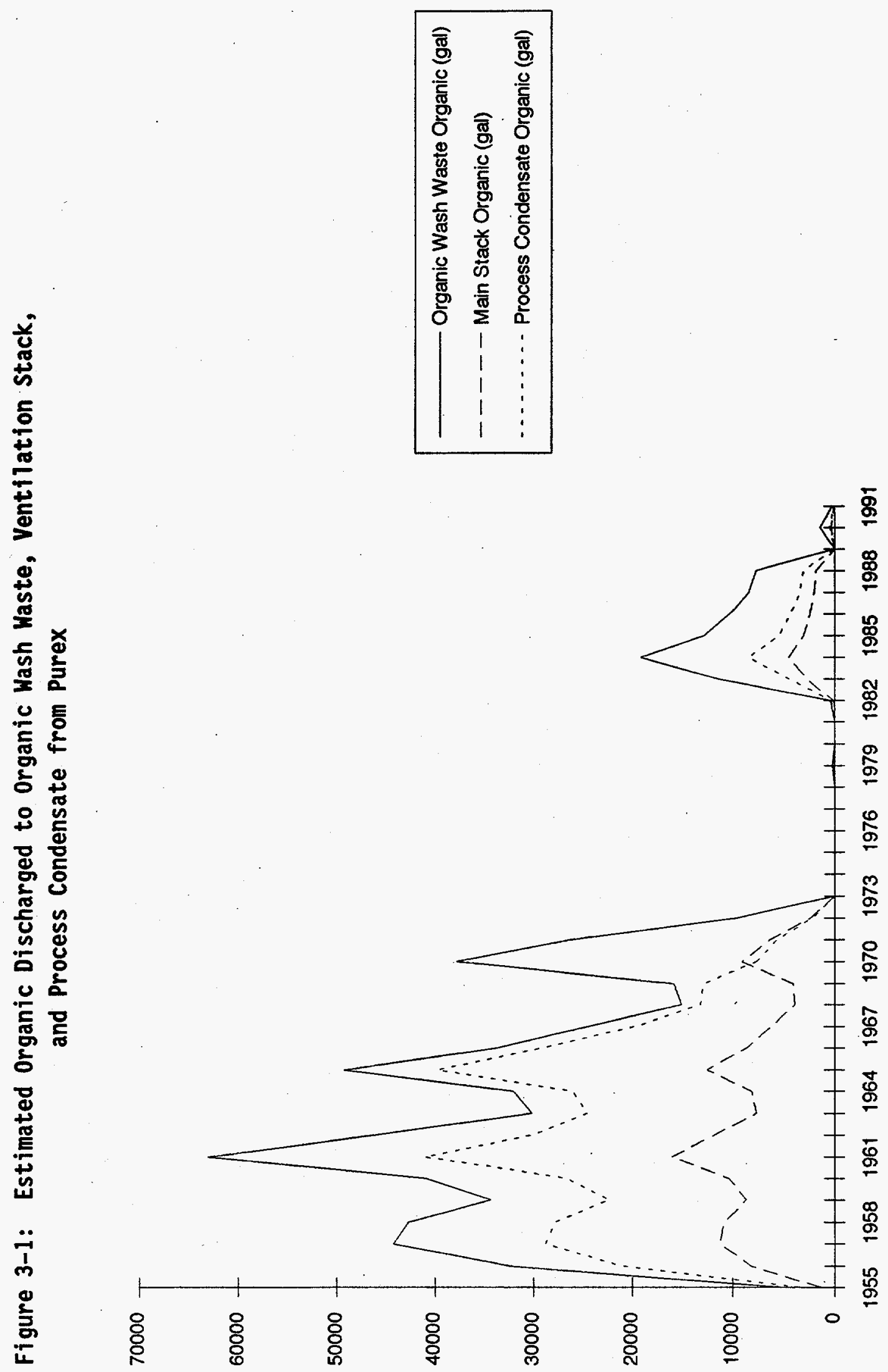
Figure 3-2: Estimated Organic Discharged to High Level Waste and in UNH Product

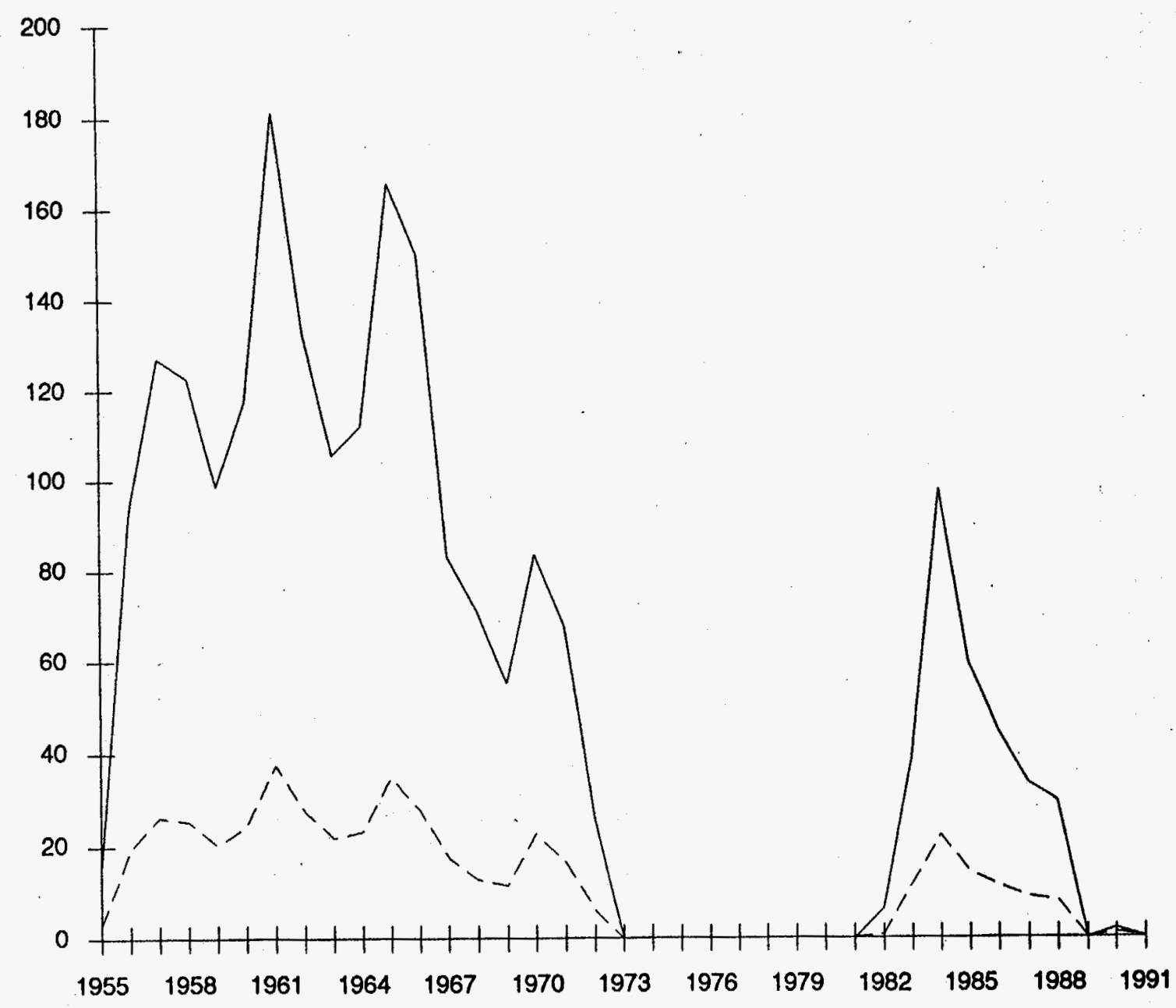

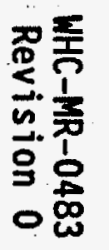


Figure 3-3: Estimated Gallons of Organic Discharged to Tank Farms in Organic Wash Waste

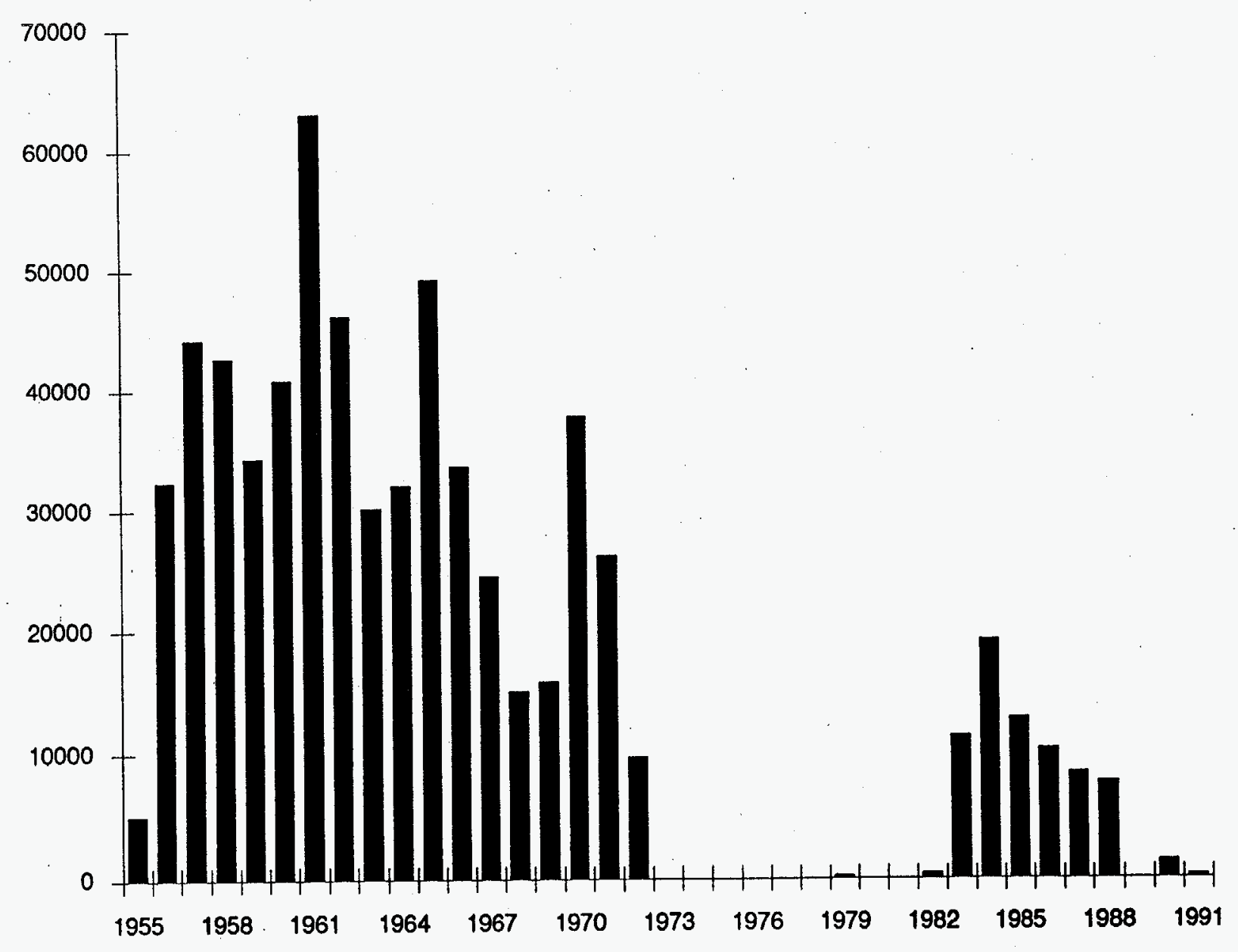


WHC-MR-0483

Revision 0

Table 3-2: Crib Disposal of Spent Organic

\begin{tabular}{|c|c|c|c|}
\hline$\frac{\text { Date }}{1955 \text { - Mav } 1956}$ & Location & $\begin{array}{c}\begin{array}{c}\text { Volume of } \\
\text { Spent Organic } \\
\text { (gal) }\end{array} \\
\end{array}$ & Record \\
\hline 1955 - May 1956 & unknown & 31,000 & HAPO Monthly Reports \\
\hline May 1956 - June 1958 & A-2 Crib & 20,605 & $\begin{array}{l}\text { HW-57649, "Radioactive Contamination in Liquid Wastes } \\
\text { Discharged to Ground at Separations Facilities Through June } \\
\text { 1958," K. F. Baldridge, October 3, } 1958 \text {. }\end{array}$ \\
\hline June 1958-Dec 1958 & A-2 Crib & 264 & $\begin{array}{l}\text { HW-59359, "Radioactive Contamination in Liquid Wastes } \\
\text { Discharged to Ground at Separations Facilities Through December } \\
\text { 1958," K. F. Baldridge. }\end{array}$ \\
\hline Dec 1958-Dec 1959 & A-2 Crib & 11,624 & $\begin{array}{l}\text { HW-64375, "Radioactive Contamination in Liquid Wastes } \\
\text { Discharged to Ground at Separations Facilities Through December } \\
\text { 1959." }\end{array}$ \\
\hline Dec 1959-June 1960 & A-2 Crib & 8,189 & $\begin{array}{l}\text { HW-69071, "Radioactive Contamination in Liquid Wastes } \\
\text { Discharged to Ground at Separations Facilities Through June } \\
\text { 1960," R. C. Henle, April 7, 1961. }\end{array}$ \\
\hline June 1960 - Dec 1960 & A-2 Crib & 20,077 & $\begin{array}{l}\text { HW-69072, "Radioactive Contamination in Liquid Wastes } \\
\text { Discharged to Ground at Separations Facilities Through December } \\
\text { 1960," R. C. Henle, April 14, 1961. }\end{array}$ \\
\hline $\begin{array}{l}\text { Shows A-2 Crib } \\
\text { Abandoned. No } \\
\text { additions after Dec. } \\
1960 .\end{array}$ & & & $\begin{array}{l}\text { HW-72956, "Radioactive Contamination in Liquid Wastes } \\
\text { Discharged to Ground at Separations Facilities Through December } \\
1961, \text { " G. E. Backman. }\end{array}$ \\
\hline $\begin{array}{l}\text { Shows no active organic } \\
\text { crib in } 1962 \text {. }\end{array}$ & & & $\begin{array}{l}\text { HW-76638, "Radioactive Contamination in Liquid Wastes } \\
\text { Discharged to Ground at Separations Facilities Through December } \\
\text { 1962," G. E. Backman. }\end{array}$ \\
\hline $\begin{array}{l}\text { Could not locate this } \\
\text { report. }\end{array}$ & & & $\begin{array}{l}\text { HW-80877, "Radioactive Contamination in Liquid Wastes } \\
\text { Discharged to Ground at Separations Facilities Through December } \\
\text { 1963," R. H. Wlson. }\end{array}$ \\
\hline $\begin{array}{l}\text { Shows no active organic } \\
\text { crib in } 1964 \text {. A-31 crib } \\
\text { is called a "specific } \\
\text { retention crib." }\end{array}$ & & & $\begin{array}{l}\text { BNWC-91, "Radioactive Contamination in Liquid Wastes } \\
\text { Discharged to Ground at Separations Facilities Through December } \\
\text { 1964," R. H. Wllson, May 4, 1965. }\end{array}$ \\
\hline $\begin{array}{l}\text { No entry for active } \\
\text { organic crib in } 1965 .\end{array}$ & & & $\begin{array}{l}\text { ISO-98, "Radioactive Contamination in Liquid Wastes Discharged } \\
\text { to Ground at Separations Facilities Through December 1965,"B. J. } \\
\text { McMurray. }\end{array}$ \\
\hline $\begin{array}{l}\text { "Purex organic wastes } \\
\text { from Jan 1963-Dec } \\
1966 \text { " }\end{array}$ & A-31 Crib & 6,340 & $\begin{array}{l}\text { ISO-698, "Radioactive Contamination in Liquid Wastes Discharged } \\
\text { to Ground at Separations Facilities Through December 1966," B. J. } \\
\text { McMurray, February 15, 1967. }\end{array}$ \\
\hline & TOTAL & 98,100 & \\
\hline
\end{tabular}


WHC-MR-0483

Revision 0

\subsection{CONCLUSIONS AND RECOMMENDATIONS}

The Purex Plant material balance for diluent and TBP should be regarded as a rough estimate. Fairly complete records exist for total consumption of organics. The distribution of lost organic among the waste streams is less certain because operations at the Purex seldom remained the same for any length of time. Numerous changes in the plant and process occurred over the years. Plant capacity, rate of operations, condensate recycle, and changing diluents 211 affected the rate of organic consumption and the paths by which organic was lost.

\subsection{REFERENCES}

Allen, G. K, D. C. Hedengren, \& L. L. Jacobs, PUREX FLOWSHEET - REPROCESSIMG N REACTOR FUELS, PFD-P-020-00001, Rev. A-8, Rockwe11 Hanford Operations, Richland, Washington, September 20, 1985.

ARH-N-134, ESSENTIAL MATERIALS CONSUMPTION LOGBOOK, Issued for use April 30, 1969.

Ballinger, M. Y., and R. B. Hall, A HISTORY OF MAJOR HANFORD FACILITIES AND PROCESSES INVOLVING RADIOACTIVE MATERIAL, PNL-6964 HEDR, Prepared for the Technical Steering Panel, Pacific Northwest Laboratory, Richland, Washington, March 1991.

Benedict, Manson, Thomas Pigford, and Hans Levi, NUCLEAR CHEMICAL ENGINEERING, Second Edition, McGraw-Hi11 Book Company, New York, 1981.

General Electric Company (GE), PUREX TECHNICAL MANUAL, HW-31000, Richiand, Washington, March 25, 1955.

HW-35225, PUREX CHEMICAL FLOWSHEET HW\#4 - INCREASED PUREX PLANT CAPACITY, March 4, 1955.

HW-89085, SELECTED MONTHLY OPERATING DATA FOR B AND T PLANTS, REDOX AND PUREX (1944-1972), Compiled by S. P. Gydesen, April, 1992.

HWN-3610 Hanford Works ESSENTIAL MATERIAL LOGBOOK, Issued for use October 2, 1964. 
Merck \& Co, THE MERCK INDEX, Eleventh Edition, Merck \& Company, Rahway, New Jersey, 1989.

Raab, George J., HIGHLIGHT HISTORY OF PUREX PLANT MAJOR PROCESS OR ENGINEERING EVENTS, Memo $11 / 17 / 77$.

Rockwe11 Hanford Operations, PUREX TECHNICAL MANUAL, RHO-MA-116, Richland, Washington, March 1980.

Walser, R. L., INTERIM EVALUATION OF PUREX PROCESS TEST - NORMAL PARAFFIN HYDROCARBON DILUENT, ISO-584, Isochem Inc., Richl and Washington November $15,1966$.

Walser, R. L., Personal list of uranium throughput by month in the Purex Plant for the period 1983 through 1990, obtained March 21, 1994. Units of MTU were converted to tons for this report.

WHC-N-676, ESSENTIAL MATERIAL CONSUMPTION LOGBOOK, December 17, 1992.

WHC, PUREX/U03 DEACTIVATION PROJECT MANAGEMENT PLAN, WHC-SP-1011D (Draft) Westinghouse Hanford Company, Richland, Washington, September 1993.

Zahn, L. L., DILUENT PROCUREMENT FOR PUREX, Isochem Memorandum to D. McDonald, June 28, 1966. 
WHC-MR-0483

Revision 0

APPENDIX A

MASS BALANCE CALCULATIONS FOR PUREX ORGANIC CONSUMPTION

A-1 


\section{DISCUSSION OF MASS BALANCE CALCULATIONS}

The purpose of the mass balance calculations is to estimate the mass flow rates of TBP, NPH and DBP through the plant to the eventual discharge streams. The result is used to develop a rough estimate of the percent of lost organics distributed to the various wastes. Mass flow rates are used to avoid extensive calculations of density changes that occur with changes in temperature and uranium and nitric acid content.

The flowsheet that forms the basis for these calculations is PFD-P-02000001 , Rev. A-8, "Purex Flowsheet - Reprocessing N-Reactor Fuels, "September 20, 1985. In particular, the flowsheet information used in this report is for processing $12 \% \mathrm{Pu}-240$ fuel at a rate of 10 short tons per day. Figures A-1 through A-6 and Table A-1 follow this discussion. The figures are simplified versions of Purex Flowsheet Figures. Table A-1 shows the results of the calculations. The calculations discussed below refer to both the figure in this Appendix and to the reference figure in the Purex Flowsheet. The Purex Flowsheet figures are the source of volumetric flow rate, temperature, specific gravity and nitric acid concentration information shown in Table A-1.

1. HAX STREAM - Figure A-1 (Purex Flowsheet Figure 13)

The HAX stream is the organic feed stream to the HA solvent extraction column from the Solvent Treatment System. This stream enters the bottom of the column, and exits the top, after extracting uranium and plutonium from the HA column feed. The Purex Flowsheet shows an organic flow rate of 87.8 liters/minute. The organic is assumed to have the mass fraction of TBP and NPH found in a 30 vol\% TBP solution in NPH at $25^{\circ} \mathrm{C}$. This is about $35.4 \mathrm{wt} \% \mathrm{TBP}$ and $64.6 \mathrm{wt} \% \mathrm{NPH}$, based on densities of $0.972 \mathrm{~g} / \mathrm{L}$ for TBP and $0.76 \mathrm{~g} / \mathrm{L}$ for $\mathrm{NPH}$ at $25^{\circ} \mathrm{C}$.

2. HAW STREAM - Figure A-1 (Purex Flowsheet Figure 13)

The HAW stream is the aqueous waste stream that exits from the bottom of the HA column. This stream contains most of the fission products from the reactor fuel. Assume 0.055 vol\% of the organic (HAX) stream is entrained in the HAW stream. This is the midpoint of the range of 0.01 vol\% - 0.1 vol\% given on page 4-80 of the Purex Technical Manual (RHO-MA-116). The original Purex Technical Manual (HW-31000, p. 584) describes entrainment as follows:

"Entrainment refers to a normally very small fraction (typically 0.01 to $0.1 \%$ ) of the other phase which is carried out with an effluent stream. It usually consists of very fine droplets, some 
of which may be colloidal in size, which have little tendency to settle out in the disengaging sections. ... Entrainment of the organic phase in the aqueous effluents represents a potentially economically important loss of solvent, and adds an additional amount of TBP to be steam stripped by the product and waste (acid) concentrators."

In addition, the solubility of TBP is assumed to be $0.22 \mathrm{~g} / \mathrm{L}$ in this stream, which contains 3.09 M Nitric Acid. (Table 6-9 of RHO-MA-116 shows that solubility of TBP in $\mathrm{HNO}$ and UNH solutions is relatively insensitive to temperature. Figure 6-1 of RHO-MA-116 gives solubilities of TBP in various solutions. The 0.22 figure is the result of an interpolation between $1.0 \mathrm{M}$ and $7.0 \mathrm{M} \mathrm{HNO3}$ at $20^{\circ} \mathrm{C}$. The solubility of NPH is less than $0.005 \mathrm{~g} / \mathrm{L}$ in water between 25 and $50^{\circ} \mathrm{C}$. Its solubility is assumed to be the same for process solutions. The calculations in Table A-1 show both the entrained and soluble mass flow in the HAW stream. The entrained portion is $0.055 \%$ of the flow in the HAX stream and the soluble portion is assumed to be TBP and NPH at the limits of solubility in the HAW stream. Calculations similar to these are performed throughout the flowsheet in the items below.

\section{1WW STREAM - Figure A-5 (Purex Flowsheet Figure 16)}

The IWW stream is the concentrated bottoms stream from the 1 WW acid waste concentrator. The feed to the concentrator comes from the HAW stream described above. The 1WW stream is assumed to contain TBP and NPH at the limit of solubility, but no entrained organic. Entrained organic is assumed to have been distilled in the IWW concentrator. The mass flow rate of this stream is the amount estimated to be discharged to the high level waste tanks from Tank F-16.

4. AAA STREAM - Figure A-5 (Purex Flowsheet Figure 16)

This stream contains concentrated nitric acid (4.1 molar) from acid absorber T-F5. Since T-F5 boils the liquid to concentrate the acid, the TBP in this stream will be significantly degraded by acid hydrolysis. TBP degradation products are assumed to be present at the limit of TBP solubility. (Entrained organic would have been removed in the overhead stream from the acid absorber. Estimated solubility is about $0.18 \mathrm{~g} / \mathrm{L}$ for TBP and $0.005 \mathrm{~g} / \mathrm{L}$ for $\mathrm{NPH}$.

5. AAD STREAM - Figure A-5 (Purex Flowsheet Figure 16)

The AAD stream is the condensate leaving condenser E-F5. This stream has a flow rate of $111.9 \mathrm{~L} / \mathrm{min}$. Of this, all but $12.45 \mathrm{~L} / \mathrm{min}$ are recycled. (The $12.45 \mathrm{~L} / \mathrm{min}$ goes to Tank $\mathrm{F}-10$.) $\mathrm{A}$ balance around the incoming HAW stream and the outgoing stream to TK-F10 and streams IWW 
and $A A A$ yields the following equation for the mass flows of organics, since 1WW, AAA and HAW are known: $A A D=(111.9 / 12.45)$ (HAW-IWW-AAA). Since the $A A D$ stream is the condensate from the boiling concentrated nitric acid solution in the T-F5 acid absorber, the TBP is assumed to be degraded by acid hydrolysis, as in the case of the AAA stream. A portion of the degraded organics in this stream actually exits the plant via the stack ventilation system. The estimate, however, assumes no stack losses.

6. AAD-F10 STREAM - Figures $A-4$ and $A-5$ (Purex Flowsheet Figure 16) This stream is simply a $12.45 \mathrm{~L} /$ min portion of the AAD stream, described in item 5 , above.

7. AFF STREAM - Figure A-5 (Purex Flowsheet Figure 16)

The AFF stream is the solution leaving TK-U5 as feed to the T-U6 acid fractionator. (The fractionator concentrates nitric acid for re-use in the plant.) The AFF stream contains the same mass flow rate of organics as stream AAA (item 4).

8. AFD EXCESS AND FLOW TO XA TOWER - Figure A-5 (Purex Flowsheet Figure 16) The AFD stream is the distillate leaving the top of the T-U6 acid vacuum fractionator, combined with some vacuum jet condensate. The AFF stream flows to the acid vacuum fractionator, which concentrates nitric acid to 10.4 molarity. All of the organic and degradation products from the AFF stream are assumed to go with the overhead from the fractionator. Half of the organic mass flow of the AFF stream goes to TK-F10 and the other half goes to the XA tower. At the XA tower, fragments may exit via the main stack, or be recycled back to the AFF stream. The AFD Excess stream is the portion going to TK-F10.

9. HAP STREAM - Figure A-1 (Purex Flowsheet Figure 13)

This stream is the overhead organic product stream leaving the HA column. It contains uranium and plutonium extracted from the feed stream. The amounts of organics are the difference between the incoming $H A X$ (item 1) stream and the exiting HAW stream (item 2).

10. IBXF STREAM - Figure A-1 (Purex Flowsheet Figure 13)

This stream originates in TK-J3 and forms the feed for the $1 B X$ column. The organic mass flow through this tank is the sum of organic inputs from streams HAP (item 9); 2BW, 3BW and 2PW (item 11), and 1BSU (item 12). 
11. 2BW, 3BW, 2PW STREAMS - Figures $A-1,3 \& 4$

(Purex Flowsheet Figures $14 \& 15$ )

The $2 \mathrm{BW}$ stream is the organic overhead from the $2 \mathrm{~B}$ column. It is assumed to contain entrained aqueous to the extent of 0.055 vol\% of the bottom stream (2BP). The balance of the mass flow of this stream, minus the uranium $(0.055 \mathrm{~g} / 1)$, plutonium $(0.001 \mathrm{~g} / 1)$ and nitric acid $(0.064 \mathrm{M})$ is assumed to be $35.4 \mathrm{wt} \% \mathrm{TBP}$ and $64.6 \mathrm{wt} \% \mathrm{NPH}$.

Similar exercises yield mass flow rates in stream $3 B W(U=0, P u=0.019$ $\mathrm{g} / 1$ ), which is the overhead organic from the $3 B$ column, and stream $2 \mathrm{PW}$ $(U=13.14 \mathrm{~g} / 1, N p=0.01 \mathrm{~g} / 1)$, which is the overhead organic from the $2 P$ column (which was used to separate neptunium).

12. IBSU STREAM - Figure A-1 (Purex Flowsheet Figure 13)

The 1BSU stream is the overhead organic from the IBS column. It is assumed to contain entrained aqueous to the extent of $0.055 \mathrm{vol} \%$ of the bottom stream (1BP). The balance of the mass flow of the stream, minus the uranium $(16.49 \mathrm{~g} / 1)$, plutonium $(0.071 \mathrm{~g} / 1)$, and nitric acid $(0.75$ $M$ ), is assumed to be 35.4 wt\% TBP and $64.6 \mathrm{wt \%}$ NPH.

12. 1BXP STREAM - Figure A-1 (Purex Flowsheet Figure 13)

This stream is the aqueous stream leaving the bottom of the IBX column. At 2.1 molar HNO3 and $18.24 \mathrm{~g} / 1$ uranium $(0.08 \mathrm{Molar})$, the solubility of TBP. is about $0.25 \mathrm{~g} / 1$. Solubility of NPH is assumed constant, at 0.005 $\mathrm{g} / 1$. As in the case of the HA column, the entrained organic is assumed to be 0.055 vol\% of the incoming organic stream IBXF.

13. 1BP STREAM - Figure A-1 (Purex Flowsheet Figure 13)

This stream is the aqueous stream leaving the bottom of the 1BS column. At 3.52 molar HNO3 the TBP solubility is about $0.20 \mathrm{~g} / \mathrm{L}$. NPH solubility is assumed to be $0.005 \mathrm{~g} / \mathrm{L}$. In addition this stream is assumed to contain 0.055 v01\% (entrained) of the 1BS stream, which is the organic feed $(17.2 \mathrm{l} / \mathrm{min})$ to the column from the Solvent Treatment System.

14. IBU STREAM - Figure A-1 (Purex Flowsheet Figure 13)

The $1 B U$ stream is the organic overhead from the $1 B X$ column. The organic in this stream is the difference between the incoming $1 B X F$ stream (item 10) and the bottoms 1BXP stream (item 12).

15. ICU STREAM - Figure A-1 (Purex Flowsheet Figure 13)

The ICU stream is the aqueous stream leaving the bottom of the $1 C$ column. At 0.047 molar nitric acid and 0.24 molar uranium, the 
solubility of TBP is about $0.18 \mathrm{~g} / \mathrm{L}$. Solubility of NPH is $0.005 \mathrm{~g} / \mathrm{L}$. In addition, the ICU stream is assumed to contain entrained organic to the extent of 0.055 vol\% of the lBU stream, which is the organic phase feed to the column.

16. 2NW STREAM - Figure A-4 (Purex Flowsheet Figure 15)

The $2 \mathrm{NW}$ stream is the aqueous discharge from the bottom of the $2 \mathrm{~N}$ column. At $5.03 \mathrm{M}$ nitric acid, the TBP solubility is about $0.16 \mathrm{~g} / \mathrm{L}$. $\mathrm{NPH}$ solubility is assumed to be $0.005 \mathrm{~g} / \mathrm{L}$. This stream is also assumed to contain entrained organic equal to 0.055 vol\% of the incoming $2 \mathrm{NX}$ stream, which is the organic feed $(12.8 \mathrm{1} / \mathrm{min})$ to the $2 \mathrm{~N}$ column from the Solvent Treatment System.

17. 2DW STREAM - Figure A-2 (Purex Flowsheet Figure 13)

The 2DW stream is the aqueous discharge from the bottom of the 20 column. At $0.94 \mathrm{M}$ nitric acid and 0.07 molar uranium, the TBP solubility is about $0.28 \mathrm{~g} / \mathrm{L}$. NPH solubility is assumed to be 0.005 $\mathrm{g} / \mathrm{L}$. This stream is also assumed to contain entrained organic equal to 0.055 vol\% of the incoming $20 X$ stream. The $20 X$ stream is the organic feed $(75.71 / \mathrm{min})$ feed to the 20 column from the Solvent Treatment System.

18. 2AW STREAM - Figure A-3 (Purex Flowsheet Figure 14)

The $2 A W$ stream is the aqueous discharge from the bottom of the $2 A$ column. At $2.95 \mathrm{M}$ nitric acid, the TBP solubility is about $0.22 \mathrm{~g} / \mathrm{L}$. $\mathrm{NPH}$ solubility is assumed to be $0.005 \mathrm{~g} / \mathrm{L}$. This stream is also assumed to contain entrained organic equal to 0.055 vol\% of the incoming $2 \mathrm{AX}$ stream. The $2 A X$ stream is the organic feed to the $2 A$ column ( 3.9 $1 /$ min) from Solvent Treatment System.

19. 3WF STREAM - Figure A-4 (Purex Flowsheet Figure 15)

The $3 W F$ stream contains the sum of the organics from the aqueous streams 2DW, 2AW, 2NW, AAD and AFD excess streams, described above. They are combined in TK-F10. Other contributors to this stream are steam condensates and are assumed not to contain organic.

20. 3WW STREAM - Figure A-4 (Purex Flowsheet Figure 15)

This stream contains concentrated nitric acid $(8.3 \mathrm{molar})$ from the $3 \mathrm{WB}$ concentrator. Since the concentrator boils the liquid to concentrate the acid, the TBP in this stream will be significantly degraded by acid hydrolysis. TBP degradation products are assumed present at the limit of TBP solubility. (Entrained organic is removed in the overhead stream from the acid absorber, so only soluble organics would be present.) Solubility is about $0.11 \mathrm{~g} / \mathrm{L}$ for TBP and $0.005 \mathrm{~g} / \mathrm{L}$ for NPH. 
21. 3WD STREAM - Figure A-4 (Purex Flowsheet Figure 15)

The 3 WD stream is the distillate from the $3 W B$ Concentrator. The $3 W D$ stream organic content is the difference between the $3 W F$ (item 19) and $3 W W$ (item 20) streams. TBP content is assumed to be degradation products due to acid hydrolys is in the $3 \mathrm{WB}$ concentrator.

22. IUC STREAM - Figure A-1 (Purex Flowsheet Figure 13)

The IUC stream contains concentrated solution from the $1 \mathrm{CU}$

Concentrator. Organics are assumed present at the limit of solubility, with no entrainment, due to heating in the concentrator. Since the nitric acid content is 0.78 molar, acid hydrolysis of TBP is assumed not to have occurred. Uranium content is 2.1 molar. TBP solubility is assumed to be $0.095 \mathrm{~g} / \mathrm{L}$ (see RHO-MA-116 page 6-25). NPH solubility is assumed to be $0.005 \mathrm{~g} / \mathrm{L}$. The distribution between TBP and its decomposition products is assumed to be the same ratio as found in the incoming streams ICU (item 15) and 3WD (item 21).

23. IUD STREAM - Figure A-1 (Purex Flowsheet Figure 13)

The IUD stream contains the difference between the ICU and 3WD streams, and the outgoing IUC stream. The IUD stream, which is condensate from the ICU Concentrator, is recycled to several locations. If not recycled, it would be disposed to the 216-A-10 Crib. Under conditions indicated in the flowsheet, some water must be added to this stream in order to make up all of the solution required in other vessels (i.e., there is no excess).

24. 2DF STREAM - Figure A-1 (Purex Flowsheet Figure 13)

This stream contains the same organic mass flow as the IUC stream (item 22). It is the feed to the $2 D$ column, collected in TK-K1.

25. 2DU STREAM - Figure A-2 (Purex Flowsheet Figure 13)

The 2DU stream is the overhead organic product from the 20 column. The organic mass flow rate is the difference between the incoming 20X (75.7 $1 /$ min from Solvent Treatment) and 2DF (item 17) streams and the outgoing 2DW (item 24) stream. Degradation products in the $20 \mathrm{~F}$ stream are assumed to go out in the 2DU stream.

26. 2EX STREAM - Figure A-2 (Purex Flowsheet Figure 13) The 2EX stream consists of $110.71 \mathrm{~L} /$ min of the 1 UD (item 23) recycled condensate. 
27. 2EU STREAM - Figure A-2 (Purex Flowsheet Figure 13)

The 2EU stream is the aqueous stream that leaves the bottom of the $2 E$ column. This stream is 0.01 molar in nitric acid and $0.24 \mathrm{molar}$ in uranium. TBP solubility is assumed to be $0.18 \mathrm{~g} / \mathrm{L}$. NPH solubility is assumed to be $0.005 \mathrm{~g} / \mathrm{L}$. In addition to the soluble species, $2 \mathrm{EU}$ is assumed to contain all of the degradation products from the 2EX stream and entrained organic of 0.055 vol\% of the incoming 2DU stream (item 25).

28. 2EW STREAM - Figure A-2 (Purex Flowsheet Figure 13)

The $2 E W$ stream is the overhead organic from the $2 E$ column. This stream contains the difference between the incoming 2EX (item 26) and 2DU (item 25) streams, and the outgoing 2EU stream (item 27). The 2EW stream is fed to solvent treatment tank R-1 (No. 2 Solvent Treatment System).

29. UNH PRODUCT STREAM - Figure A-2 (Purex Flowsheet Figure 13)

This stream is assumed to contain TBP and NPH at the limits of solubility. Uranium is 2.13 molar. TBP solubility is about $0.011 \mathrm{~g} / \mathrm{L}$. $\mathrm{NPH}$ solubility is assumed to be $0.005 \mathrm{~g} / \mathrm{L}$.

30. 2UD STREAM - Figure A-2 (Purex Flowsheet Figure 13)

This stream contains the difference between the incoming 2EU stream (item 27) and the outgoing UNH product stream. It is discharged to the 216-A-10 Crib.

31. ICX STREAM - Figure A-1 (Purex, Flowsheet Figure 13)

The 1CX stream is the aqueous extractant fed to the $1 C$ column. The $1 C X$ stream contains $114 \mathrm{~L} / \mathrm{min}$ of the 1 UD recycled condensate (item 23).

32. ICW STREAM - Figure A-1 (Purex Flowsheet Figure 13)

The $1 \mathrm{CW}$ stream is the organic leaving the top of the $1 \mathrm{C}$ column. The $1 \mathrm{CW}$ stream is the difference between the incoming $1 \mathrm{CX}$ (item 31 ) and IBU (item 14) streams, and the outgoing $1 \mathrm{CU}$ stream (item 15). The $1 \mathrm{CW}$ stream is then transferred to the No. 1 Solvent Treatment System.

\section{SOLVENT TREATMENT}

The 1CW (item 32) and 2EW (item 28) streams form the feeds to the No.1 and No. 2 Solvent Treatment Systems. At this point, estimates for these streams include TBP degradation products resulting from acid hydrolysis in concentrators. According to the original Purex Plant Technical Manual, 
however, TBP degradation al so occurs in the amount of 10 to $20 \mathrm{ppm}$ of solvent while passing through the solvent extraction columns, $90 \%$ of which goes to solvent treatment ( $\mathrm{HW}-31000, \mathrm{p} .903$.$) For solvent treatment, the estimates$ for TBP degradation products include this extra amount based on $15 \mathrm{ppm}$ of total solvent $($ TBP $+N P H)$. The extra amount is rather small. The remainder of the mass balance is for solvent treatment.

33. 1OW STREAM (Purex Flowsheet Figure 17)

The 10W stream is the combined organic wash waste from both solvent treatment systems. This stream is assumed to contain all of the TBP degradation products from the feed streams $1 \mathrm{CW}$ and $2 \mathrm{EW}$. It is also assumed to contain soluble TBP and NPH. Soluble TBP is assumed present at $0.12 \mathrm{~g} / \mathrm{L}$ which is the solubility in water at $50^{\circ} \mathrm{C}$. (Feed streams to Tank G-8 are at $50^{\circ} \mathrm{C}$ ). Soluble $\mathrm{NPH}$ is assumed present at $0.005 \mathrm{~g} / \mathrm{L}$.

At this point, all of the organic losses, except entrainment in the organic wash waste and evaporation have been accounted for. As expected, the sum of the losses estimated thus far is less than the 114 gallons per operating day identified in the flowsheet as fresh organic makeup.

As a result, the amount of organic entrained in the organic stream is assumed to be $80 \%$ of the balance of the organic losses needed to add up to the 114 gallons per day of fresh solvent. (The other $20 \%$ is assumed to have been evaporated.)

The organic loss to each stream leaving the plant estimated above is not used directly to estimate losses during Purex Plant operations. Rather, the fractions of organics lost to each location are calculated below. Then, the fractions are applied to the organic losses from Purex (Table 2-3), as recorded in monthly reports and essential materials consumption records.

\section{RESULTS}

Four cases were evaluated in estimating the distribution of organic losses among the exit streams. These cases are shown on the last four pages of Table A-1. They are necessary due to operating changes during the life of the plant. Purex experienced numerous process and capacity changes.

Case 1 corresponds to flowsheet conditions (PFD-P-020-00001) and would be applicable to operations in 1982 and thereafter. Flowsheet total solvent losses were 114 gallons per day. This case includes recycling of process condensate within the plant. 
Case 2 also includes recycling of process condensate, but adjusts the total solvent losses upward to 200 gallons per day. The 200 gallon per day rate was identified as the historical solvent addition rate prior to restart in 1983 (RHO-MA-116, p 4-138). (The reduction in 1983 was expected to occur due to closer control over transfers from Tank G-8.) Case 2 is assumed to apply to the years $1970-1981$.

Case 3 assumes 260 gallon per day losses (based on average losses per operating day in 1963-1966), but does not include recycle of process condensate, since the condensate was not recycled during earlier plant operations. When the process condensate is not recycled, more of the organic is discharged via the condensate to a crib. A larger portion of the TBP degradation products is also disposed to the crib. Case 3 is assumed to be applicable to operations with Soltrol from 1963 to 1966 and NPH from 1966 to 1969.

Case 4 assumes total losses of 300 gallons per day and no condensate recycle. This rate is based on average losses per operating day in 19561962. The change between 1962 and 1963 occurred in October of 1962, when the Plant began recycling organic wash solution from the No. 2 Solvent Treatment System to the No.1 Solvent Treatment System. This resulted in a reduction in solvent losses. Case 4 is assumed to apply to operations from 1955 to 1962 .

Please note that these are very rough estimates, which are not verified by sample data. Waste samples were visually inspected for organic layers, but were not analyzed for the organics. The actual distribution of TBP degradation products is not extremely reliable, since the behavior of $D B P$, MBP, butanol and phosphoric acid differs. DBP tends to follow the organic phase (until it is washed out in solvent treatment), while MBP, butanol and phosphoric acid are more soluble in water. In the estimate, however, the degradation products are assumed to travel as a group. Not enough information is available to estimate the individual distributions. The most prevalent species, however, appears to be DBP. In addition, flowsheet changes that occurred over the years have not been accounted for, except for the change in condensate recycle, and wash waste recycle. 


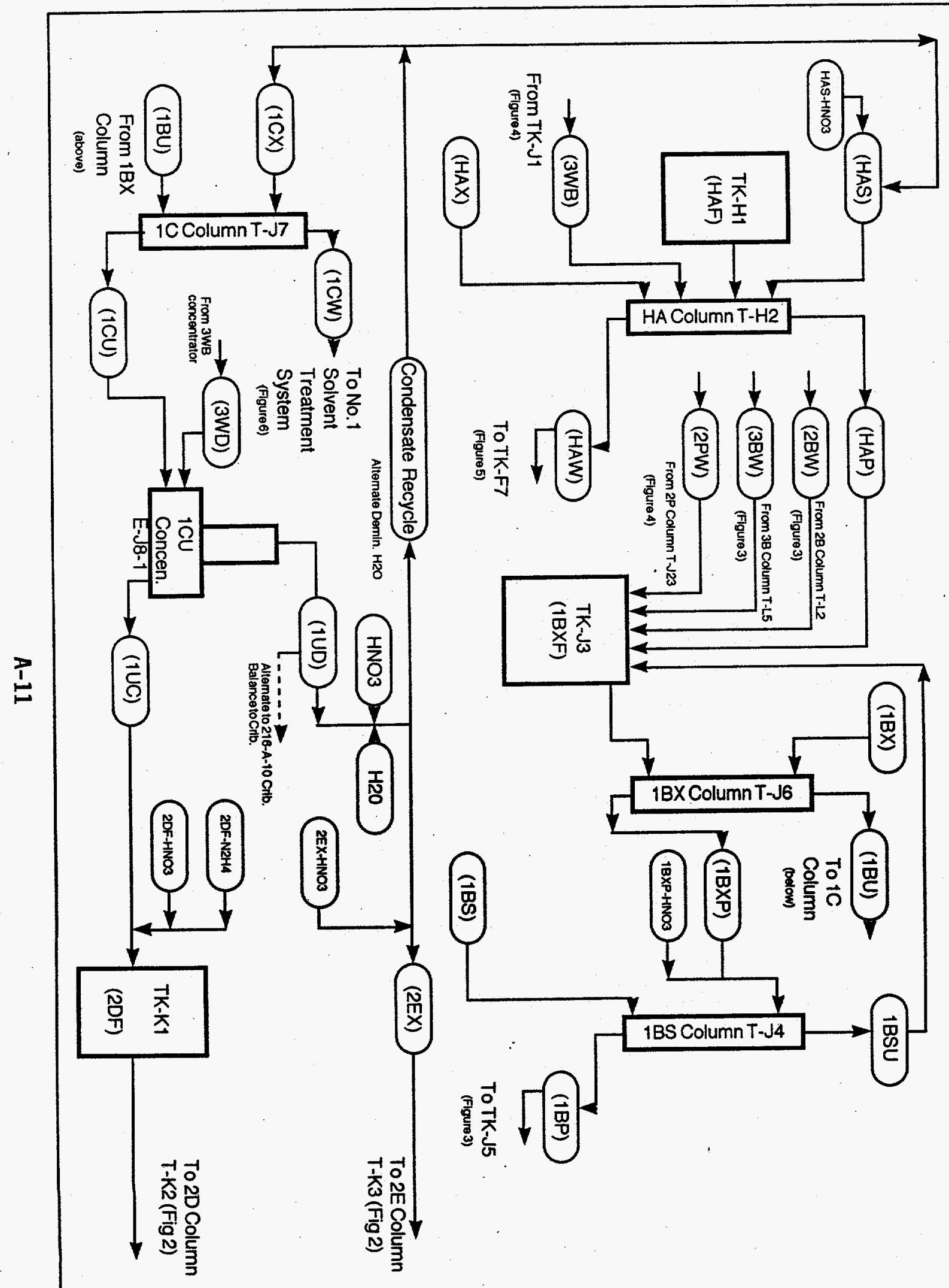

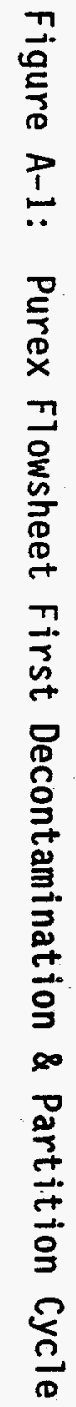




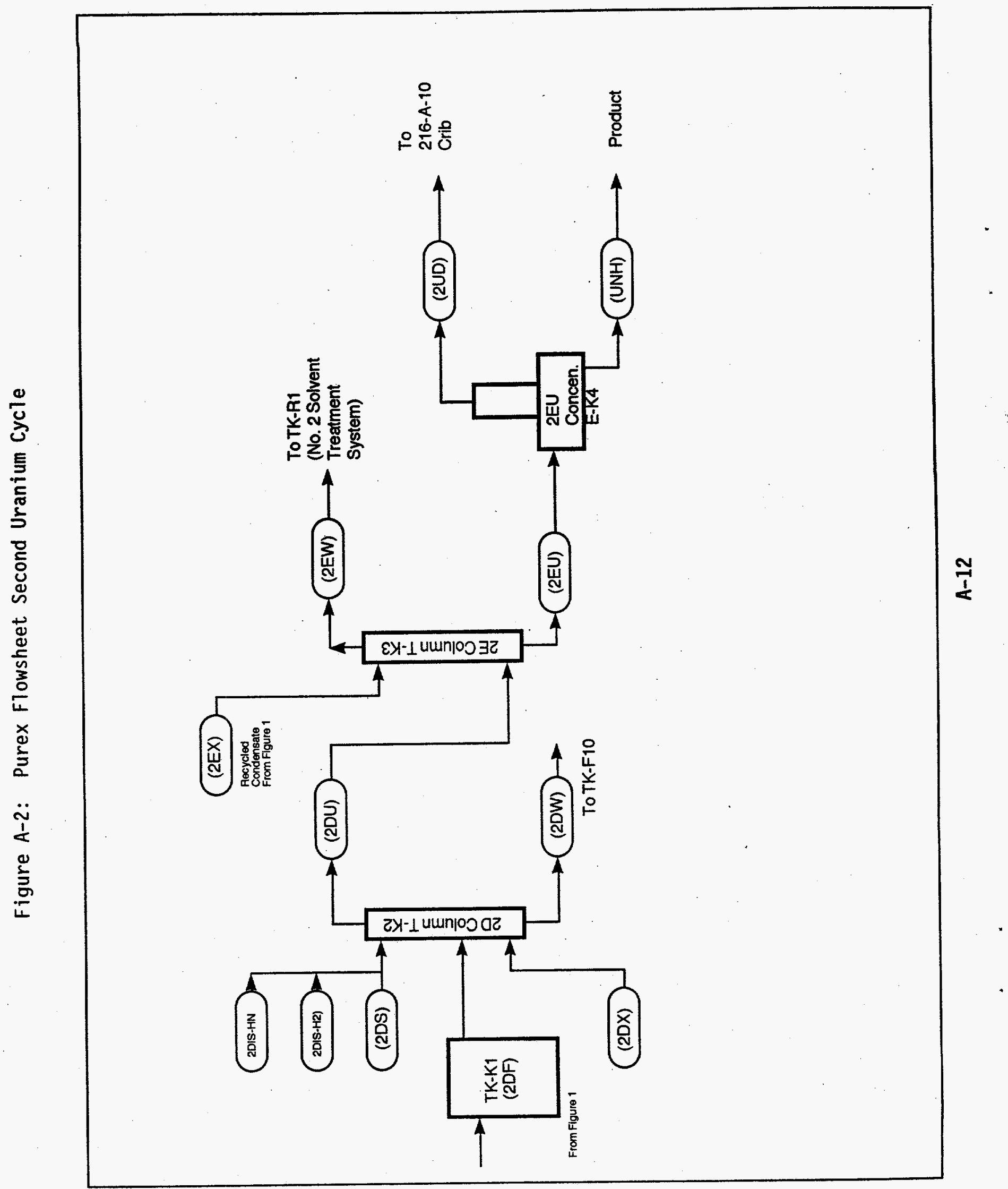


WHC-MR-0483

Revision 0

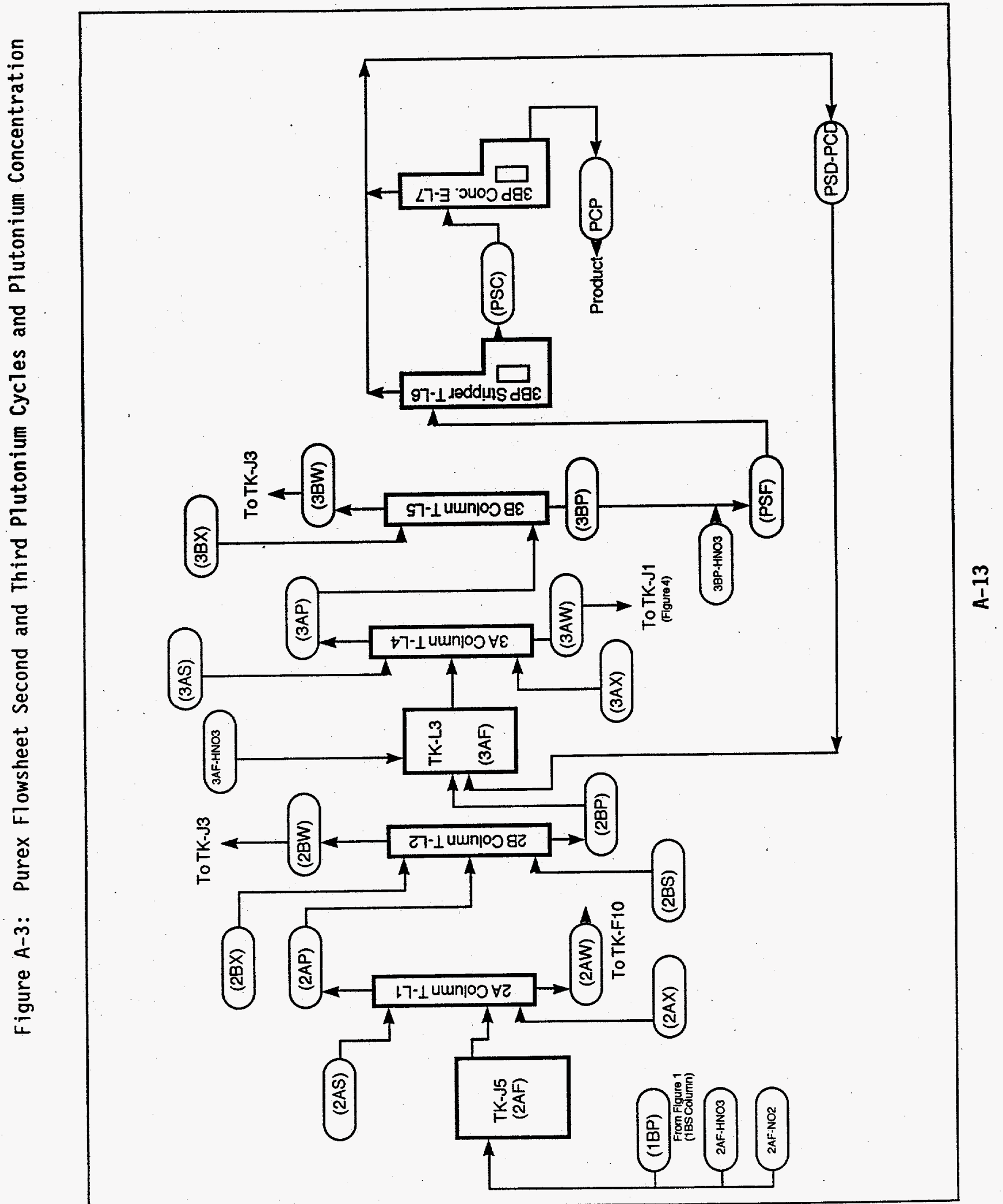


Figure A-4: Purex Flowsheet Backcycle Waste System Phase 1 and Second Neptunium Cycle Phase 1

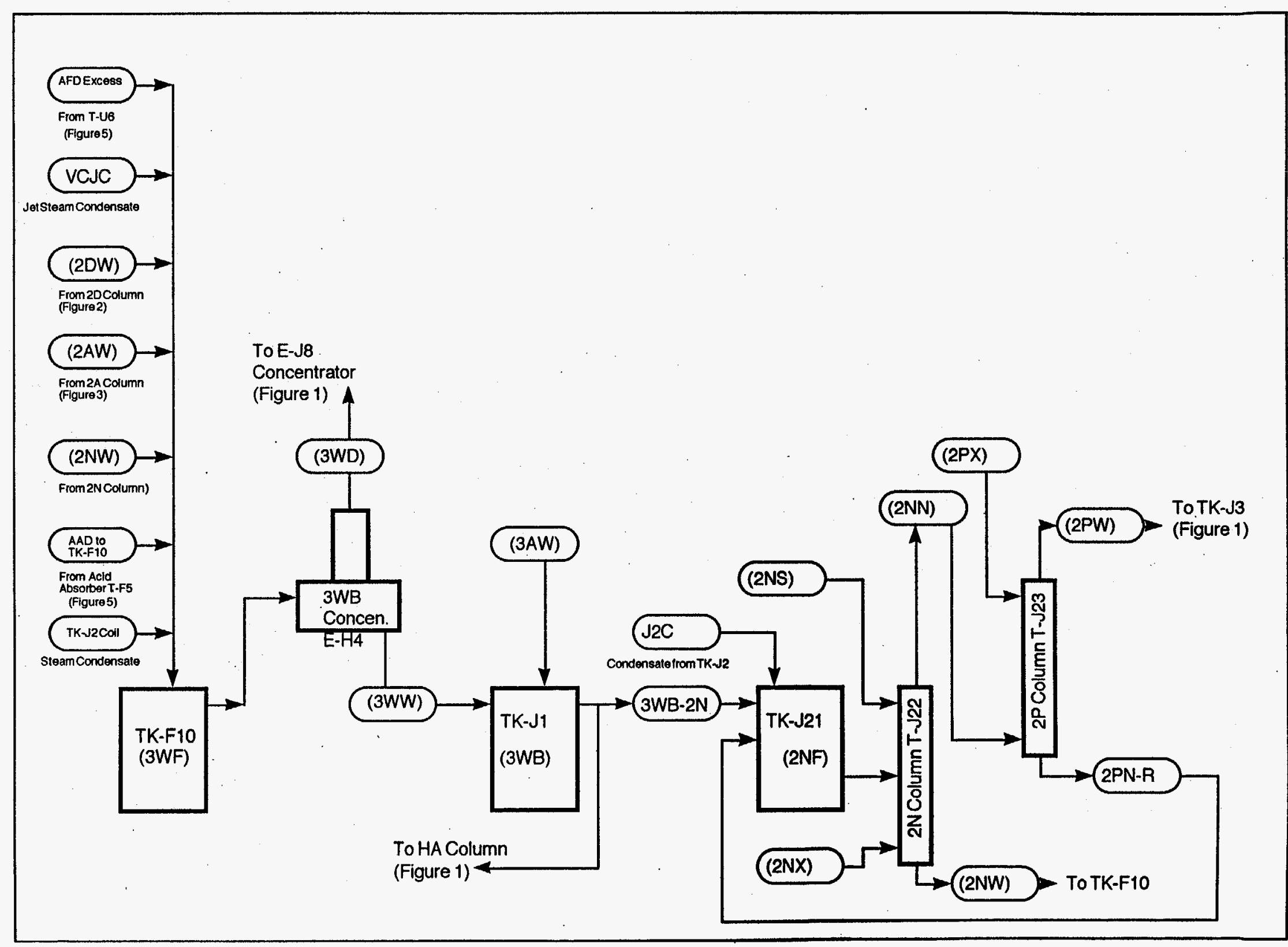

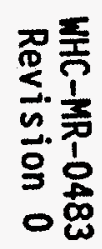




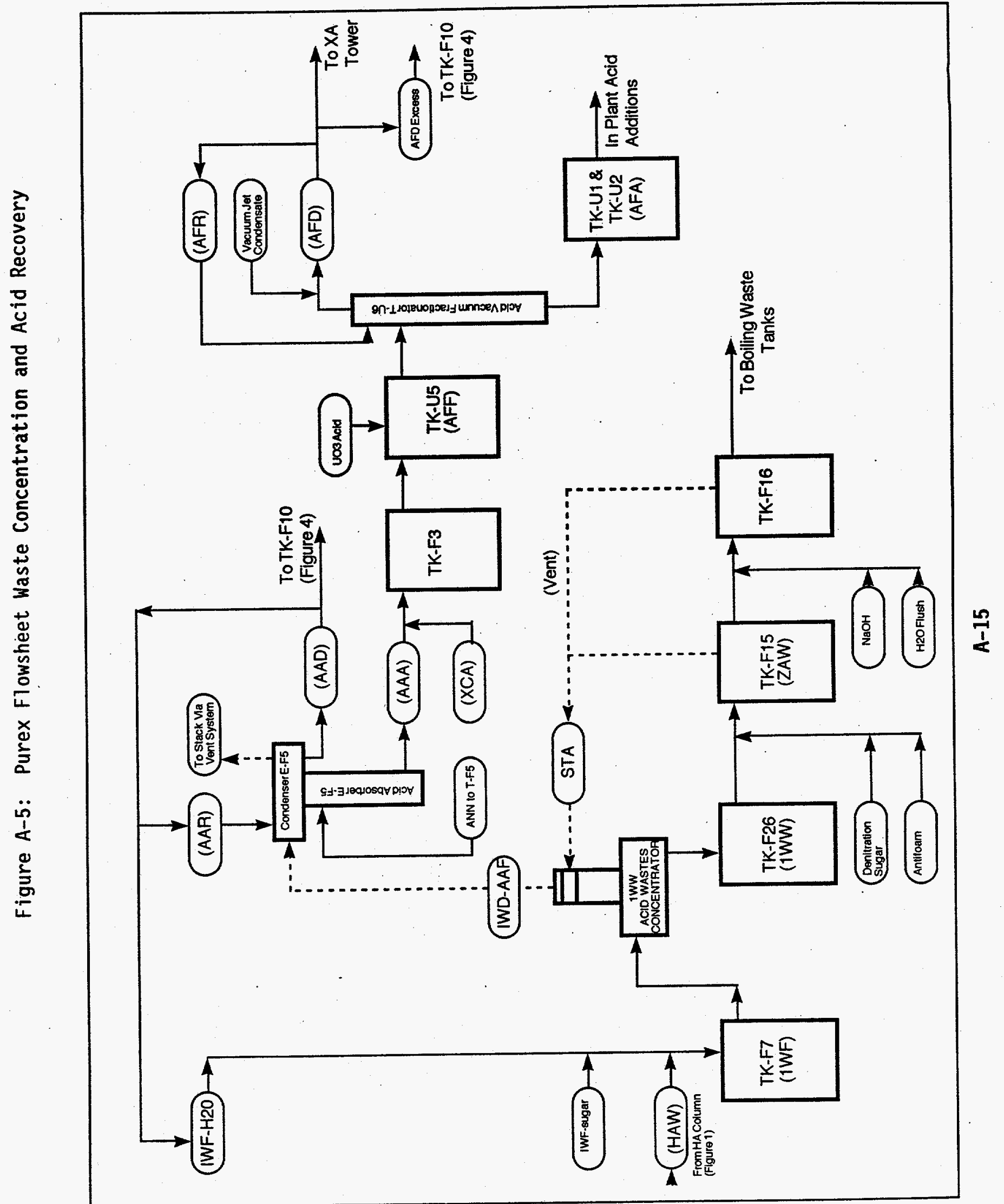


Figure A-6: Purex Flowsheet - Solvent Treatment

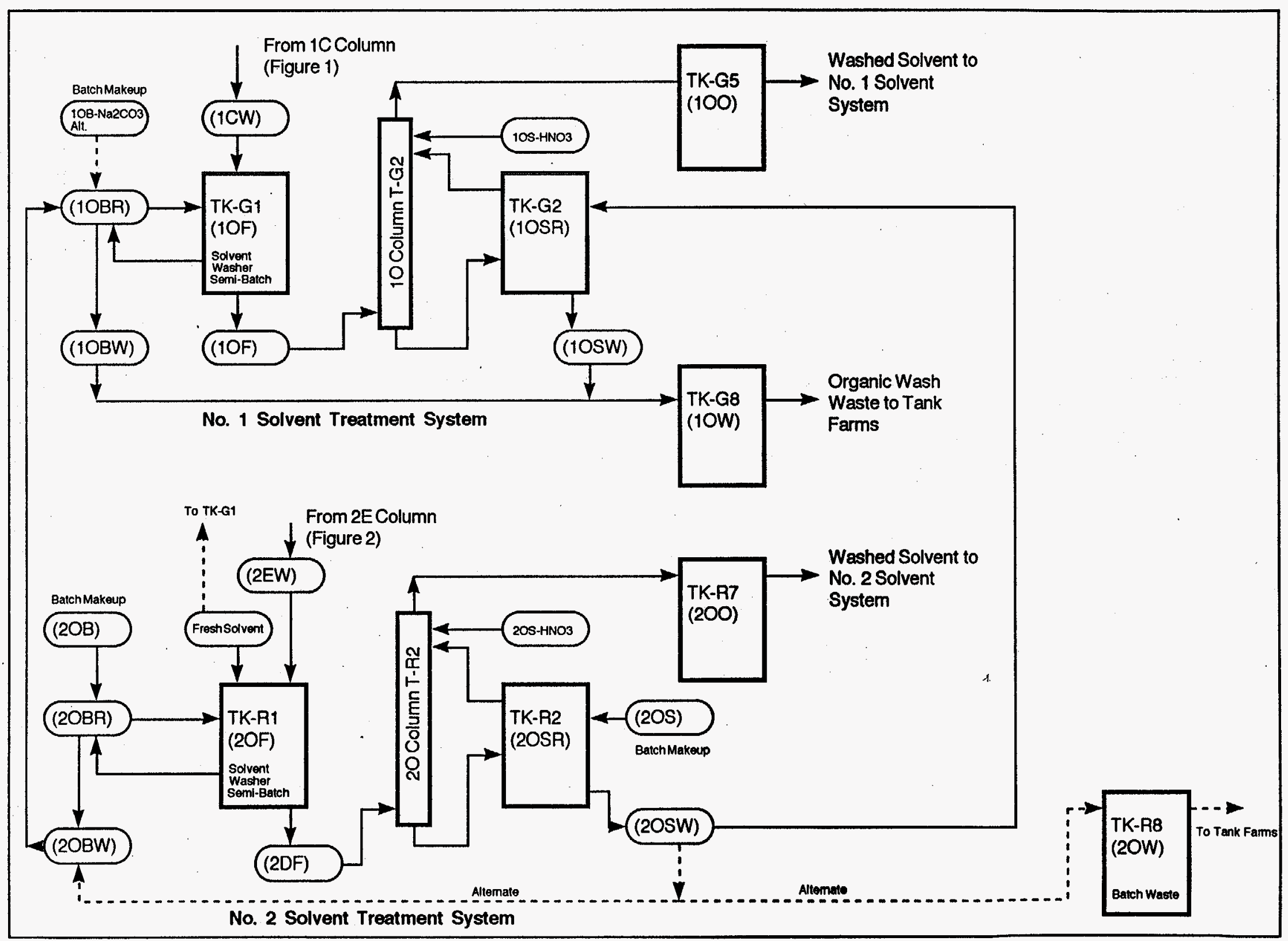


Table A-1: Purex Plant TBP/Diluent Material Balance Calculations

\begin{tabular}{|c|c|c|c|c|c|c|c|c|c|c|c|c|}
\hline & Soluble & Entrained & Total TBP & TBP & Soluble & Entrained & Total & & & & & Notes \\
\hline & TBP & TBP & TBP & d-prod. & $\mathrm{NPH}$ & NPH & NPH & flow rate & & SpG & HNO3 & \\
\hline \multirow[t]{2}{*}{ Stream } & $\mathrm{g} / \mathrm{min}$ & $\mathrm{g} / \mathrm{min}$ & $\mathrm{g} / \mathrm{min}$ & $\mathrm{g} / \mathrm{min}$ & $\mathrm{g} / \mathrm{min}$ & $\mathrm{g} / \mathrm{min}$ & $\mathrm{g} / \mathrm{min}$ & $\mathrm{L} / \mathrm{min}$ & $\mathrm{T}^{\circ} \mathrm{C}$ & $\mathrm{g} / \mathrm{ml}$ & Molar & \\
\hline & & & & - & & & & & & & & \\
\hline HAX & 25,358 & - & 25,358 & & 46,199 & - & 46,199 & 87.8 & 40 & 0.815 & 0.01 & \\
\hline HAW & 8.49 & 13.9 & 22.4 & & 0.19 & 25.4 & 25.6 & 38.61 & 50 & 1.11 & 3.09 & \\
\hline $1 W W$ & 1.06 & - & 1.06 & & 0.02 & - & 0.02 & 4.82 & 50 & 1.25 & 2.83 & \\
\hline AAA & & & & 4.63 & 0.13 & & 0.13 & 25.72 & 50 & 1.13 & 4.1 & \\
\hline AAD & & & & 150.6 & & & 228.7 & 111.9 & 55 & 1.0 & 0.1 & \\
\hline \multicolumn{13}{|c|}{ Note: some AAD organics would actually go to the stack via the vent system. } \\
\hline \multicolumn{2}{|c|}{ AAD-F10 } & & & 16.8 & & & 25.5 & 12.45 & 55 & 1.0 & 0.1 & \\
\hline AFF & & & & 4.63 & 0.13 & & 0.13 & 54.04 & 50 & 1.1 & 3.76 & \\
\hline To XA & & & & 2.31 & 0.06 & & 0.06 & 18.09 & 25 & 1.0 & 0.005 & $\begin{array}{l}\text { Exit system - } \\
\text { assume main } \\
\text { stack }\end{array}$ \\
\hline \multicolumn{2}{|c|}{ AFD excessTo F-10 } & & & 2.31 & 0.06 & & 0.06 & 18.09 & 25 & 1.00 & 0.01 & \\
\hline & & & & & & & & & & & & \\
\hline \multicolumn{13}{|l|}{ TK-F16 } \\
\hline ZAW & 1.06 & - & 1.06 & & 0.02 & - & 0.02 & 5.12 & 50 & 1.2 & & \\
\hline NZAW & 1.06 & - & 1.06 & & 0.02 & - & 0.02 & 7.35 & 70 & 1.25 & - & $\begin{array}{l}\text { Exit system - } \\
\text { high level waste }\end{array}$ \\
\hline \multicolumn{13}{|c|}{ NZAW High Level Waste } \\
\hline & TBP & 0.42 & \multicolumn{2}{|l|}{ gallons/day } & & & & & & & & \\
\hline & $\mathrm{NPH}$ & 0.01 & & & & & & & & & & \\
\hline & & & & & & & & & & & & \\
\hline & & & & & & & & & & & & \\
\hline HAP & 25,335 & - & 25,335 & & 46,174 & - & 46,174 & 91.1 & 45 & 0.92 & 0.214 & \\
\hline $1 \mathrm{BXF}$ & 36,035 & - & 36,035 & & 65,712 & - & 65,712 & 127.6 & 50 & 0.9 & 0.26 & \\
\hline $2 B W$ & 1,783 & - & 1,783 & & 3,255 & - & 3,255 & 6.2 & amb. & 0.817 & 0.064 & \\
\hline
\end{tabular}


Table A-1: Purex Plant TBP/Diluent Material Balance Calculations

\begin{tabular}{|c|c|c|c|c|c|c|c|c|c|c|c|c|}
\hline & Soluble & Entrained & Total TBP & TBP & Soluble & Entrained & Total & & & & & Notes \\
\hline & TBP & TBP & TBP & d-prod. & $\mathrm{NPH}$ & \begin{tabular}{|l|}
$\mathrm{NPH}$ \\
\end{tabular} & NPH & flow rate & & SpG & HNO3 & \\
\hline Stream & $\mathrm{g} / \mathrm{min}$ & $\mathrm{g} / \mathrm{min}$ & $\mathrm{g} / \mathrm{min}$ & $\mathrm{g} / \mathrm{min}$ & $\mathrm{g} / \mathrm{min}$ & $\mathrm{g} / \mathrm{min}$ & $\mathrm{g} / \mathrm{min}$ & $\mathrm{L} / \mathrm{min}$ & $\mathrm{T}^{\circ} \mathrm{C}$ & $\mathrm{g} / \mathrm{ml}$ & Molar & \\
\hline $3 B W$ & 190 & - & 190 & & 346 & - & 346 & 0.655 & amb. & 0.82 & 0.013 & \\
\hline $2 \mathrm{PW}$ & 3,716 & - & 3,716 & & 6,784 & - & 6,784 & 12.86 & 40 & 0.83 & trace & \\
\hline $1 \mathrm{BSU}$ & 5,010 & - & 5,010 & & 9,153 & - & 9,153 & 17.82 & 50 & 0.86 & 0.75 & \\
\hline 1BXP & 3.84 & 19.8 & 23.7 & & 0.08 & 36.1 & 36.2 & 15.34 & 50 & 1.1 & 2.1 & \\
\hline $1 \mathrm{BP}$ & 3.93 & 2.7 & 6.7 & & 0.10 & 5.0 & 5.07 & 19.63 & 45 & 1.12 & 3.52 & \\
\hline $1 \mathrm{BU}$ & - & - & 36,011 & & - & - & 65,676 & 126.4 & 50 & 0.89 & 0.042 & \\
\hline $1 \mathrm{CU}$ & 20.9 & 19.8 & 40.7 & & 0.58 & 36.1 & 36.70 & 116.3 & 55 & 1.08 & 0.047 & \\
\hline $2 \mathrm{NW}$ & 2.6 & 2.03 & 4.67 & & 0.08 & 3.70 & 3.79 & 16.5 & 45 & 1.17 & 5.03 & \\
\hline $20 W$ & 6.6 & 12.00 & 18.56 & & 0.12 & 21.90 & 22.02 & 23.42 & amb. & 1.05 & 0.94 & \\
\hline $2 A W$ & 5.3 & 0.62 & 5.92 & & 0.12 & 1.13 & 1.25 & 24.11 & 45 & 1.1 & 2.95 & \\
\hline $3 W F$ & 14.5 & 14.7 & 29.2 & 19.1 & 0.38 & 26.74 & 52.57 & 153.8 & amb. & 1.04 & 1.15 & . \\
\hline $3 W W$ & - & - & - & 2.3 & 0.1 & - & 0.1 & 20.71 & 110 & 1.3 & 8.3 & \\
\hline $3 W D$ & - & - & - & 45.9 & 0.67 & 51.80 & 52.47 & 133.1 & 50 & 1 & 0.04 & 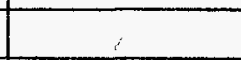 \\
\hline $1 U \mathrm{C}$ & 0.60 & - & 0.6 & 0.7 & 0.07 & - & 0.07 & 13.49 & 110 & 1.69 & 0.78 & \\
\hline IUD & - & - & 40.1 & 45.3 & - & - & 89.10 & 235.9 & 50 & 1 & tr. & $\begin{array}{l}\text { Goes to A-10 } \\
\text { Crib if not } \\
\text { recycled. }\end{array}$ \\
\hline $2 \mathrm{DF}$ & - & - & 0.6 & 0.7 & 0.07 & - & 0.07 & 14.58 & 50 & 1.66 & 1.5 & \\
\hline $2 \mathrm{DX}$ & - & - & 21,823 & & & & 39,824 & 75.7 & 40 & 0.815 & 0.01 & \\
\hline $2 \mathrm{DU}$ & - & - & 21,805 & 0.7 & - & - & 39,803 & 78.15 & amb. & 0.92 & 0.008 & \\
\hline
\end{tabular}


Table A-1: Purex Plant TBP/Diluent Material Balance Calculations

\begin{tabular}{|c|c|c|c|c|c|c|c|c|c|c|c|c|}
\hline & Soluble & Entrained & Total TBP & TBP & Soluble & Entrained & Total & & & & & Notes \\
\hline & TBP & TBP & TBP & d-prod. & $\mathrm{NPH}$ & $\mathrm{NPH}$ & $\mathrm{NPH}$ & flow rate & & SpG & HNO3 & \\
\hline Stream & $g / \min$ & $\mathrm{g} / \mathrm{min}$ & $g / \min$ & $g / \min$ & $\mathrm{g} / \mathrm{min}$ & $\mathrm{g} / \mathrm{min}$ & $\mathrm{g} / \mathrm{min}$ & $\mathrm{L} / \min$ & $\mathrm{T}^{\circ} \mathrm{C}$ & $\mathrm{g} / \mathrm{ml}$ & Molar & \\
\hline $2 \mathrm{EX}$ & - & - & 18.8 & 21.2 & - & - & 41.8 & 110.8 & 50 & 1 & 0.01 & \\
\hline 2EU & 20.3 & 12.0 & 32.3 & 21.2 & 0.56 & 21.9 & 22.46 & 112.9 & 50 & 1.08 & 0.01 & \\
\hline & & & & & & & & & & & & \\
\hline 2EW & - & - & 21,792 & 0.7 & - & - & 39,822 & 75.67 & 55 & 0.815 & tr. & $\begin{array}{l}\text { Goes to No. } 2 \\
\text { Solvent } \\
\text { Treatment } \\
\text { System }\end{array}$ \\
\hline & & & & & & & & & & & & \\
\hline UNH Pr. & 0.14 & $\overline{-}$ & 0.14 & $=$ & 0.06 & $\overline{-}$ & 0.06 & 12.48 & 50 & 1.68 & 0.08 & Product Stream \\
\hline & & & & & & & & & & & & \\
\hline 2UD & - & - & 32.2 & 21.2 & - & - & 22.4 & 100.4 & 50 & 1 & tr. & $\begin{array}{l}\text { Goes to } 216-A- \\
10 \text { Crib }\end{array}$ \\
\hline $1 \mathrm{CX}$ & - & - & 19.4 & 21.9 & - & - & 43.1 & 114 & 55 & 1 & 0.01 & \\
\hline & & & & & & & & & & & & \\
\hline $1 \mathrm{CW}$ & - & - & 35,990 & 21.9 & - & - & 65,682 & 123.6 & 55 & 0.815 & tr. & \begin{tabular}{|l|} 
Goes to No. 1 \\
Solvent \\
Treatment. \\
\end{tabular} \\
\hline & & & & & & & & & & & & \\
\hline SOIVEN & TPEATM & & & & & & & & & & & \\
\hline $1 \mathrm{CW}$ & Thrר & - & 35,990 . & $23.2^{\prime}$ & - & - & 65.682 & 123.6 & 55 & 0.815 & tr. & $\begin{array}{l}\text { No. } 1 \text { Solvent } \\
\text { Treatment Feed }\end{array}$ \\
\hline $2 \mathrm{EW}$ & - & - & 21,792 & 1.5 & - & - & 39,822 & 75.67 & 55 & 0.815 & tr. & $\begin{array}{l}\text { No. } 2 \text { Solvent } \\
\text { Treatment Feed }\end{array}$ \\
\hline & & & & & & & & & & & & \\
\hline $10 \mathrm{~W}$ & 0.47 & & & 24.8 & 0.02 & & & 3.92 & 40 & 1.02 & $\overline{-}$ & \\
\hline
\end{tabular}


Table A-1: Purex Plant TBP/Diluent Material Balance Calculations

\begin{tabular}{|c|c|c|c|c|c|c|c|c|c|c|c|c|}
\hline \multicolumn{13}{|c|}{ SUMMARY MASS BALANCE } \\
\hline & & & & & & & & & & & & \\
\hline \multicolumn{13}{|c|}{ Case 1 - Flowsheet Input } \\
\hline \multicolumn{13}{|c|}{ (est 1982-1991 operations) } \\
\hline \multicolumn{2}{|c|}{ Fresh Solvent } & 114.1 & \multicolumn{3}{|c|}{ gallons per day TBP $+\mathrm{NPH}$} & & & 0.3 & amb. & 0.82 & - & \\
\hline & & & & & & & & & & & & \\
\hline \multicolumn{13}{|c|}{ Outgoing Streams } \\
\hline & & TBP & TBP-dp & $\mathrm{NPH}$ & Total & \multicolumn{2}{|c|}{ Destination } & & & & & \\
\hline Stream & & gal/day & gal/day & gal/day & gal/day & & & & & & & \\
\hline To XA & & 0.0 & 0.9 & 0.03 & 0.9 & \multicolumn{2}{|c|}{ assume main stack } & & & & & \\
\hline NZAW & & 0.4 & 0.0 & 0.01 & 0.4 & \multicolumn{2}{|c|}{ aging waste } & & & & & \\
\hline UNH Pr. & & 0.1 & 0.0 & 0.03 & 0.1 & \multicolumn{2}{|c|}{ uranium product } & & & & & \\
\hline $2 U D$ & & 12.6 & 8.3 & 11.21 & 32.1 & \multicolumn{2}{|c|}{ 216-A-10 Crib } & & & & & \\
\hline $10 W$ & & 0.2 & 9.7 & 0.01 & 9.9 & \multicolumn{4}{|c|}{ organic wash waste (solubles) } & & & \\
\hline \multicolumn{2}{|c|}{ Subtotal } & 13.2 & 18.9 & 11.3 & 43.4 & & & & & & & \\
\hline \multicolumn{2}{|c|}{ Balance Gallons } & 21.2 & & 49.5 & 70.7 & \multicolumn{7}{|c|}{ assume $20 \%$ to stack, balance entrained in organic wash waste } \\
\hline & & . & & & & & & & & & & \\
\hline \multirow[t]{2}{*}{ Total } & & 34.4 & 18.9 & 60.8 & 114.1 & & 46.75 & vol\% TBP & & & & \\
\hline & & & & & & & & & & & & \\
\hline \multirow[t]{2}{*}{$1 \mathrm{UD}^{*}$} & & 15.7 & 17.7 & 44.60 & 78.0 & \multicolumn{7}{|c|}{ would have gone to A-10 crib without condensate recycle. } \\
\hline & & & & & & & & & & & & \\
\hline \multicolumn{13}{|c|}{ ESTIMATED DISTRIBUTION IN OUTGOING STREAMS WITH CONDENSATE RECYCLE } \\
\hline & & $\%$ of lost & $\%$ of lost & TBP & NPH & Total & & & & & & \\
\hline & & TBP & NPH & gal/day & gal/day & gal/day & Fraction & TBP that & $s \mathrm{dp}$ & & & \\
\hline \multicolumn{2}{|c|}{ Main Stack } & 9.6 & 16.3 & 5.15 & 9.93 & 15.07 & 0.18 & & & & & \\
\hline \multicolumn{2}{|c|}{ Aging Waste } & 0.78 & 0.02 & 0.42 & 0.01 & 0.43 & 0 & & & & & \\
\hline \multicolumn{2}{|c|}{ Uranium Product } & 0.10 & 0.05 & 0.05 & 0.03 & 0.08 & 0 & & & & & \\
\hline \multicolumn{2}{|c|}{ A-10 Crib } & 39.2 & 18.4 & 20.9 & 11.21 & 32.12 & 0.40 & & & & & \\
\hline \multicolumn{2}{|c|}{ Organic Wash Waste } & 50.3 & 65.1 & 26.8 & 39.59 & 66.42 & 0.36 & & & & & \\
\hline & Total & 100.0 & 100.0 & 53.4 & 60.77 & 114.12 & & & & & & \\
\hline & & & & & & & & & & & & \\
\hline
\end{tabular}


Table A-1: Purex Plant TBP/Diluent Material Balance Calculations

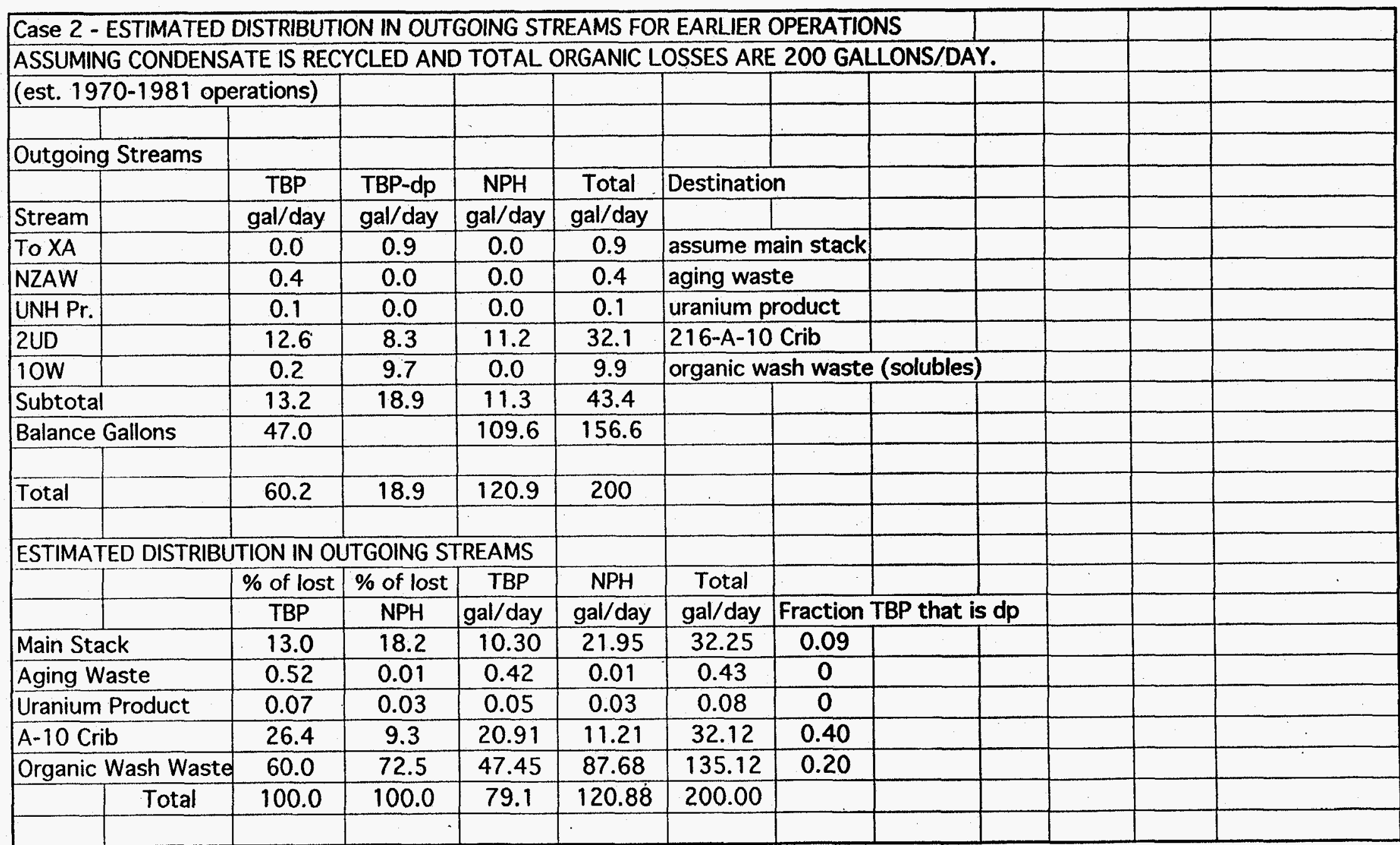


Table A-1: Purex Plant TBP/Diluent Material Balance Calculations

\begin{tabular}{|c|c|c|c|c|c|c|c|c|c|c|c|c|}
\hline Case 3 & & & & & & & & & & & & \\
\hline ESTIMAT & ED DISTRIBU & ITION IN OL & TTGOING ST & REAMS F & OR EARLIE & R OPERATIC & ONS & & & & & \\
\hline ASSUMII & IG NO CONDE & ENSATE RE & CYCLE AND & TOTAL & RGANIC L & OSSES OF & $260 \mathrm{GALL}$ & ONS/DAY & & & & \\
\hline (est 196 & 3 to 1969$)$ & & & & & & & & & & & \\
\hline Outgoing & Streams & & & & & & & & & & & \\
\hline & & TBP & TBP-dp & $\mathrm{NPH}$ & Total & Destinatio & & & & & & \\
\hline Stream & & gal/day & gal/day & gal/day & gal/day & & & & & & & \\
\hline To XA & & 0.00 & 0.91 & 0.03 & 0.94 & assume $\mathrm{m}$ & ain stack & & & & & \\
\hline NZAW & & 0.42 & 0.00 & 0.01 & 0.43 & aging was & & & & & & \\
\hline UNH Pr. & & 0.05 & 0.00 & 0.03 & 0.08 & uranium $p$ & roduct & & & & & \\
\hline $2 U D$ & & 12.6 & 0.0 & 11.2 & 23.8 & $216-A-10$ & Crib & & & & & \\
\hline $10 W$ & & 0.18 & 0.90 & 0.01 & 1.09 & organic w & ash waste & (solubles) & & & & \\
\hline $1 \mathrm{UD}$ & & 15.7 & 17.7 & 44.6 & 78.0 & $216-A-10$ & Crib & & & & & \\
\hline Subtotal & & 29.0 & 19.5 & 55.9 & 104.4 & & & & & & & \\
\hline Balance & Gallons & 46.7 & & 108.9 & 155.6 & assume 2 & $0 \%$ to sta & ck, balanc & e entr & ained in & organic & wash waste \\
\hline & & & & & & & & & & & & \\
\hline Total & & 75.6 & 19.5 & 164.8 & 260.0 & & & & & & & \\
\hline & & & & & & & & & & & & \\
\hline ESTIMAT & ED DISTRIBU & ITION IN OL & ITGOING ST & REAMS & & & & & & & & \\
\hline & & $\%$ of lost & $\%$ of lost & TBP & NPH & Total & & & & & & \\
\hline & & TBP & $\mathrm{NPH}$ & gal/day & gal/day & gal/day & Fraction & TBP that is & $s d p$ & & & \\
\hline Main Sta & & 10.76 & 13.2 & 10.24 & 21.82 & 32.06 & 0.088 & & & & & \\
\hline Aging $W$ & aste & 0.44 & 0.01 & 0.42 & 0.01 & 0.43 & 0 & & & & & \\
\hline Uranium & Product & 0.06 & 0.02 & 0.05 & 0.03 & 0.08 & 0 & & & & & \\
\hline $\mathrm{A}-10 \mathrm{Cri}$ & & 48.4 & 33.9 & 46.02 & 55.81 & 101.82 & 0.385 & & & & & \\
\hline Organic & Nash Waste & 40.4 & 52.9 & 38.44 & 87.16 & 125.60 & 0.023 & & & & & \\
\hline & Total & 100.0 & 100.0 & 95.2 & 164.84 & 260.00 & & & & & & \\
\hline & & & & & & & & & & & & \\
\hline
\end{tabular}


Table A-1: Purex Plant TBP/Diluent Material Balance Calculations

\begin{tabular}{|c|c|c|c|c|c|c|c|c|c|c|c|c|}
\hline \multicolumn{13}{|l|}{ Case 4} \\
\hline \multicolumn{13}{|c|}{\begin{tabular}{|l|l|l|l|} 
ESTIMATED DISTRIBUTION IN OUTGOING STREAMS FOR EARLIER OPERATIONS & & \\
\end{tabular}} \\
\hline \multicolumn{13}{|c|}{ ASSUMING NO CONDENSATE RECYCLE AND TOTAL ORGANIC LOSSES OF 300 GALLONS/DAY. } \\
\hline \multicolumn{13}{|c|}{\begin{tabular}{|l|l|l|l|l|l|l|} 
(est 1955-1962) & & & & & & \\
\end{tabular}} \\
\hline \multicolumn{13}{|c|}{ Outgoing Streams } \\
\hline & & TBP & TBP-dp & $\mathrm{NPH}$ & Total & \multicolumn{2}{|c|}{ Destination } & & & & & \\
\hline Stream & & gal/day & gal/day & gal/day & gal/day & & & & & & & \\
\hline To XA & & 0.00 & 0.91 & 0.03 & 0.94 & \multicolumn{2}{|c|}{ assume main stack } & & & & & \\
\hline NZAW & & 0.42 & 0.00 & 0.01 & 0.43 & \multicolumn{2}{|c|}{ aging waste } & & & & & \\
\hline UNH Pr. & & 0.05 & 0.00 & 0.03 & 0.08 & \multicolumn{2}{|c|}{ uranium product } & & & & & \\
\hline $2 U D$ & & 12.6 & 0.00 & 11.2 & 23.8 & \multicolumn{2}{|c|}{ 216-A-10 Crib } & & & & & \\
\hline $10 \mathrm{~W}$ & & 0.18 & 0.90 & 0.01 & 1.09 & \multicolumn{4}{|c|}{ organic wash waste (solubles) } & & & \\
\hline 1UD & & 15.7 & 17.7 & 44.6 & 78.0 & \multicolumn{2}{|c|}{$216-\mathrm{A}-10$ Crib } & & & & & \\
\hline \multicolumn{2}{|c|}{ Subtotal } & 29.0 & 19.5 & 55.9 & 104.4 & & & & & & & \\
\hline \multicolumn{2}{|c|}{ Balance Gallons } & 58.7 & & 136.9 & 195.6 & \multicolumn{7}{|c|}{ assume $20 \%$ to stack, balance entrained in organic wash waste } \\
\hline & & & & & & & & & & & & \\
\hline Total & & 87.6 & 19.5 & 192.8 & 300.0 & & & & & & & \\
\hline & & & & & & & & & & & & \\
\hline \multicolumn{13}{|c|}{ ESTIMATED DISTRIBUTION IN OUTGOING STREAMS } \\
\hline & & $\%$ of lost & $\%$ of lost & TBP & NPH & Total & & & & & & \\
\hline & & \begin{tabular}{|l|l} 
TBP & \\
\end{tabular} & $\mathrm{NPH}$ & gal/day & $\mathrm{gal} / \mathrm{day}$ & gal/day & \multicolumn{3}{|c|}{ Fraction TBP that is $d p$} & & & \\
\hline \multicolumn{2}{|c|}{ Main Stack } & 11.80 & 14.2 & 12.64 & 27.42 & 40.06 & 0.072 & & & & & \\
\hline \multicolumn{2}{|c|}{ Aging Waste } & 0.39 & 0.01 & 0.42 & 0.01 & 0.43 & 0 & & & & & \\
\hline \multicolumn{2}{|c|}{ Uranium Product } & 0.05 & 0.02 & 0.05 & 0.03 & 0.08 & 0 & & & & & \\
\hline \multicolumn{2}{|c|}{ A-10 Crib } & 42.9 & 28.9 & 46.02 & 55.81 & 101.82 & 0.385 & & & & & \\
\hline \multicolumn{2}{|c|}{ Organic Wash Waste } & 44.8 & 56.8 & 48.04 & 109.56 & 157.60 & 0.019 & & & & & \\
\hline & Total & 100.0 & 100.0 & 107.2 & 192.84 & 300.00 & & & & & & \\
\hline & & & & & & & & & & & & \\
\hline
\end{tabular}




\section{DISTRIBUTION}

\section{Number of copies}

ONSITE

8

U.S. Department of Energy, Richland Operations office

S. 0. Branch (5)

S7-54

W. F. Hendrickson

S7-54

G. W. Rosenwald

ST-54

Public Reading Room

Al-65

MACTEC

S. T. Murff

Westinghouse Hanford Company

A. T. Alstad

$\mathrm{R} 2-70$

H. Babad

S7-30

J. J. Badden

S5-01

R. M. Bean

D. C. Board

P8-08

G. L. Borsheim

S1-57

D. E. Bowers

H5-49

V. C. Boyles

S6-01

L. R. Burks

RI-49

K. G. Carothers

G6-14

D. M. Camaioni

R1-51

J. A. Campbel1

K2-44

R. J. Cash

R. A. Dodd

P8-08

M. A. Gerber

S7-15

R2-70

J. M. Grigsby

P8-38

M. N. Istam

S7-15

N. W. Kirch

R3-08

J. E. Meacham

R2-11

R. $\mathrm{Ni}$

S7-15

M. A. Payne

S5-07

M. G. Plys

A. K. Postma

S7-14

H4-62

R. E. Raymond

S7-15

G. W. Reddick (2)

R2-54

D. A. Reynolds

H5-49

R. C. Roal

R2-11

H5-27

R. D. Scheele

G. F. Schiefelbein

P7 -25

J. P. Sederburg

P8-38

R2-11 


\section{WHC-MR-0483}

Revision 0

\section{DISTRIBUTION (cont)}

Westinghouse Hanford Company (cont)

M. J. Sutey

L. E. Thomas

D. A. Turner (8)

T. S. Vail

R. D. Scheele

T4-07

R3-08

Central Files

DPC-2

OSTI (2)

S7-15

R2-54

P7 -25

L8-04

G6-51

L8-07 